University of San Diego

Digital USD

2015-5

\title{
A Phenomenological Study of Health Professionals' Perceptions of Good and Bad Pediatric Hospital Deaths, Self-Care Needs and Lingering Distress
}

Carmen Nichole Spalding

University of San Diego

Follow this and additional works at: https://digital.sandiego.edu/dissertations

\section{Digital USD Citation}

Spalding, Carmen Nichole, "A Phenomenological Study of Health Professionals' Perceptions of Good and Bad Pediatric Hospital Deaths, Self-Care Needs and Lingering Distress" (2015). Dissertations. 12. https://digital.sandiego.edu/dissertations/12 
A PHENOMENOLOGIC STUDY OF HEALTH PROFESSIONALS' PERCEPTIONS OF GOOD AND BAD PEDIATRIC HOSPITAL DEATHS, SELF-CARE NEEDS AND LINGERING DISTRESS

A dissertation submitted

by

Carmen Nichole Spalding

to

FACULTY OF THE HAHN SCHOOL OF NURSING AND HEALTH SCIENCE UNIVERSITY OF SAN DIEGO

in partial fulfillment of

the requirement for the degree of

DOCTOR OF PHILOSOPHY

in

NURSING

This dissertation has been accepted for the faculty of University of San Diego by:

Jane M. Georges, PhD, RN

Cynthia D. Connelly, PhD, RN, FAAN

Ann. M. Mayo, DNSc, RN, FAAN 
Abstract

The death of a child is devastating. Although death is a part of every life, a child dying seems out of order in current times and in the context of Western Healthcare. Health professionals (HP) caring for dying children frequently report suffering. In the past four decades, HP have been concerned with providing a "good death" for patients at the end-of-life (EOL). While studies have shown what a good death includes in elderly patients in various settings, few studies have examined what constitutes a good death for pediatric patients within the hospital setting. No studies were found examining healthcare workers in all care areas within a children's hospital in the context of a specific death event.

This qualitative study applied an interpretive phenomenological approach which is ideal in studying this topic because the researcher is attempting to interpret the meaning of the phenomena-namely HP lived experiences of good and bad deaths in the pediatric hospital setting, self-care needs being met subsequent to a pediatric hospital death and ongoing distress after caring for a dying child in the pediatric hospital.

Health professionals working in an urban children's hospital in Southern California provided this data. Pre collected, open-ended text entries were analyzed from over 300 surveys. Directed content analysis was performed utilizing the method described by Hsieh and Shannon (2005). Analysis of good and bad death data was directed by empirical domains of the Quality of Dying and Death instrument proposed by Downey et al. (2010). Themes were categorized under four domains: symptom control, preparedness, connectedness, and transcendence. Several subthemes were nested under each domain. Data related to meeting the needs of HP fell under the themes: focus on 
patient and family, resources, and cohesion. Emerging themes related to HP report of ongoing distress were: bad death, external factors, and internal factors. Implications for future research as a result of this study include: exploration of sudden pediatric death events, exploration of the concepts, parents letting go, and everything done, and the subjective nature of a good death among HP. 
Copyright 2015. 


\section{Dedication}

This work is dedicated to all the children and families who have allowed me to grieve with and for them during this difficult and sacred time in their lives. It is also

dedicated to my brother, Allan, with the wish above all wishes that it was not. We all miss you everyday. Thanks for the butterflies. 


\section{Acknowledgements}

I am eternally grateful to my committee members: Dr. Georges, Dr. Connelly, and Dr. Mayo. Your guidance and support during this journey has been very much needed and appreciated. You each brought your unique strengths, but allowed me latitude to develop my own research process.

To the members of my cohort-what amazing men and women you are! You have each inspired me with your unique talents and passion for your research. I am grateful to have had all of you on this journey with me. Special thanks to my dear friend and research partner, Deena Drake; to my qualitative partner in crime, Sharon Kepple; and to my Navy colleague and fellow social planner, Jen Buechel.

To Mary Fagan, thank you for connecting me with Rebecca Bennett and her research. Rebecca thanks for the use of your data, and I look forward to continuing our research dissemination together.

To my parents, I cannot begin to thank you for all the support and cheerleading you have given me all my life. I know I would not have ever made it here without your confidence in me. I love you so very much. Shannon- thanks for your help with my boys, for being their crazy aunt and mostly for our friendship- I cherish it. You are the sunshine in my life. To my children, my heart swells with love for you. Please remember now and forever that I always will love you and be cheering for your success. Thank you for letting me focus on this for the past three years. I have confidence you both have everything you need to make your dreams come true. 
My darling husband, words cannot express the depth of my love and gratitude for you. Your unwavering love for me, your steadfast belief in me, and your support of my PhD journey and research means the world to me. I look forward to doing research with you- and the rocking chairs, but not just yet. 


\section{CONTENTS}

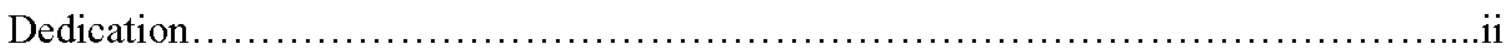

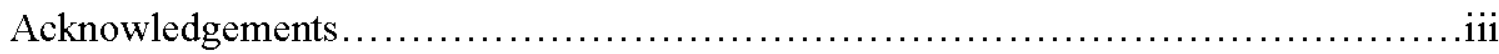

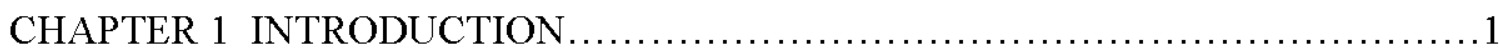

Statement of Problem..................................................

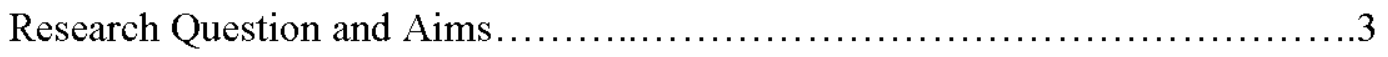

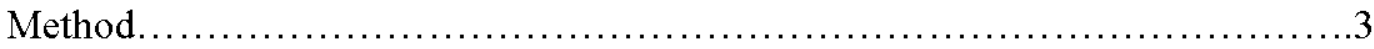

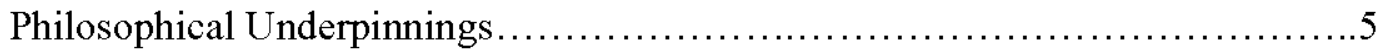

Assumptions....................................................

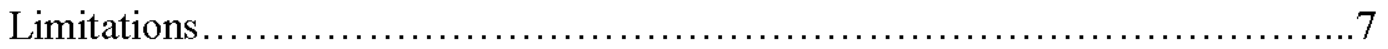

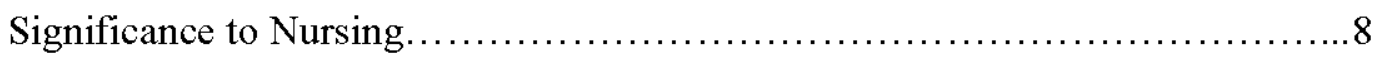

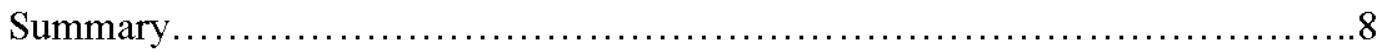

CHAPTER 2 REVIEW OF THE LITERATURE $\ldots \ldots \ldots \ldots \ldots \ldots \ldots \ldots \ldots \ldots \ldots \ldots \ldots \ldots$

Historical Context............................................... 10

Destabilization of Death....................................... 10

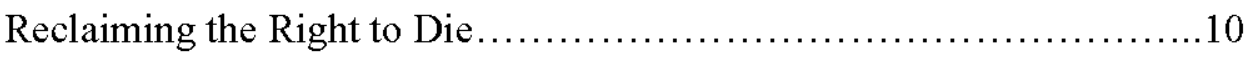

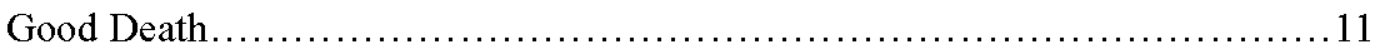

Good Death in the Pediatric Population............................13

Good Hospital Death in Pediatrics.............................. 14

Health Professionals Perspective of a Good Pediatric Hospital Death............. 14

Meeting the Needs of the Caregiver................................... 16 


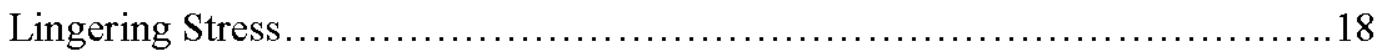

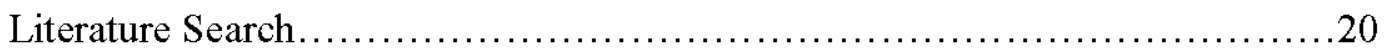

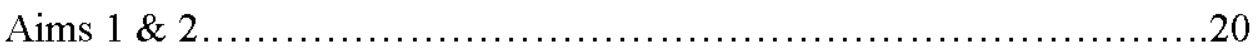

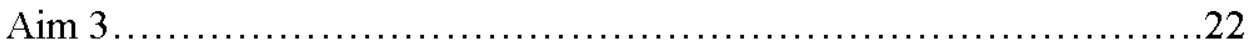

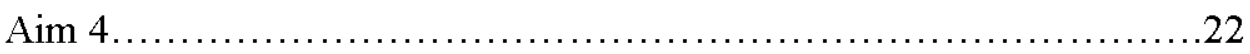

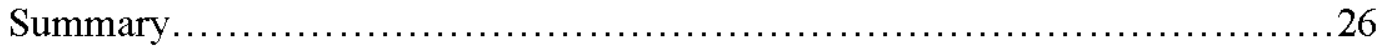

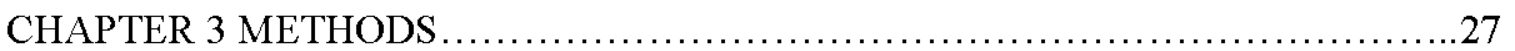

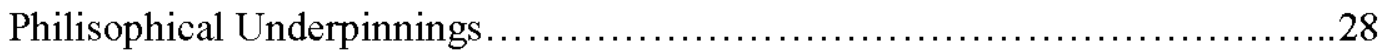

Researcher's Context and Assumptions...............................29

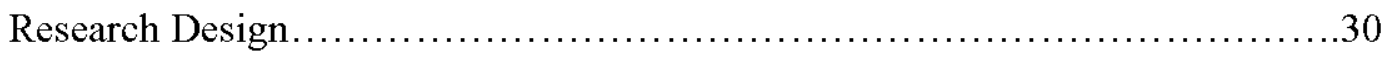

Parent Study Inclusion and Exclusion Criteria....................... 31

Parent Study Recruitment.................................... 31

Human Subjects Protection................................... 31

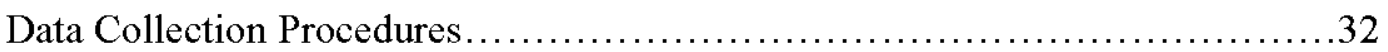

Content Analysis.................................................. 34

Use of Quality of Dying and Death Questionnaire: Empirical Domains...........36

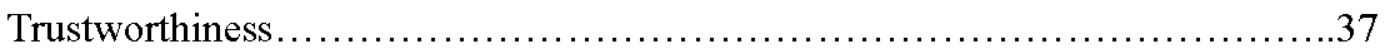

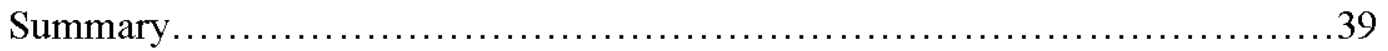

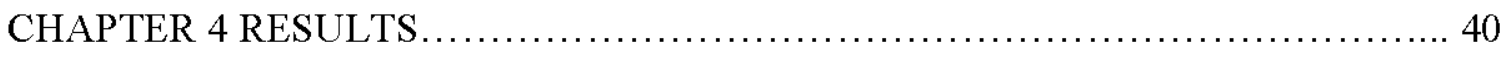

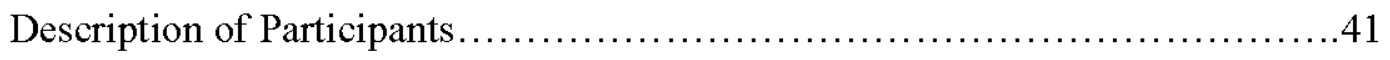

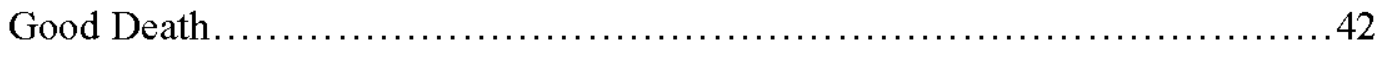

Symptom Control ........................................43

Relief of and/or Absence of Pain..........................44 


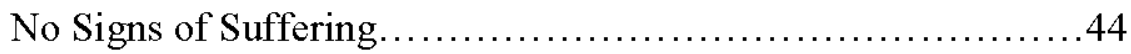

Appropriate Orders .......................................... 44

Palliative Care Team........................................45

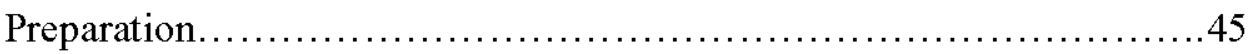

Families Let Go............................................. 45

Support in Decision Making..................................46

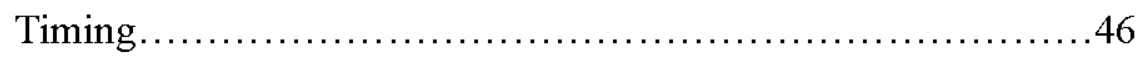

Not Rushed ........................................47

Not Prolonged ..................................... 47

Acknowledgment of Imminent Death....................... 47

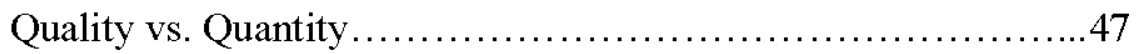

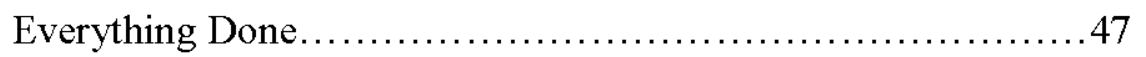

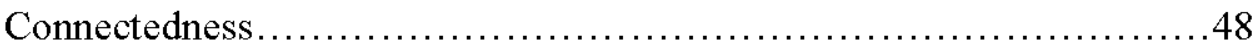

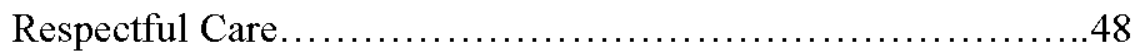

Patient and Family Wishes.............................48

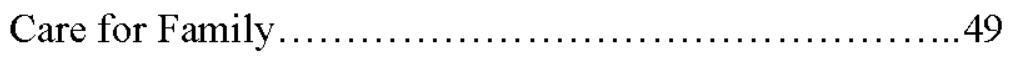

Care of Siblings......................................... 49

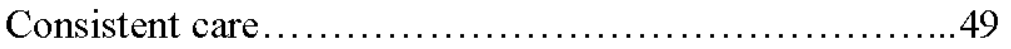

Continued care ..........................................49

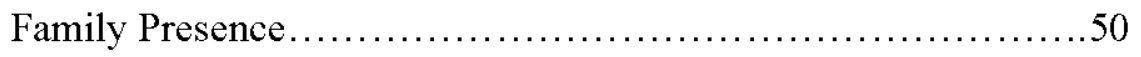

Patient Not Alone .......................................50

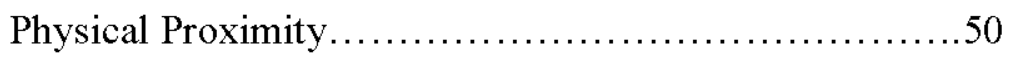

Parent Alone Time......................................51 
Communication

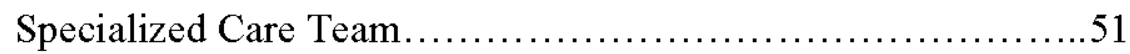

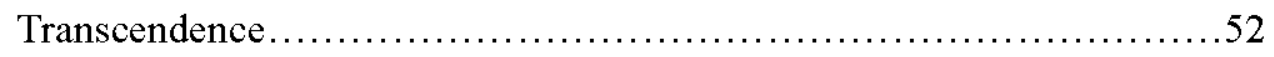

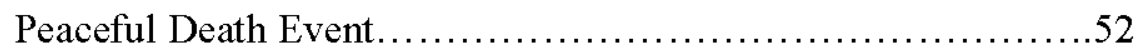

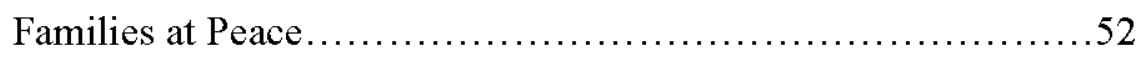

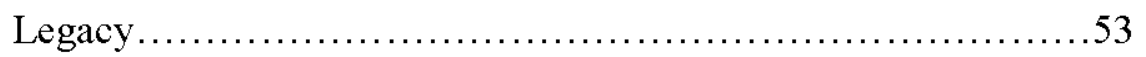

Organ Donation.................................... 53

Memory Making Activities.......................54

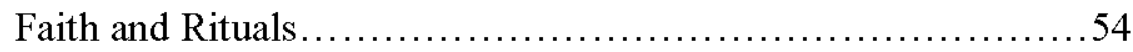

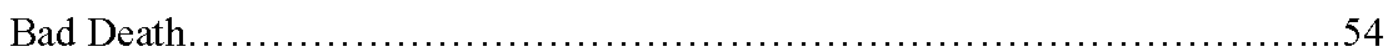

Symptom Control........................................56

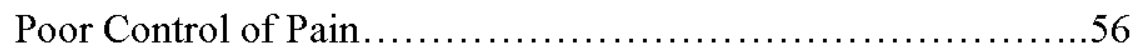

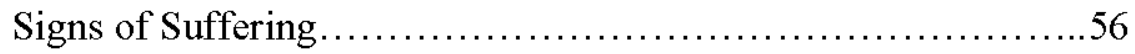

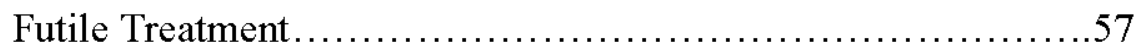

Shift to Palliative Care Too Late or Not at all.................57

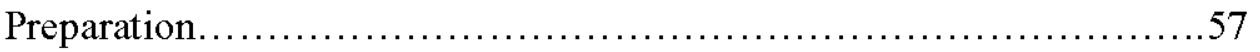

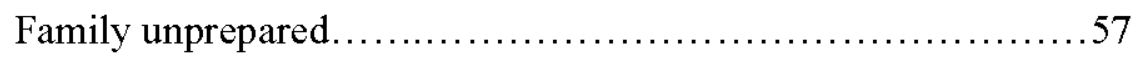

Lack of Awareness of Imminent Death.....................58

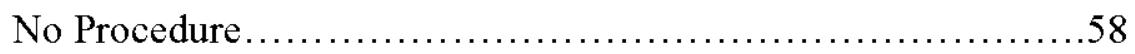

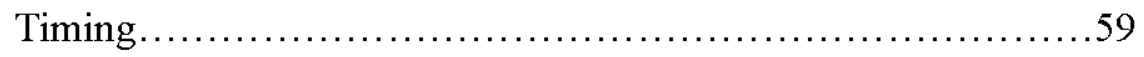

Traumatic and/or unexpected.....................59

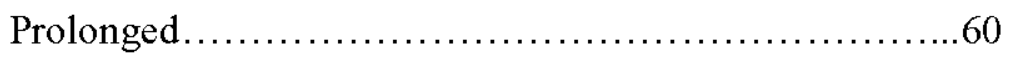

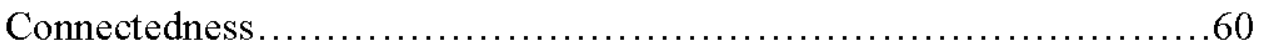




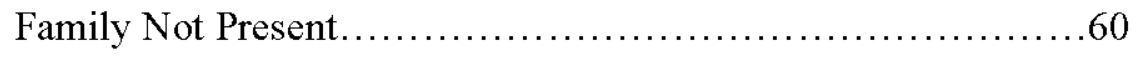

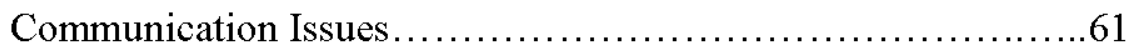

Disconnected....................................61

Dishonest......................................61

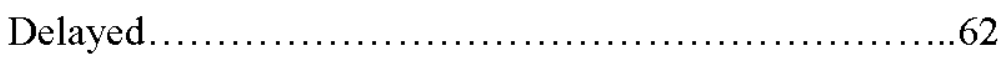

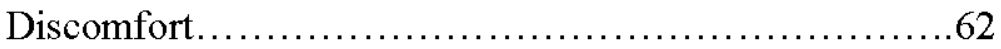

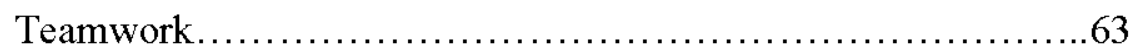

Uncivil .......................................... 63

Unavailable............................................

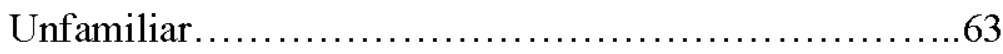

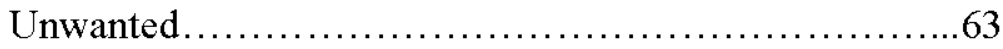

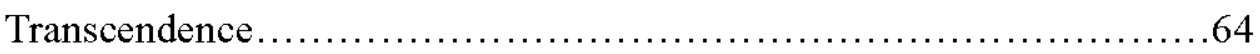

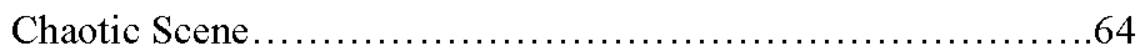

Lack of Space.................................64

Unsuccessful Code..............................65

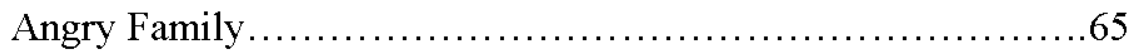

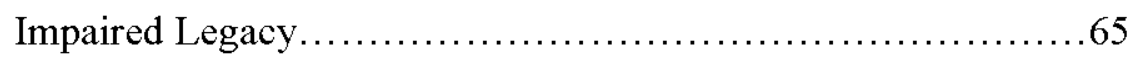

Inability to donate organs $\ldots \ldots \ldots \ldots \ldots \ldots \ldots \ldots \ldots \ldots \ldots$

Delayed memory making..........................66

Meeting the Needs of the HP........................................6

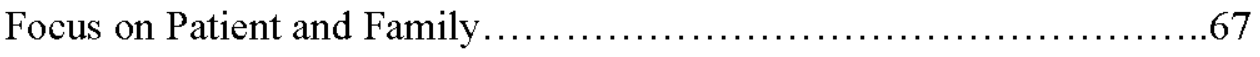

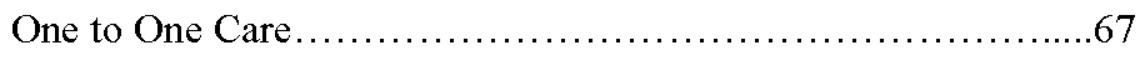

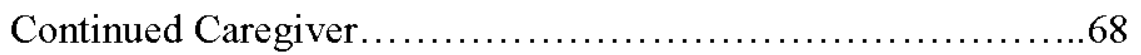




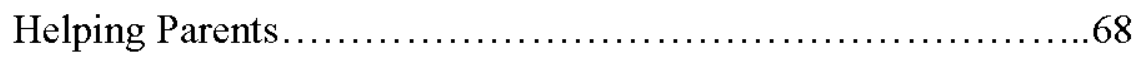

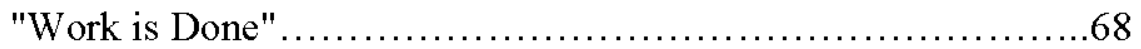

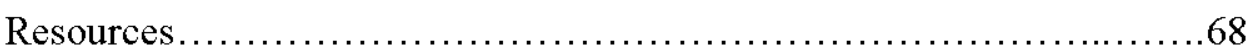

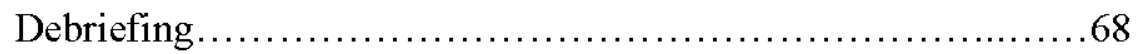

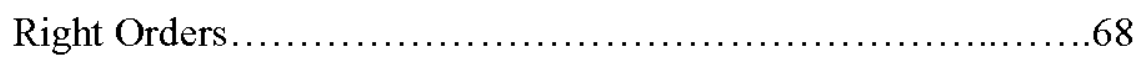

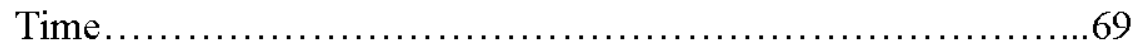

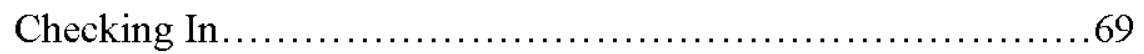

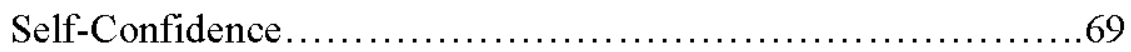

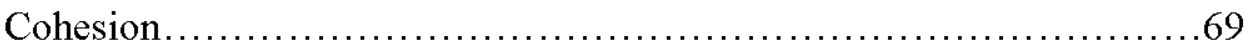

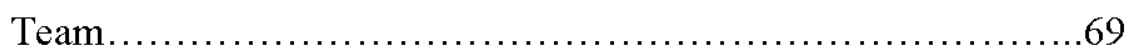

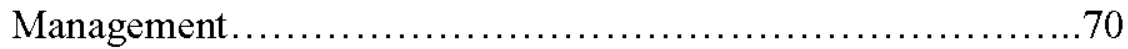

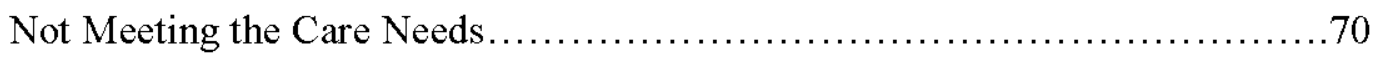

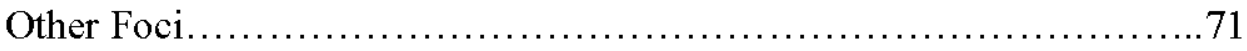

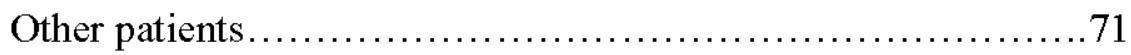

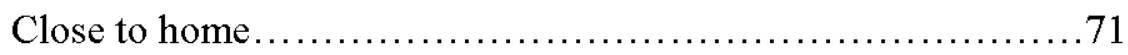

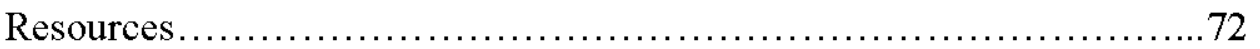

Team Member Not Available............................ 72

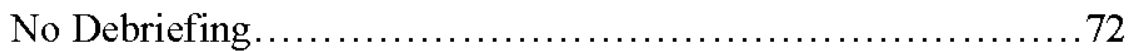

No Time........................................... 73

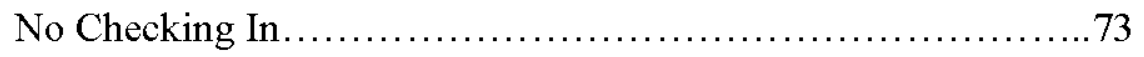

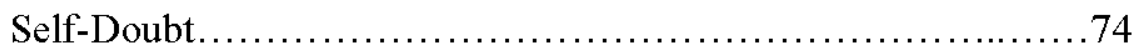

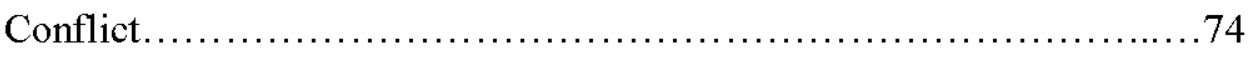

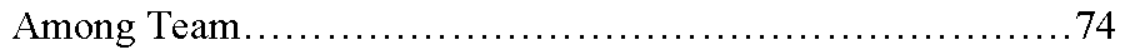


With Family.

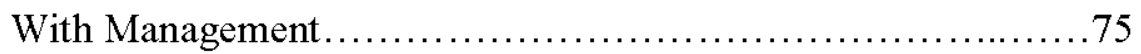

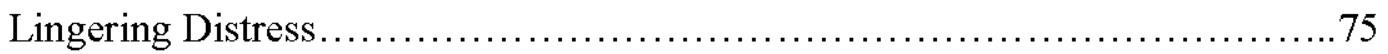

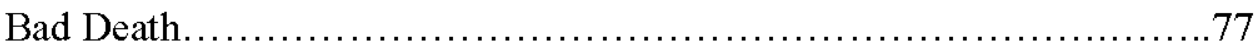

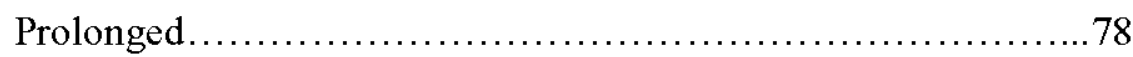

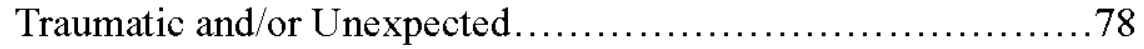

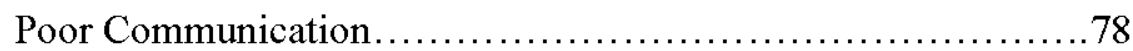

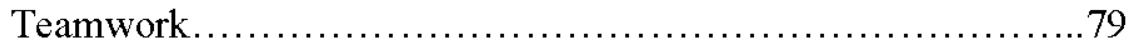

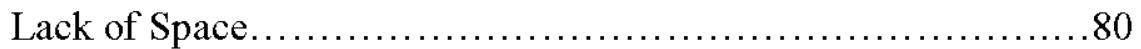

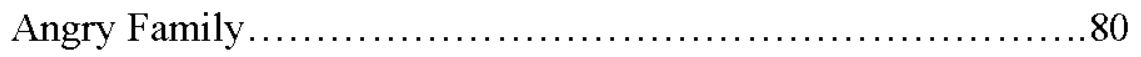

External Factors............................................... 81

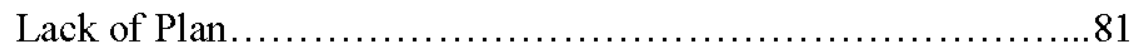

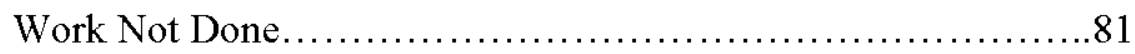

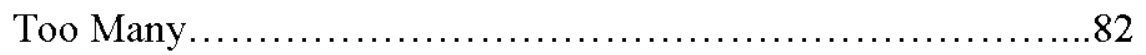

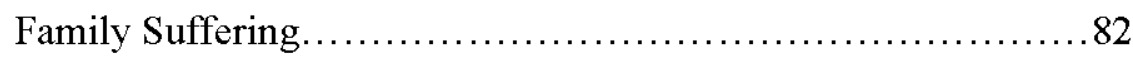

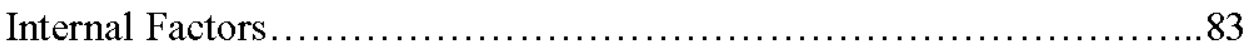

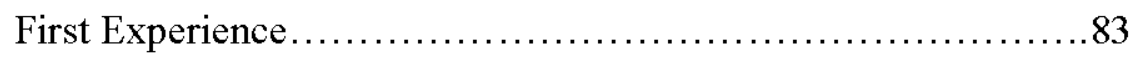

Helplessness $/$ Self-Doubt................................... 83

End of Relationship................................. 84

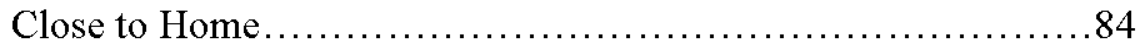

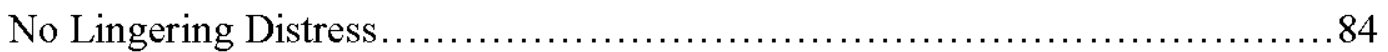

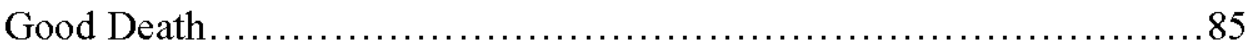

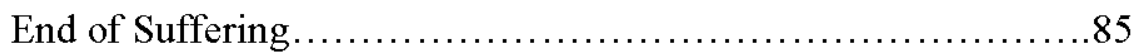


Everything Done.................................... 85

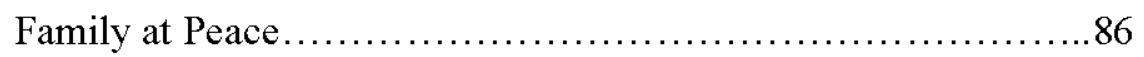

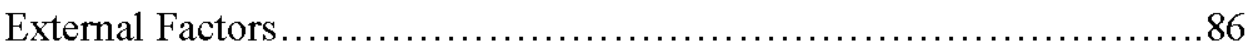

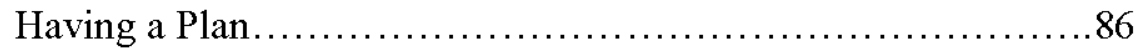

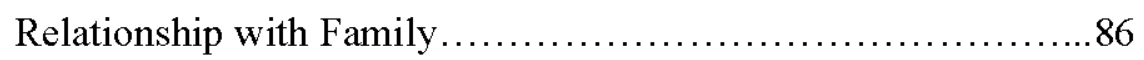

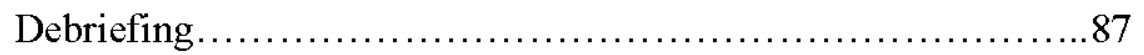

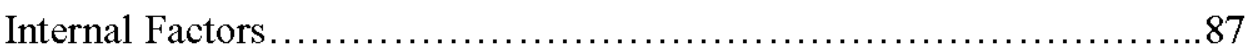

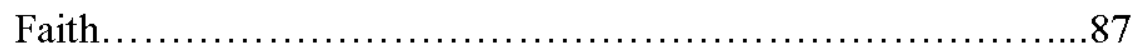

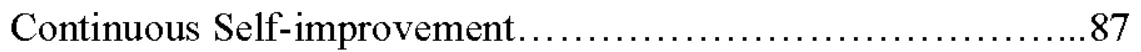

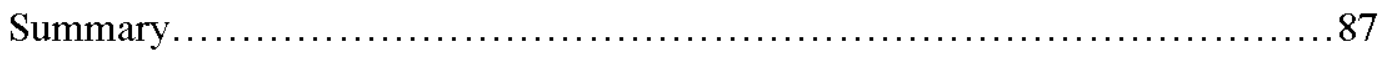

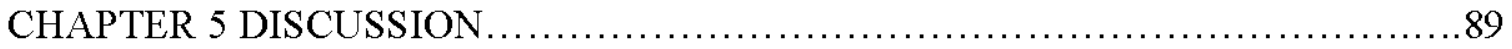

Good and Bad Death Data........................................... 89

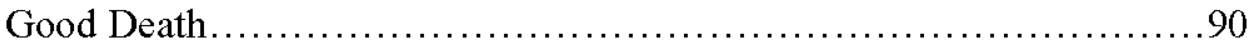

Symptom Control $\ldots \ldots \ldots \ldots \ldots \ldots \ldots \ldots \ldots \ldots \ldots \ldots \ldots \ldots \ldots \ldots$

Preparation......................................... 91

Families letting go $\ldots \ldots \ldots \ldots \ldots \ldots \ldots \ldots \ldots \ldots \ldots \ldots . \ldots 1$

Everything done $\ldots \ldots \ldots \ldots \ldots \ldots \ldots \ldots \ldots \ldots \ldots \ldots \ldots, \ldots \ldots \ldots$

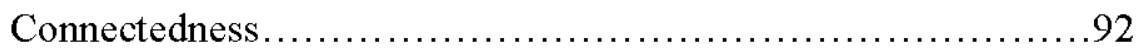

Transcendence....................................93

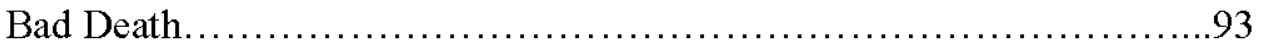

Symptom Control $\ldots \ldots \ldots \ldots \ldots \ldots \ldots \ldots \ldots \ldots \ldots \ldots \ldots \ldots \ldots . \ldots 3$

Preparation........................................ 93

Connectedness $\ldots \ldots \ldots \ldots \ldots \ldots \ldots \ldots \ldots \ldots \ldots \ldots \ldots \ldots \ldots \ldots . \ldots 4$ 


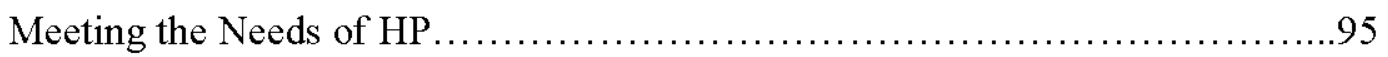

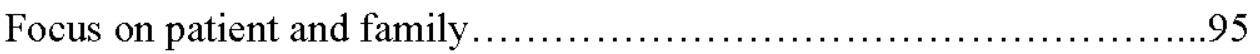

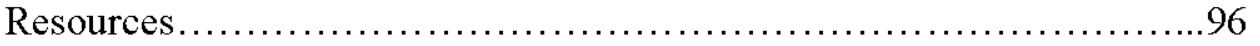

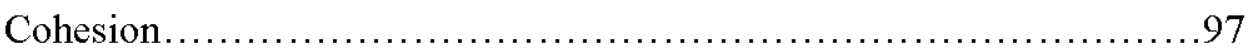

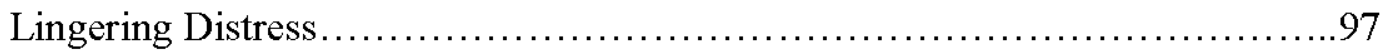

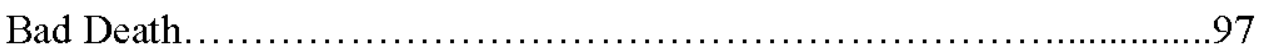

External Factors.............................................. 98

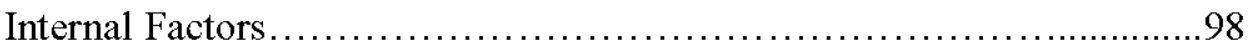

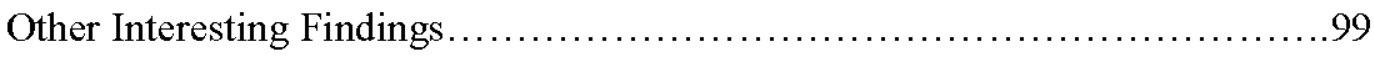

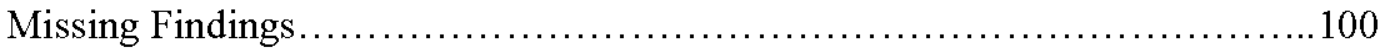

Theoretical Considerations .......................................... 101

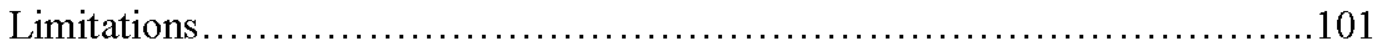

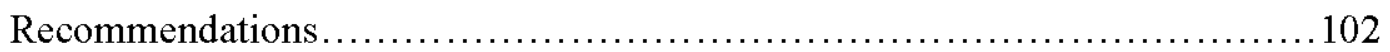

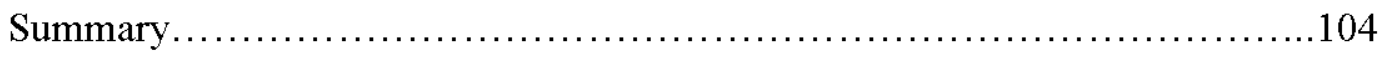

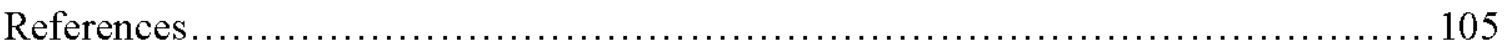

APPENDIX A, University of San Diego, Institutional Review Board Approval Letter. 117

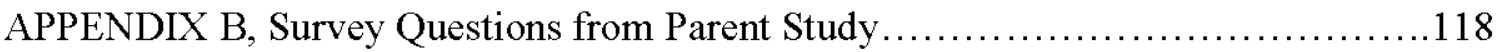




\section{List of Figures}

FIGURE

1. Good Death Data Clustering Using Downey et al. Constructs $\ldots \ldots \ldots \ldots \ldots \ldots \ldots \ldots+\ldots \ldots$

2. Bad Death Data Clustering Using Downey et al. Constructs ....................55

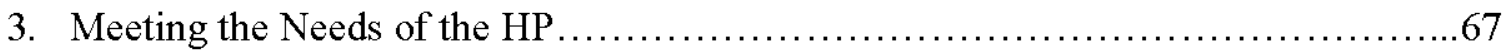

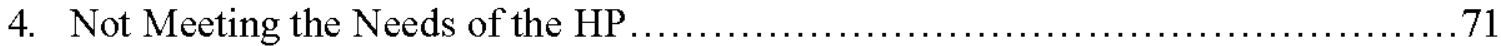

5. HP Reporting Unresolved Feelings.................................... 77

6. HP Not Reporting Unresolved Feelings $\ldots \ldots \ldots \ldots \ldots \ldots \ldots \ldots \ldots \ldots \ldots \ldots \ldots \ldots \ldots \ldots$ 


\section{List of Tables}

Table

Page

1. Number of Institutions Providing Services (Conte, 2011) $\ldots \ldots \ldots \ldots \ldots \ldots \ldots \ldots \ldots$

2. Relevant Articles for Aims \#3 and \#4 of the Study $\ldots \ldots \ldots \ldots \ldots \ldots \ldots \ldots \ldots \ldots \ldots \ldots \ldots \ldots \ldots \ldots .24-26$

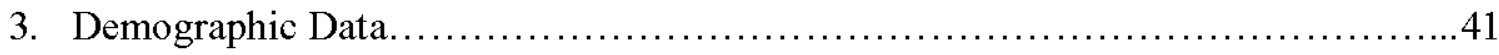




\section{CHAPTER 1}

\section{Introduction}

The death of a baby is like a stone cast into the stillness of a quiet pool; the concentric ripples of despair sweep out in all directions, affecting many, many people. John DeFrain, author

It is every parent's worst nightmare. A child dying is one of the most excruciating experiences a parent may face. Health professionals (HP) working with dying children are all too aware of the devastation these families endure in the time between a terminal diagnosis and the death itself. The disclosure of death awareness by the healthcare team starts a cascade of torment, and actions performed by the HP at the request of the parents may create ethical concerns related to prolonged suffering and medical futility. Health professionals also suffer in these situations. They often know these patients well, and develop meaningful relationships with their families.

In the context of Western healthcare and its prizing of rescue, death is often viewed as a failure. With twentieth century advances in sanitation, vaccination and emergent surgical techniques in childbirth, the rates of childhood death have been greatly reduced. Unfortunately, children still die, and their families and HP are affected by these deaths. Considering this, it is imperative that dying children, their families, and professionals caring for them, experience the most comprehensive and compassionate care possible. 


\section{Statement of the Problem}

Achieving a good death in a pediatric hospital setting can be difficult for a number of reasons. Western society values self-reliance, heroism, and technological superiority (Chapple, 2010) all of which has led to the development of a culture of death denial (Tucker, 2009). Programs of nursing and medicine place little emphasis on how to best care for dying patients; HP are therefore ill equipped to recognize, prognosticate, and communicate impending death to the patients, their families or even each other (Hancock et al., 2007). The death of a child is particularly difficult to acknowledge and discuss. Parents of dying children are asked to make medical decisions as the child's legal proxy, adding stress to an already overwhelming situation, and parents report increased stress from either receiving too much or not enough information (McGrath, Kail-Buckley, \& Phillips, 2007). Because of this, it is difficult to know how much they are ready to hear or able to comprehend given the ongoing crisis in which they now find themselves (Ringner, Jansson, \& Graneheim, 2011).

Published research surrounding the concept of a "good death" is primarily related to adults. Of the research on patients' and families' understanding of a good death, the majority of studies suggest one's home would be the preferred location (Hales, Zimmerman, \& Rodin, 2010), implying a good death in the hospital is more difficult to achieve. This is also seen in the few studies on this topic within the pediatric population; however, it is far from a consensus (Bluebond-Langner, Beecham, Candy, Langner, \& Jones, 2013).

Health professionals are not immune to grief resulting from a pediatric patient's death. Doka (1989) identified HP as sufferers of disenfranchised grief. This term is 
attributed to persons who grieve that do not conform to societal expectations. Because of this widely held belief, nurses often report distancing themselves from their patients in order to maintain professional boundaries (Georges, Grypdonck, \& Dierckx de Caterle, 2002; Peterson et al., 2010). One study suggests lack of self-care, chronic grief, and ineffective coping in caring for dying patients increase the rate of burnout among nurses (Peterson et al., 2010). Identifying the most beneficial sources of support for HP working with dying pediatric patients and their families is needed in order to understand their grief and suffering in these situations and prevent burnout.

\section{Research Question and Aims}

This study proposes a qualitative approach to explore several factors of the HP lived experience of a good or bad pediatric hospital death. The specific aims of the study are to: (1) explore themes corresponding to HP report of good pediatric hospital deaths, (2) explore themes corresponding to HP report of bad pediatric hospital deaths, (3) identify themes related to HP report of their own needs being met in response to a pediatric patient death in the hospital, and (4) identify themes corresponding to HP report of lingering distress subsequent to a pediatric patient death in the hospital.

\section{Method}

The researcher reviewed all open text entries from a previously performed study. The parent study consisted of a survey that was completed by over 300 participants. To address the first two aims of this study, question 9 of the survey asked: "Overall, how would you rate the quality of the patient's dying?" The question offered a Likert response from best possible to worst possible. The responses to the Likert scale were collapsed into good or bad, and text comments were analyzed in both responses to 
identify themes of each aim. Additionally, data provided under the questions: "What were good things about the child's end of life care?", "What were challenges about the patient's end of life care?", and "What would have made this child's end-of-life care better?" were analyzed as these data provided further evidence related to quality of death. To address the third aim, question 10 of the survey sought HP perspective of their own needs being met at the time of death of their patient; possible responses for this question included yes, no, and don't know. Open text comments corresponding to participants' report of adequate support will be analyzed for themes. Another question asked: "Did you feel supported by fellow staff while caring for this patient?", which is closely related to support, so text responses to this question were analyzed for this aim. To address the fourth aim, question 11 of the survey asked if the HP is experiencing lingering stress subsequent to the specific death event. The possible responses included yes, no, don't know. Open text comments corresponding to participants' report of lingering stress were analyzed for identification of themes. Another question, "Did you feel any distress from?" provided open text data related to lingering feelings, and were included in analysis of this aim. The negative responses and comments were analyzed as well to further validate themes related to the specific aims of the study. The parent study utilized the Quality of Death and Dying Instrument for Clinicians (QODD-C) with modifications to include open-ended text responses added to many of the questions. The qualitative analysis of these open-ended text responses is sensitized by this instrument's conceptual framework.

Before, during and after the interview, the following methodology was employed: 
- The researcher developed a thorough understanding of the topics of good and bad pediatric hospital deaths, sources of self-care support for HP caring for dying children, and lingering distress among HP caring for dying children through an extensive review of the literature.

- The researcher obtained permission from the primary investigator of the parent study to use the entire de-identified dataset. The University of San Diego's Institutional Review Board (IRB) provided study oversight at the exempt level.

- The researcher read and reread all the text entries corresponding to each of the study's aims to allow for the emergence of themes.

- The researcher worked with a methodological expert to assist in initial coding. As a novice researcher, these sessions were invaluable in developing the expertise necessary to allow themes to emerge, and potentially identify areas of researcher bias that will be discussed in the analysis and results section.

- Once themes emerged, the researcher analyzed the survey data to identify verbatim quotes that provide the "texture" of the theme (Holloway \& Wheeler, 2010, p. 286).

\section{Philosophical Underpinunings}

In fields of study where little is already known, a qualitative method is ideal (Polit \& Beck, 2012). There are several types of qualitative study; in this study, the researcher was focused on the following four phenomena: (1) HP perceptions of a good death in a pediatric hospital, (2) HP perceptions of a bad death in a pediatric hospital, (3) HP perspective of self-care needs being met subsequent to a pediatric hospital death, and (4) 
concepts surrounding reports of lingering distress among HP after a pediatric hospital death. Therefore, a phenomenological approach was used. Of the various types of phenomenologic study found in the literature, this researcher employed an interpretive phenomenology in the Heideggerian or Hermeneutic tradition. By doing this, the researcher derived meaning from the HP experiences, rather than simply describing them. As a researcher of "passionate inquiry", with a post-modern, feminist perspective, (Aranda, 2006) the bracketing method employed by Husserl (Holloway \& Wheeler, 2010) fails to allow for the role of researcher as participant. Hermeneutic research also includes the concept of Dasein, the idea that a person's perspective is temporal in nature. The following five constructs are presented by Leonard (1994) to better understand Heideggerian phenomenology:

1. Each individual has a world, which has been created from his or her language, culture and history. A person's being in the world is so innate that it is overlooked and requires deep thought and analysis.

2. This person's world includes things he or she holds valuable. The person's perspective can only be understood through evaluating his or her context.

3. A person is able to self-interpret. Gaining understanding is both a result of and further development of the person's gestalt.

4. A person's body is more than the vehicle upon which their existence relies. It also facilitates the essence of his or her experiences and thereby their lebenswelt.

5. A person's world is affected by time. 


\section{Assumptions}

In embarking on this research study, the following assumptions were held by the researcher:

1. The research facility, a children's hospital in Southern California would provide a rich environment to elicit the lived experience of HP perceptions of good and bad deaths within a pediatric hospital, sources of self-care support among HP caring for dying children and concepts surrounding lingering distress among HP caring for dying children.

2. Engaging in qualitative research would provide a "thick description" of the phenomena of interest.

3. Health professionals would have some opinions on the phenomena, which will be shaped by their own lebenswelt.

4. The researcher would engage in continuous reflection and reflexivity, to consciously recognize the impact of her role in the research, from research question development, through analysis.

\section{Limitations}

Prior to the study, the researcher considered the following as possible limitations in seeking to answer these questions:

1. Open text narratives may not provide "thick" description needed for phenomenologic study.

2. Despite over 300 responses, many participants did not provide text comments for analysis on items related to study aims, potentially limiting the ability to obtain theoretical saturation of themes. 
3. Since this research is being performed on a pre-existing dataset, the researcher did not have the opportunity to frame the questions to encourage open text comments from the participant.

4. Additionally related to analysis of pre-existing data, the researcher cannot consider aims not included in the original research instrument.

\section{Significance to Nursing}

It is imperative that HP, including nurses, provide the best quality care to dying children and their families. Nurses in the hospital often report distress in providing EOL care. Understanding HP perspectives in what constitutes a good or bad hospital death is crucial for identifying the best resources and support to achieve this. Understanding factors that are associated with HP report of their own needs being met as well as ongoing stress will provide meaningful insight into what approaches are most valuable in reducing burnout among healthcare providers working with dying children and families.

\section{Summary}

Care for patients at the end of life is challenging for many HP, especially when the patient is a child. These challenges often result in chronic suffering, which can have profound effects if not acknowledged and resolved. Using interpretive phenomenology, this researcher identified themes HP report as important considerations of both good and bad hospital deaths as well as identified themes related to HP emotional support and ongoing stress. 


\title{
CHAPTER 2
}

\section{Review of the Literature}

\author{
The idea of death, the fear of it \\ Haunts the human animal like nothing else; \\ It is a mainspring of human activity- \\ Designed largely to avoid the fatality of death, \\ To overcome it by denying in some way \\ That it is the final destiny of man. \\ Ernest Becker
}

The major concepts of this study are presented in this chapter. First, an exploration of the historical context of the issues surrounding EOL in the Western perspective will be delineated. This will include the widespread adoption of various medical technologies that led to the destabilization of death. It will discuss efforts made in the attempt to reclaim an individual's right to die without such heroic measures. The call among patients and HP reclaiming the right to die led to the emergence of the concept of a "good death." This concept will be explored in detail, to include a theoretical definition and consequences thereof. Determinants of a good death in the context of pediatric patients will also be highlighted. A related concept- "good hospital death" will be discussed. An exploration of a good hospital death in pediatric settings will be presented, including perspectives of HP. It will conclude with the critique of pertinent studies identifying HP support when caring for a dying pediatric patient, and HP report of 
lingering stress after caring for a dying pediatric patient to provide justification for the need for the proposed study.

\section{Historical Context}

Americans as a culture, have a tendency to admire triumphant stories over adversity (Chapple, 2010). They also have a particular fascination with technology. Social forces and public policy also play roles in this issue. In the current U. S. healthcare system, technologies are developed and sold at exorbitant prices, and physicians are reimbursed on procedures done, all resulting in higher levels of aggressive treatments and therapies, while fulfilling the belief in the American public's mind, the U.S. as having the best healthcare in the world (Weitz, 2013).

Destabilization of death. The fascination with technology and American exceptionalism aided in the widespread adoption of various lifesaving measures. These measures have grayed the area surrounding death, a concept that was until very recently quite evident. Helen Chapple defines this situation as "destabilizing death" (2010, p. 12). Weitz (2013) describes this phenomenon further as part of a larger societal expectation. All resuscitative efforts including cardiopulmonary resuscitation, defibrillation, and vasopressive medications are provided to all patients in need of rescue from death as a means of "death brokering"; actions healthcare providers engage in during a patient's EOL to make death "explainable, acceptable, and individually meaningful" (p. 252).

Reclaiming the right to die. As early as 1968 , members of the medical community were writing about the suffering sustained by terminally ill patients undergoing repeated resuscitative efforts, which were in fact prolonging death and distress (Symmers, 1968). Ethical arguments ensued, and ultimately a presidential 
commission was formed, whose report in 1983 reflected a larger movement in medicine at the time, which was focused on patient autonomy (Burns et al., 2003). Despite this report, aggressive resuscitative measures persisted, mainly due to fear of litigation among practitioners, and legal cases moved through the justice system eventually being heard by the Supreme Court. In Cruzan v. Missouri Department of Health, the court ruled competent individuals have the right to make their own healthcare choices ("Cruzan V. Director," 1990). In further recognition of the patients' right of autonomy, federal legislation passed in 1990 guaranteeing a patient's right to make choices regarding their health care (Patient Self-Determination Act, 2014). It mandated various healthcare agencies, excluding individual providers, be required to discuss advanced directives with patients upon admission to the hospital.

\section{Good Death}

The term "good death" has been in the healthcare literature since the early 1970's (Fox, 1974). Like many terms, its definition has evolved over time. Initially, a good death was associated with euthanasia; however with the advancement of hospice and palliative care in the U.S., this perceived connection has diminished (Kehl, 2006). Several definitions of a good death have been published, including the Institute of Medicine, which defined it as one that is: "free from avoidable distress and suffering for patients, families, and caregivers; in general accord with patients' and families' wishes; and reasonably consistent with clinical, cultural, and ethical standards" (Field \& Cassel, 1997; p. 24). The National Consensus Project for Quality Palliative Care identified eight domains of EOL care to be used to measure quality (Ferrell, 2005). These include:

- $\quad$ Structure and Process of Care 
- Physical Aspects of Care

- Psychological and Psychiatric Aspects of Care

- Social Aspects of Care

- Spiritual, Religious and Existential Aspects of Care

- Cultural Aspects of Care

- Care of the Imminently Dying Patient

- Ethical and Legal Aspects of Care

According to the NCP, all domains must be supported in order to achieve a good death.

Kehl (2006) published a concept analysis on a good death. In her analysis, the defining attributes of a good death included:

- A sense of being in control

- The patient being comfortable

- A sense of closure

- The affirmation of dying person

- The patient's trust in care providers

- A recognition of impending death

- The person's beliefs and values are honored

- A minimization of burden

- An optimization of relationships

- The appropriateness of death

- A legacy of the dying person

- The care of the family. 
Good death in pediatric population. Achieving a good death in the pediatric setting is more difficult. The death of a child seems unnatural in developed countries. Less than one percent of children who die from life-threatening conditions receive palliative or hospice services (Hendrickson \& McCorkle, 2008). This can be attributed to many factors: high cure rates among many pediatric cancers, difficulties in prognosticating the course of childhood terminal illnesses (Docherty, Miles, \& Brandon, 2007), and poor understanding or denial of prognosis among parents, the medical decision-makers for pediatric patients (Wolfe et al., 2000). In her concept analysis of a good death of a child, Welch (2008) identifies "journey, comfort, and loving presence" (p. 122) as key attributes of a good pediatric death. In their dimensional analysis of a good death of a child with cancer, Hendrickson and McCorkle (2008) identified seven dimensions of this concept, which includes:

1. Age appropriate participation

2. Personal style

3. Quality of life

4. Preparation for death

5. Aspects of care

6. Legacy

7. Impact on survivors

The authors also differentiated these dimensions among the dying child, the family and HP. In their limitations, the authors conceded the lack of literature among pediatric palliative care, and the need to interpret studies performed on adults. 
Good hospital death in pediatrics. The majority of studies investigating preferred place of death is focused on adults. The findings from these studies indicate the preferred place of death is in the home (Gott et al., 2008; Paddy, 2011; Yao et al., 2007). Adults reported barriers to dying at home include: fear of dying alone (Seale, 2004), burdening loved ones, or causing distress to the caregivers (Evans \& Walsh, 2002).

There is limited information on a dying child's preferred place of death. Bluebond-Langner et al. (2013) published a systematic review of the literature on preferred place of death among children with life-limiting and life-threatening conditions. The authors identified nine total studies, only one of which surveyed the adolescent patient. While most of the studies suggest a preference for a home death, results were not conclusive. Most of these studies were retrospective in nature and based on parent report; therefore, it is difficult to draw meaningful conclusions from existing research.

Achieving a good hospital death can be challenging in any patient population.

Decisions to withhold or withdraw treatment are more likely to occur in the hospital. Transition to comfort care only is also unique to the hospital setting; persons in the home usually have already made that decision. Having the time and ability to make these decisions has implications among patients' and families' perceptions of a good death (DelVecchio-Good et al., 2004).

\section{Health Professionals' Perceptions of a Good Pediatric Hospital Death.}

In order to better understand what constitutes a good hospital death in pediatrics, it is important to also consider the perspective of the health care providers. Few studies exist seeking information on HP perceptions of a "good death" within the pediatric hospital setting. One study asked 30 adult palliative care staff in Buenos Aires to describe 
their experiences with "good deaths" and "bad deaths" (Luxardo, Padros, \& Tripodoro, 2014). When discussing "good deaths" abstractly, their responses were encompassed in the following main themes: control of physical symptoms, patient was on good terms with family, and the patient was at peace with their life and God. "Bad deaths" were associated with poor management of symptoms, especially pain, poor family interactions, and poor communication between the patient, the family and the staff members.

Researchers in another study sought nurses' opinions on facilitators and barriers to providing a good death in the adult critical care area (Beckstrand, Callister, \& Kirchhoff, 2005). The respondents identified environmental supports to promote dying with dignity, presence, management of pain, adhering to patient wishes, earlier withholding or withdrawing of aggressive treatment, and effective communication among HP as being facilitators of a good death in the hospital. Barriers included not enough nurses, poor communication among healthcare team members, and unilateral treatment decisions based on physician's needs, not the patient's.

Beckstrand, Rawle, Callister, \& Mandleco (2010) asked pediatric intensive care nurses throughout the U.S. to identify facilitators and barriers to EOL care via a mailed questionnaire. Respondents identified actions that facilitated high quality EOL care included: family having time with their child alone after death, family being able to hold the dying child as life support is removed, providing a calm setting for families, and clear communication of code status among healthcare workers. Barriers identified included: language barriers, parental discomfort in withholding or withdrawing life support, poor interprofessional communication, and denial of impending death among parents. Although large in scope $(n=474)$, this study looked solely at nurses in critical care areas. 
Contro, Larson, Scofield, Sourkes, and Cohen (2004) examined HP perspectives of quality pediatric palliative care as part of a study comparing their attitudes with those of the bereaved family members. Hospital staff in the participant pool included doctors, residents, nurses, social workers, psychosocial support staff, and ancillary staff members working at a children's hospital in Northern California. Care areas represented in the sample included the neonatal intensive care unit, pediatric intensive care units, oncology unit, general pediatrics, and specialty care areas. Themes related to quality of hospital death shared by staff and family members were: communication, pain management, and ongoing support. A limitation to this study was that it asked hospital staff participants about their comfort with EOL care in general, not related to a specific death event. It also failed to recruit HP from the emergency department.

\section{Meeting Needs of the Caregiver}

Not surprisingly, palliative care professionals ranked death of a young person as the most emotionally difficult situation they face (Luxardo et al., 2014). A seminal study by Papadatou, Papazoglou, Petraki, \& Bellali (1999) identified common areas of support desired by nurses' who care for dying children. The nurses identified informational support, clinical support, emotional support, and meaning-making support as central to providing optimal care of dying pediatric patients. This support may be operationalized formally or informally, by involvement in support groups and debriefing sessions, or by providing time for reflection and collaboration among care providers. In another review

of the literature Carton \& Hupcey (2014) highlighted two observational studies on available supports for nurses caring for dying children. These studies showed healthcare workers in the U.K. report higher percentage of available support when compared to 
nurses in the U.S. The authors also note "A lack of representation of the full range of health disciplines is evident within the literature. Further clarification is needed on the prevalence of health care provider grief in the context of patient population, as well as on the efficacy of interventions among a variety of health care disciplines" (p. 301). Conte (2011) sought to identify formalized support services among members of the Children's Oncology Group, the main research consortium for pediatric oncology in the U. S. Seventy-eight of 193 eligible institutions participated in this telephone survey.

Respondents identified available supports within the work setting which are listed in table 1 below:

Table 1:

Number of Institutions Providing Services (Conte 2011)

\begin{tabular}{cl}
\hline a) $\begin{array}{c}\text { \# Of Institutions } \\
\text { Providing Service (\%) }\end{array}$ & b) Description of Service Provided \\
\hline $19(24 \%)$ & Caregiver grief addressed in orientation \\
$7(9 \%)$ & Continuing education for caregiver grief \\
$40(51 \%)$ & Debrief sessions after death of a child \\
$7(9 \%)$ & Mental health referral (formal) \\
$6(8 \%)$ & Memorial services \\
$6(8 \%)$ & Consultation with chaplain or social worker (informal) \\
$2(3 \%)$ & Staff retreats \\
$2(3 \%)$ & Grief luncheons \\
$1(1 \%)$ & Bi-weekly team meetings
\end{tabular}

These results suggest a need for increased focus on formal support services at the organizational level.

Peer support as a coping strategy has been identified in several studies (Contro et al., 2004; Liben, Papadatou, \& Wolfe, 2008; Peterson et al., 2010; Wright, Prasun, \& Hilgenberg, 2011). Spending time with the family after a patient died was recognized as helpful to nurses as well (Wright et al., 2011). Reliance on religion and maintaining relationships with families were also positive supportive measures identified on an 
individual level (Peterson et al., 2010). Other self-care support has been mentioned anecdotally, including meditation, exercise, journaling, and seeking educational opportunities (Wolfe, 2008). Self-care practices that may have negative consequences include emotional distancing and depersonalization (Contro et al., 2004). Further research is needed to establish which supports offered are most helpful to HP after caring for a dying child, and discover other sources of support HP recalling a specific death event may find valuable.

\section{Lingering Stress}

Closely related to sources of support, ongoing stress has been reported among HP working with dying pediatric patients. Lingering stress among HP has been identified as a result of: personal grief related to the loss of the child, feelings of failure to rescue (Liben, et al., 2008), witnessing prolonged suffering and futile treatments, lack of agreement among HP regarding treatment plan (Beckstrand et al., 2010), and communicating with the patient and their family about imminent death (Brunard, 2008). Further sources of ongoing stress among nurses include lack of proper training (Burns \& Rushton, 2004; Contro et al., 2004; Liben et al., 2008; Peterson et al., 2010; Wright et al., 2011), internal and external pressure to suppress expression of grief (Georges et al., 2002; Peterson et al., 2010), and inadequate orders for pain relief (Luxardo et al., 2014).

Lingering stress is a concern for HP. Grief takes time to resolve, which is in short supply in the hospital setting. Liben et al. (2008) define the grieving process as "an ongoing fluctuation between experiencing grief by focusing on the loss, and avoiding or repressing grief by moving away from it" (p. 859). This is considered to be a healthy grief response. The authors assert problems arise when "care providers do not have 
fluctuating feelings and are either submerged in their grief, or systematically suppress and deny it" (p.859). Suppression of feelings of grief has important ramifications in HP ability to provide care. Long-term suppression of emotions can result in compassion fatigue. Compassion fatigue is a term coined to describe emotional consequences of HP working in traumatic situations. Although compassion fatigue is typically attributed to professions such as emergency medical technicians and emergency department personnel, Rourke (2007) asserts HP working with dying children are subject to intense traumas on a regular basis.

Compassion fatigue may be manifested in the psychological, cognitive, or interpersonal domains (Rourke, 2007), and common symptoms include: strong emotions, anxiety, increased sense of personal responsibility, withdrawing from others, and detachment from emotional situations or experiences. This emotional detachment can cause impaired relationships with patients and their families, and inadvertently increase their suffering. A story from a parent interviewed by Contro et al. (2004) exemplifies this:

I know he had to ask if we didn't want our son resuscitated. It's just the way he did it. It was very cold.... It was very negative talk about our son dying. He had him sold down the road. Then he looked at whomever else was in the room and said, "Okay, let's go to lunch!" That sent me. It just sent me. I though, "How can you be so cold?" I do remember that, and it made me very angry. (p. 1250) Compassion fatigue may result in burnout among HP caring for dying children, leading to increased turnover and decreased patient satisfaction scores in the affected 
patient care areas. It is important to identify and alleviate ongoing stress as a precursor to compassion fatigue and burnout.

\section{Literature Search}

A literature search was performed for each aim. All literature searches were conducted on MEDLINE (1950-November 2014) and CINAHL (1982-November 2014) on December 6, 2014. Dates were limited to 2008-2014 for currency. Only English articles were included in the search. For the first two aims, the keywords "quality of death", "quality of dying", "good death" and "bad death" were entered using the connector "or" to locate articles using any of these terms. A separate search for "pediatrics" or "child*" keywords was performed. These two search results were combined with "and" to search for articles relating specifically to quality of pediatric EOL. This final search resulted in 240 articles, which were reviewed individually. Four research articles were identified as appropriate for this aim, two of which (Luxardo et al., 2014; Beckstrand et al., 2010) have already been discussed. The third and fourth are highlighted below.

Aim \#1 and \#2. A qualitative study by Price, Jordan, and Prior (2013), sought HP perspectives of challenges regarding caring for children at EOL. A total of 35 participants included physicians, hospital, hospice and community nurses, health care assistants, play specialists, teachers, and physiotherapists caring for dying children in the U.K.

Challenges in the context of caring for dying children were explored in focus groups; emerging themes related to these challenges included: honest communication, symptom management, relationships between staff and families, emotional impact, treatment withdrawal, and support of siblings. Limitations to generalizability include cultural and 
policy differences between HP in the U.S. and U.K., and focus groups discussing EOL care in the abstract, not related to a specific death event.

A recent quantitative study by Sellers, Dawson, Cohen-Bearak, Solomond, and Truong (2014) assessed the reliability and validity of a newly developed instrument: the Clinician PICU quality of dying and death 20 (PICU-QODD-20). This instrument was adapted from the adult QODD, after focus groups of HP, interviews with parents, and a review of the literature, resulting in 13 emergent themes corresponding with the quality of dying and death:

- Communication

- Privacy and environmental control

- Withdrawal of life-sustaining treatment

- EOL decision-making

- Symptom management

- Emotional support of the child

- Emotional support of the family

- Physical and logistic needs of the family

- Spiritual and cultural support

- Continuity of care

- Parent as caretaker

- Grief and bereavement

- The death event

The results showed strong reliability with an overall Cronbach alpha of .89 or greater among various HP with data produced by various HP that demonstrated high 
construct validity to the three theoretically proposed constructs $(\mathrm{r}=.14-.80)$ with significance ( $\mathrm{p}<.05$ or less) or trending toward significance in all measures. However, this study only included nurses, physicians, and psychosocial professionals working in the PICU of two hospitals in one region of the U.S. Also, as this article sought to demonstrate the reliability and validity of the modified QODD, there was no exploration of how these themes corresponded in the overall quality of the particular death event.

Aim \#3. To find literature related to the third aim, the subject headings "clinician", "healthcare worker", "nurse", "doctor", "physician", "chaplain", "social worker", and "respiratory therapist" were entered with "or" as the connector. A second search of the subject headings: "end-of-life care", "death", or "dying" was then performed. A third search of the subject headings "child*" or "pediatric" was run. Lastly, a fourth search of "support" or "promoters" was created. These four searches were then combined using the connector term "and", which resulted in 37 studies. These were reviewed individually, and eleven research articles met the description for the second aim of the proposed study. See table 2 below for a review of these articles.

Aim \#4 . To find relevant literature for the fourth aim, the subject headings "stress", "compassion fatigue", "grief", and "burnout" were run using the connector "or" to locate articles using any of these terms. A second search of the subject headings: "endof-life-care", "death", or "dying" was then performed. A third search of the subject headings "child*" or "pediatric" was run. A fourth search of the subject headings "clinician", "healthcare worker", "nurse", "doctor", "physician", "chaplain", "social worker", and "respiratory therapist" were entered with "or" as the connector was performed. These four searches were then combined using the connector term "and", 
which resulted in 50 studies. These were reviewed individually; ten met the description of Aim 3, five of which were discovered in the literature search for Aim 2. Because of the high correlation between perceived support and lingering stress, several of the articles provide findings important to both aims $\# 3$ and $\# 4$; consequently, these 16 articles are combined and presented in the table below: 
Table 2

Relevant Articles for Aims \#3 and \#+ of the Study:

\begin{tabular}{|c|c|c|c|c|c|}
\hline Authors & Participants & Method & Location & Findings & Limitations \\
\hline $\begin{array}{l}\text { Peterson et } \\
\text { al. }(2010)\end{array}$ & 15 nurses & $\begin{array}{l}\text { Grounded } \\
\text { Theory. } \\
\text { Individual } \\
\text { Interviews } \\
\text { asking } \\
\text { participants } \\
\text { about } \\
\text { perceived } \\
\text { supports for } \\
\text { EOL care }\end{array}$ & $\begin{array}{l}\text { University } \\
\text { Hospital in } \\
\text { Midwest }\end{array}$ & $\begin{array}{l}\text { Supports that emerged fell into } \\
\text { one of two types } \\
\text { Internal Resources: } \\
\text { - } \quad \text { Evaluating the death } \\
\text { - Maintaining professional } \\
\text { distance } \\
\text { External Resources: } \\
\text { - Peer support } \\
\text { - Religion } \\
\text { - Patients and families }\end{array}$ & $\begin{array}{l}\text { Focused on } \\
\text { adult EOL } \\
\text { Not related to } \\
\text { specific death } \\
\text { event } \\
\text { Nurses only }\end{array}$ \\
\hline $\begin{array}{l}\text { Wright et } \\
\text { al. (2011) }\end{array}$ & $\begin{array}{l}50 \mathrm{NICU} \\
\text { nurses }\end{array}$ & $\begin{array}{l}\text { Quantitative } \\
\text { cross- } \\
\text { sectional } \\
\text { questionnaire } \\
\text { asking } \\
\text { participants to } \\
\text { describe } \\
\text { facilitators to } \\
\text { EOL care } \\
\text { practices in } \\
\text { the NICU }\end{array}$ & $\begin{array}{l}\text { Medical } \\
\text { center in } \\
\text { Midwest }\end{array}$ & $\begin{array}{l}\text { Eight facilitators to EOL care } \\
\text { practices: } \\
\text { - } \quad \text { Support from medical staff } \\
\text { - } \quad \text { Parental decision-making } \\
\text { - } \quad \text { Informed parents } \\
\text { - } \quad \text { Support for palliative care } \\
\text { - } \quad \text { Staffing } \\
\text { - } \quad \text { Time with patient and family } \\
\text { - } \quad \text { Palliative care policies } \\
\text { - } \quad \text { Counseling for staff }\end{array}$ & $\begin{array}{l}\text { NICU focused } \\
\text { Not focused } \\
\text { on a specific } \\
\text { death event } \\
\text { Nurses only }\end{array}$ \\
\hline $\begin{array}{l}\text { Puia, D. M., } \\
\text { Lewis, L., } \\
\text { \& Beck, C. } \\
\text { T. (2013) }\end{array}$ & $\begin{array}{l}\text { Members of } \\
\text { Association } \\
\text { of Women's } \\
\text { Health, } \\
\text { Obstetric } \\
\text { and } \\
\text { Neonatal } \\
\text { Nurses }\end{array}$ & $\begin{array}{l}\text { Secondary } \\
\text { data analysis } \\
91 \text { cases - } \\
\text { descriptions } \\
\text { of experience } \\
\text { with fetal or } \\
\text { infant death } \\
\text { experience }\end{array}$ & Nationwide & $\begin{array}{l}\text { Six themes emerged: } \\
\text { "Getting through the shift" } \\
\text { (p. 321) } \\
\text { - Physical grief response } \\
\text { Frustrations at inadequate } \\
\text { care } \\
\text { - } \quad \text { Providing best care possible } \\
\text { Lingering grief }\end{array}$ & $\begin{array}{l}\text { Perinatal } \\
\text { focused } \\
\text { Not focused } \\
\text { on specific } \\
\text { death event } \\
\text { Lack of } \\
\text { temporality } \\
\text { Nurses only }\end{array}$ \\
\hline $\begin{array}{l}\text { Beckstrand } \\
\text {, R. L., } \\
\text { Collette, J., } \\
\text { Callister, } \\
\text { L., \& Luthy, } \\
\text { K. E. (2012) }\end{array}$ & $\begin{array}{l}380 \\
\text { oncology } \\
\text { nurses }\end{array}$ & $\begin{array}{l}69 \text { item } \\
\text { survey } \\
\text { seeking EOL } \\
\text { care barriers } \\
\text { and } \\
\text { facilitators }\end{array}$ & Nationwide & $\begin{array}{l}\text { Supportive behaviors identified: } \\
\text { - } \quad \text { Family time with deceased } \\
\text { - } \quad \text { Calm environment } \\
\text { - } \quad \text { Access to patient as desired } \\
\text { - } \quad \text { Palliative care team }\end{array}$ & $\begin{array}{l}\text { Not pediatric } \\
\text { specific } \\
\text { Oncology } \\
\text { specific } \\
\text { Nurses only }\end{array}$ \\
\hline $\begin{array}{l}\text { Brown- } \\
\text { Saltzman, } \\
\text { K., } \\
\text { Upadhya, } \\
\text { D., Larner, } \\
\text { L, \& } \\
\text { Wenger, N. } \\
\text { S. (2010) }\end{array}$ & $\begin{array}{l}78 \\
\text { respiratory } \\
\text { therapists } \\
\text { (RT) }\end{array}$ & $\begin{array}{l}\text { Intervention } \\
\text { study with } \\
\text { repeated } \\
\text { measures } \\
\text { questionnaire }\end{array}$ & $\begin{array}{l}\text { Los Angeles } \\
\text { university and } \\
\text { community } \\
\text { hospital }\end{array}$ & $\begin{array}{l}\text { An intervention consisting of a 1- } \\
\text { day education program including } \\
\text { didactic and role-play sessions } \\
\text { increased: } \\
\text { - } \quad \text { RT comfort with EOL } \\
\text { - } \quad \text { RT role identification } \\
\text { - }\end{array}$ & $\begin{array}{l}\text { RT only } \\
\text { One specific } \\
\text { intervention }\end{array}$ \\
\hline $\begin{array}{l}\text { Baverstock } \\
\text { A., \& } \\
\text { Finlay, F. } \\
\text { (2008) }\end{array}$ & $\begin{array}{l}61 \text { pediatric } \\
\text { consultants }\end{array}$ & $\begin{array}{l}\text { Mailed survey } \\
\text { with open text } \\
\text { responses } \\
\text { regarding } \\
\text { their } \\
\text { experience } \\
\text { caring for a } \\
\text { dying child. }\end{array}$ & $\begin{array}{l}\text { U. K. } \\
\text { Southwest } \\
\text { region }\end{array}$ & 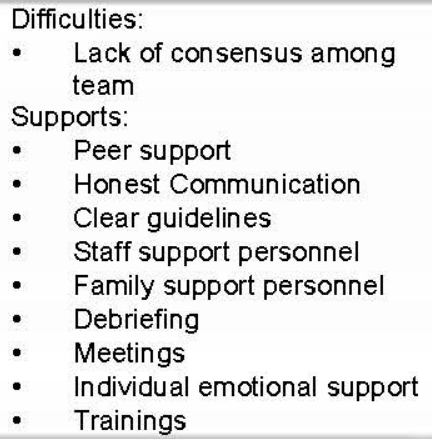 & $\begin{array}{l}\text { U.K. health } \\
\text { system } \\
\text { Consultants } \\
\text { only }\end{array}$ \\
\hline $\begin{array}{l}\text { Macpherso } \\
\text { n, C. F. } \\
(2008)\end{array}$ & $\begin{array}{l}6 \text { pediatric } \\
\text { oncology } \\
\text { nurses } \\
\text { reporting } \\
\text { lingering } \\
\text { grief }\end{array}$ & $\begin{array}{l}\text { Intervention } \\
\text { study } \\
\text { repeated } \\
\text { measures } \\
\text { questionnaire }\end{array}$ & $\begin{array}{l}\text { Seattle. WA } \\
\text { tertiary care } \\
\text { unit }\end{array}$ & $\begin{array}{l}\text { Intervention of dyad storytelling } \\
\text { of the dying child resulted in } \\
\text { - Verbalization of support } \\
\text { - } \quad \text { Able to make meaning }\end{array}$ & $\begin{array}{l}\text { Small number } \\
\text { of participants } \\
\text { Oncology } \\
\text { nurses only } \\
\text { Single } \\
\text { intervention }\end{array}$ \\
\hline
\end{tabular}




\begin{tabular}{|c|c|c|c|c|c|}
\hline $\begin{array}{l}\text { Keene, E. } \\
\text { A., Hutton, } \\
\text { N., Hall, B., } \\
\text { \& Rushton, } \\
\text { C. (2010) }\end{array}$ & $\begin{array}{l}184 \\
\text { responses } \\
\text { from various } \\
\text { healthcare } \\
\text { professionals } \\
\text { experiencing } \\
\text { pediatric } \\
\text { patient death }\end{array}$ & $\begin{array}{l}\text { Intervention } \\
\text { study } \\
\text { Repeated } \\
\text { measures } \\
\text { survey }\end{array}$ & $\begin{array}{l}\text { Johns } \\
\text { Hopkins' } \\
\text { Hospital }\end{array}$ & $\begin{array}{l}\text { Intervention of debriefing } \\
\text { - } \quad \text { Helpful } \\
\text { impacilitator experience is } \\
\text { important }\end{array}$ & $\begin{array}{l}\text { Single support } \\
\text { intervention } \\
\text { Quality } \\
\text { Improvement } \\
\text { project }\end{array}$ \\
\hline $\begin{array}{l}\text { Hansen, L., } \\
\text { Goodell, T. } \\
\text { T., } \\
\text { DeHaven, } \\
\text { J., \& } \\
\text { Smith, M.-- } \\
\text { D. (2009) }\end{array}$ & $\begin{array}{l}91 \text { critical care } \\
\text { nurses }\end{array}$ & $\begin{array}{l}\text { Intervention } \\
\text { study, } \\
\text { repeated } \\
\text { measures } \\
\text { questionnaire } \\
\text { including one } \\
\text { open-text } \\
\text { response item }\end{array}$ & $\begin{array}{l}\text { One } \\
\text { hospital in } \\
\text { Oregon }\end{array}$ & $\begin{array}{l}\text { Multiple interventions: } \\
\text { - } \quad \text { Family bereavement group } \\
\text { - } \quad \text { Palliative care team } \\
\text { - } \quad \text { Mental hithdrawal order set } \\
\quad \text { specialist for staff } \\
\text { - } \quad \text { EOL care education } \\
\text { Resulted in: } \\
\text { - Increased knowledge } \\
\text { - Improved work environment } \\
\text { - Increased staff support } \\
\text { - Increased family support } \\
\quad \text { Decreased work stress }\end{array}$ & $\begin{array}{l}\text { Nurses only } \\
\text { Adult patients } \\
\text { Lack of post- } \\
\text { hoc analysis } \\
\text { to identify } \\
\text { which } \\
\text { interventions } \\
\text { were most } \\
\text { helpful }\end{array}$ \\
\hline $\begin{array}{l}\text { Gallagher, } \\
\text { R., \& } \\
\text { Gormley, } \\
\text { D. K. } \\
(2009)\end{array}$ & $\begin{array}{l}30 \text { Bone } \\
\text { Marrow } \\
\text { Transplant } \\
\text { nurses }\end{array}$ & $\begin{array}{l}\text { Descriptive, } \\
\text { nonexperimen } \\
\text { tal } \\
\text { Maslach } \\
\text { Burnout } \\
\text { Inventory and } \\
\text { questionnaire } \\
\text { regarding } \\
\text { perceptions of } \\
\text { work stress } \\
\text { and support }\end{array}$ & $\begin{array}{l}\text { Pediatric } \\
\text { hospital in } \\
\text { the Midwest }\end{array}$ & $\begin{array}{l}\text { Top three stressors: } \\
\text { - Workload } \\
\text { - Dying patients } \\
\text { Improving support suggestions: } \\
\text { - } \quad \text { Workload relief } \\
\quad \text { Improved teamwork and } \\
\text { - } \quad \text { Administrative support }\end{array}$ & $\begin{array}{l}\text { Bone Marrow } \\
\text { Transplant } \\
\text { nurses only } \\
\text { Article I. } \\
\text { Article II. }\end{array}$ \\
\hline $\begin{array}{l}\text { Wenzel, J., } \\
\text { Shaha, M., } \\
\text { Klimmek, } \\
\text { R., \& } \\
\text { Krumm, s. } \\
\text { (2011) }\end{array}$ & $\begin{array}{l}34 \text { oncology } \\
\text { nurses }\end{array}$ & $\begin{array}{l}\text { Qualitative } \\
\text { descriptive } \\
\text { focus groups }\end{array}$ & $\begin{array}{l}\text { Cancer } \\
\text { center Mid- } \\
\text { Atlantic } \\
\text { university } \\
\text { teaching } \\
\text { hospital }\end{array}$ & $\begin{array}{l}\text { Support suggestions: } \\
\text { - } \quad \text { Time and space for self-care } \\
\text { - } \quad \text { debriefings } \\
\text { - } \quad \text { Palliative care teams } \\
\text { - } \quad \text { Nime with patients and families } \\
\text { - } \quad \text { Organization considerations, } \\
\text { including knowledge } \\
\text { infrastructure }\end{array}$ & $\begin{array}{l}\text { Not pediatric } \\
\text { focused } \\
\text { Not focused } \\
\text { on specific } \\
\text { death event } \\
\text { Oncology } \\
\text { nurses only }\end{array}$ \\
\hline $\begin{array}{l}\text { Aycock, N., } \\
\& \text { Boyle, } \\
\text { D., (2008) }\end{array}$ & $\begin{array}{l}103 \text { Oncology } \\
\text { Nurse Society } \\
\text { (ONS) } \\
\text { members }\end{array}$ & $\begin{array}{l}\text { Descriptive } \\
\text { survey } \\
\text { seeking } \\
\text { supports to } \\
\text { manage } \\
\text { compassion } \\
\text { fatigue }\end{array}$ & $\begin{array}{l}\text { Surveys } \\
\text { distributed } \\
\text { at local } \\
\text { ONS } \\
\text { chapter } \\
\text { meetings } \\
\text { nationwide }\end{array}$ & $\begin{array}{l}\text { Onsite resources available: } \\
\quad \text { Employees Assistance } \\
\quad \text { Programs } \\
\text { - } \quad \text { Pastoral counseling } \\
\text { Limited access to mental health } \\
\text { professionals } \\
\text { Lack of educational opportunity to } \\
\text { develop self-care reported }\end{array}$ & $\begin{array}{l}\text { Oncology } \\
\text { nurses only } \\
\text { Not focused } \\
\text { on specific } \\
\text { death event }\end{array}$ \\
\hline $\begin{array}{l}\text { Conte, T. } \\
\text { M. (2014) }\end{array}$ & $\begin{array}{l}11 \text { pediatric } \\
\text { oncology } \\
\text { nurses }\end{array}$ & $\begin{array}{l}\text { Qualitative } \\
\text { interviews } \\
\text { exploring the } \\
\text { phenomenon } \\
\text { of being a } \\
\text { pediatric } \\
\text { oncology } \\
\text { nurse. }\end{array}$ & $\begin{array}{l}\text { Children's } \\
\text { hospital on } \\
\text { the West } \\
\text { Coast }\end{array}$ & $\begin{array}{l}\text { Five themes emerged related to the } \\
\text { phenomenon of being a pediatric } \\
\text { oncology nurse: } \\
\text { - Connectedness- to patients and } \\
\text { nurses } \\
\text { - Alienation-from loved ones } \\
\text { related to protection } \\
\text { Action-"doing for" the patient } \\
\text { - Maintaining control-of their } \\
\text { emotions (distancing) } \\
\text { A changed perspective-on their } \\
\text { life }\end{array}$ & $\begin{array}{l}\text { Pediatric } \\
\text { oncology } \\
\text { nurses only }\end{array}$ \\
\hline
\end{tabular}




\begin{tabular}{|c|c|c|c|c|c|}
\hline $\begin{array}{l}\text { Meade, K., } \\
\text { Pope, J., } \\
\text { Weise, K., } \\
\text { Prince, L., \& } \\
\text { Friebert, S. } \\
\text { (2012) }\end{array}$ & $\begin{array}{l}155 \text { nurses } \\
\text { and RT } \\
\text { working in } \\
\text { the PICU }\end{array}$ & $\begin{array}{l}\text { Survey based- } \\
\text { scenario } \\
\text { Survey measured } \\
\text { Moral Distress, } \\
\text { Mismatch of } \\
\text { expectation, and } \\
\text { Job dissatisfaction } \\
\text { giving a total } \\
\text { distress score }\end{array}$ & $\begin{array}{l}3 \text { academic } \\
\text { tertiary care } \\
\text { pediatric } \\
\text { hospitals in } \\
\text { Northeast } \\
\text { Ohio }\end{array}$ & $\begin{array}{l}\text { Scenario consists of vignette } \\
\text { describing critically ill pediatric } \\
\text { patient with complex } \\
\text { medical/neurological history } \\
\text { Survey sought participants' level of } \\
\text { agreement with aggressive } \\
\text { treatment plan; a statistically } \\
\text { significant correlation was found } \\
\text { between subjects reporting } \\
\text { preference for less aggressive } \\
\text { treatment and high level of total } \\
\text { distress }\end{array}$ & $\begin{array}{l}\text { Imagined } \\
\text { scenario, } \\
\text { RT and } \\
\text { nurses only, } \\
\text { PICU only }\end{array}$ \\
\hline $\begin{array}{l}\text { McCloskey, } \\
\text { S., \& } \\
\text { Taggart, L. } \\
\text { (2010) }\end{array}$ & $\begin{array}{l}18 \text { palliative } \\
\text { care nurses }\end{array}$ & $\begin{array}{l}\text { Qualitative focus } \\
\text { groups seeking } \\
\text { information on } \\
\text { occupational } \\
\text { stress }\end{array}$ & $\begin{array}{l}\text { Children's } \\
\text { hospice } \\
\text { nurses, } \\
\text { community } \\
\text { children's } \\
\text { nurses and } \\
\text { hospital } \\
\text { nurses in } \\
\text { Northern } \\
\text { Ireland }\end{array}$ & $\begin{array}{l}\text { Emergent themes: } \\
\text { Demands-emotional, ethical, } \\
\text { practical, logistical, administrative, } \\
\text { and geographical (living and } \\
\text { working in the same area) } \\
\text { Relationships-between nurse and } \\
\text { patient and family (can be difficult, } \\
\text { under-developed, or enmeshed) } \\
\text { Maintaining control-of workload } \\
\text { Support and role- lack of support, } \\
\text { unclear role, lack of recognition }\end{array}$ & $\begin{array}{l}\text { Palliative } \\
\text { care nurses } \\
\text { only } \\
\text { U. K. health } \\
\text { system } \\
\text { Not related } \\
\text { to a specific } \\
\text { death event }\end{array}$ \\
\hline $\begin{array}{l}\text { Lyndes, K. } \\
\text { A., Fitchett, } \\
\text { G. Berlinger, } \\
\text { N., Cadge, } \\
\text { W., Misasi, } \\
\text { J., \& } \\
\text { Flanagan, E. } \\
\text { (2012) }\end{array}$ & $\begin{array}{l}\text { Eight } \\
\text { chaplains } \\
\text { and eight } \\
\text { medical } \\
\text { directors of } \\
\text { established } \\
\text { pediatric } \\
\text { palliative } \\
\text { care centers }\end{array}$ & $\begin{array}{l}\text { Part two of two- } \\
\text { phase study. } \\
\text { Qualitative, } \\
\text { individual } \\
\text { interviews to } \\
\text { ascertain themes } \\
\text { of spiritual care } \\
\text { services and staff } \\
\text { relationships }\end{array}$ & $\begin{array}{l}\text { Eight } \\
\text { pediatric } \\
\text { palliative } \\
\text { care } \\
\text { centers } \\
\text { nationwide }\end{array}$ & $\begin{array}{l}\text { Themes emerging from the } \\
\text { interviews included: } \\
\text { - Caring for patients and } \\
\text { families- includes spiritual, } \\
\text { ritual, community connections } \\
\text { - Facilitating communication- } \\
\text { among family and staff } \\
\text { Support team-during conflict, } \\
\text { also provides education } \\
\text { related to spiritual issues }\end{array}$ & $\begin{array}{l}\text { Focused on } \\
\text { chaplain's } \\
\text { roles, and } \\
\text { spiritual } \\
\text { services }\end{array}$ \\
\hline
\end{tabular}

\section{Summary}

The preceding section summarized both the current state of the science surrounding HP perspectives of facilitators and barriers to a good pediatric hospital death as well as provided context demonstrating the need for further study. Existing literature also supports the current lack of understanding of effective support measures among various HP working with dying children and their families, and themes related to lingering stress reported among various HP related to a specific death event. Exploring the lived experience of various HP working with dying children and families in specific reference to these aims will add meaningfully to the current level of understanding of this topic. 


\section{CHAPTER 3}

\section{Methods}

"Research is supposed to train the mind into channels of scientific (and therefore respectable) thought, but does not this kind of research sometimes encourage the erroneous belief that only that which can be measured is worthy of serious attention?

Not everything we count counts. Not everything that counts can be counted" Lord Platt, 1967

This chapter provides an overview of the methods and procedures used in this study. It also presents the parent study; the research design utilized for the current study, the sample description and size, the data collection procedures, and analysis methods employed. It begins with a description of the research methodology and philosophy chosen for the proposed study.

The overall purpose of this study was to explore HP lived experience of a good pediatric death in the hospital setting. Specifically, the aims of this study were to:

1. Explore themes that HP associate with a good hospital death in the pediatric setting.

2. Explore themes that HP associate with a bad hospital death in the pediatric setting.

3. Explore concepts surrounding HP identification of their own needs being met when caring for a dying child in the hospital.

4. 
5. Explore concepts surrounding HP report of unresolved feelings or stress experienced after caring for a dying child in the hospital.

Due to the dearth of research on this topic, as well as its sensitive nature and involvement with a highly vulnerable population, phenomenology was an appropriate choice in terms of both philosophy and methodology. According to Polit and Beck, phenomenologic research asks, "What is the essence of this phenomenon as experienced by these people and what does it mean?" (2012, p. 494).

\section{Philosophical Underpinunings}

In order to appreciate the use of phenomenology as a research methodology, it is imperative to understand its philosophical underpinnings. Edmond Husserl introduced phenomenology as a philosophy. Husserl's concept of phenomenology evolved over time and several of Husserl's students' concepts evolved even further. Husserl proposed phenomenology was based upon examining intentionality, or conscious thought towards an object (Holloway \& Wheeler, 2010). Central to Husserl's philosophy is the concept of bracketing- the "putting aside" of the researcher's preconceived notions to prevent a biased analysis of the data. All humans view the world from their own perspective (lebenswelt); therefore, the conscious effort to bracket the researcher's biases is crucial in Husserl's phenomenology to prevent misinterpretation of the data.

A student of Husserl, Heidegger further developed phenomenology to include the idea of temporality that is innate in humans (Leonard, 1994). Heidegger believed in addition to describing a phenomenon, it is possible to interpret the findings to explore the meaning of the phenomena under study in a specific time. He further argued since their 
unique ontologic perspective binds all humans, it is necessary to consider this to more fully understand their epistemologic stance on the phenomena under study.

From these similar but distinct schools of phenomenological philosophy emerged two methodologies for phenomenologic study: descriptive and interpretive. Based on the original definition from Husserl, descriptive phenomenology attempts to remove the researcher's stance as a potential confounder of the data under study. Conversely, interpretive phenomenology is intentional in including each participant's perspectiveincluding the researcher- as contextual and necessary for understanding and making meaning of the phenomenon under study.

\section{Researcher's Context and Assumptions}

Congruent with the tenets of phenomenology, it is necessary to render salient my own context as a researcher in analyzing the data from this study. I have worked with children throughout my 20 year nursing career, and I have born witness to or been made aware of the passing of several children for whom I provided care. Most recently, I worked in a school program for medically homebound students, as well as students who reside in a long-term convalescent center for children. While in this role, several students died during their tenure in the program, and I was struck by the variance of the quality of the death as described by the HP that cared for them. I also lost a sibling quite suddenly when he was a child, and because I was not there at the time of his dying, I cannot know the quality of his death. The story the social worker told detailing how the paramedic at the scene attempted resuscitative efforts to the point of her own physical exhaustion, echoes in my mind in a peculiar collision of my identity as both family member and nurse. I can only hope these findings will help make the journey of dying in the pediatric 
hospital more comforting to those unfortunate enough to go through it: children, their families, and their caregivers.

\section{Research Design}

This study utilized an interpretive phenomenological analysis of pre-collected data from a previously performed study. The parent study consisted of an online survey, containing both quantitative and qualitative data regarding HP opinions and attitudes regarding pediatric death, conducted at a large children's hospital in Southern California. In the current study, the open-ended qualitative responses from the online survey were analyzed using an interpretive phenomenological approach. Specifically, this text was analyzed for themes associated with the HP lived experience of good or bad pediatric hospital deaths, identification of HP needs being met, and unresolved feelings or stress experienced by HP when caring for a dying child in the context of a specific death event. Thus, this analysis of pre-collected data constituted a secondary data analysis approach. Secondary datasets offer unique benefits and challenges to researchers (Boslaugh, 2007). The benefits include: savings of time, expense, and effort on the part of the researcher. The possible limitations include: lack of control on the part of the researcher to design the research questions, and the absence of any individual participant's identifying information, due to lack of consent for such, when clarification was needed. Additionally, the use of secondary data can involve conceptualizations of key attributes that may not align with this researcher's definition. A particular concern related to qualitative analysis using a secondary dataset is one of epistemologic closeness; described by Irwin (2013, p. 297) as, "the possibility of effective interpretation and analysis of data by those who come to it from a distance, uninvolved in the process of data creation." Since the data in 
this study are obtained from a parent study in which the researcher was not involved, it is difficult to know if the researcher was effectively able to obtain epistemologic closeness.

Parent study inclusion and exclusion criteria. Eligible participants in the parent study included nurses, respiratory therapists, social workers, pastors, nurse practitioners, medical doctors, palliative team members, or any other supportive care team member at a large children's hospital in Southern California. Staff members working in the pediatric intensive care unit, the neonatal intensive care unit, the hematology/oncology unit, the medical or surgical floors, the emergency department, and the convalescent center were eligible to participate in the survey. To be eligible for the parent study, the participant must have worked with a pediatric patient who died within three days following their providing care to the participant. All participants were over 18 years and English speaking.

Parent study recruitment. Information regarding participation in the survey was sent via email to all eligible participants at the onset of the study. Over 300 employees responded over a two-year period. Purposeful sampling was utilized to identify participants in the following manner. In addition to the informational email at study launch, nursing supervisors from the various units within the hospital would notify the primary investigator after a patient death. A group email was sent from the primary investigator with a request for all HP caring for the child in his or her final three days of life to complete the survey.

Human subjects protection. Participation in the parent study was completely voluntary and the institutional review board of the hospital provided study oversight. Consent was implied with completion of the study as approved in the research plan. To 
reduce the potential for coercion, the unit supervisors did not encourage participation; rather they sent an email to the primary investigator with notification of a death on the unit. The primary investigator then sent an email to potential participants requesting participation. For the current study, the researcher obtained permission from the primary investigator of the parent study to access the complete de-identified dataset of for the purposes of analyzing the qualitative portion of the survey. For the purposes of this study, oversight was provided by the institutional review board of University of San Diego (Appendix A).

\section{Data Collection Procedures}

The data for the proposed study consists of open-text entries from an online survey (see Appendix B). This original parent survey contained a total of 48 items in the following formats:

- 11 sought demographic information

- 6 asked to rate the quality of various aspects related to the patient's death and the HP experience thereof, three of these offered open-ended text responses

- 20 asked yes or no questions related to various elements of the child's death, 16 of these offered open-ended text responses

- 7 questions asking participants to identify multiple factors related to an element of the death experience, 5 of these offered open-ended text responses

- 4 open-ended text responses to questions. 
The data analyzed for this study were located within these textual comments. For example, to address the first two specific aims of the study, textual comments associated with question $\# 9$ ("Overall, how would you rate the quality of the patient's dying"?) were analyzed. This question offered scaled responses that included: best possible, good, neutral, poor, worse possible, not applicable, and I don`t know. Responses marked as best possible and good were collapsed into a new category termed "good", and responses marked as poor or worse possible were collapsed into a new category termed "bad." The open text corresponding to each of these collapsed groups were analyzed for themes corresponding to each selection. To address the third aim of the study, question 10 asked: "Were your needs as a caregiver to a dying child met"? Optional responses included: yes, no, do not know, not applicable, as well as open text area labeled "comments." The open text comments that correspond to the answer "yes" and "no" were each analyzed for themes corresponding to each selection. To address the fourth aim of the study, question 11 asked: "After your patient's death, are you having unresolved feelings or stress from this experience"? This question offered the same optional responses as the preceding question. Thematic analysis of these data was performed in the same manner as for the third aim.

As the researcher began reviewing the open-text entries corresponding to each entry, it became evident that the comments did not always describe the participant's choice, but rather an "exception" to the choice. An example is provided for clarificationa nurse selected "no" in response to the question related to unresolved feelings of stress, and then goes on to say in the open text comments: "I do feel bad for the family." Because of these contrary responses, the researcher looked through all open text 
comments of all choices allowed to get a better understanding of the participant's Gestalt of the question at hand. If the responses seemed to be contrary to the question at hand, this data was included in the alternative data (i.e. lingering feeling versus no lingering feelings).

Another unexpected finding when analyzing the data was multiple open-ended questions that provided data pertaining to the research questions at hand. The survey provided open-text responses to answer the following questions: "What were good things about the child's end-of-life care?", "What were challenges about the patient's end-of-life care?" and "What would have made this child's end-of-life care better?". While not directly connected to the "good death" or "bad death" questions, these responses provided rich data related to quality of death that aided the researcher in better understanding these phenomena. Further, open-text responses to the question "Did you feel supported by fellow staff while caring for this patient?" were closely aligned with caregiver needs, and responses to the question, "Did you feel any distress from?" were similar to unresolved feelings and stress. Therefore these data were included in the data analysis for each of the related aims.

\section{Content Analysis}

The directed method of content analysis of open-ended text responses as defined by Hsieh and Shannon (2005) was used in this study. Content analysis was directed by the framework of the QODD, which was being validated in the parent study, and was also used in second-level coding in this study using the factors identified by Downey et al. (2010). Constant comparative analysis as described by Holloway and Wheeler (2010) was also employed. The researcher first read and reread the text answers corresponding 
with each aim. With each response, the researcher identified emerging themes and then read the next entry and so forth.

Initially, the researcher entered a respondent number for each entry. Then, the data was sorted to eliminate any surveys that did not contain open-ended text responses. Of the 309 completed surveys, 187 included open text comments and were included in preliminary data analysis. Four separate spreadsheets were then created- all of which included columns including respondent number, unit on which care was provided, respondent's role, and shift. The first spreadsheet included responses on quality of death marked as "best possible" and "good" as well as the corresponding open-text entries. Additionally, this spreadsheet included comments regarding good things about, challenges related to, and suggestions for improving this child's EOL care. The second spreadsheet was created in the same manner, but included responses on quality of death marked as "poor" and "worse possible", as well as "I don't know", "not applicable" and "neutral." The third spreadsheet included "yes", "no", and "I don't know" responses to the questions, "Were your needs as a caregiver to a dying child met?" along with corresponding open text entries and "Did you feel supported by fellow staff while caring for this patient? (comments)." The final spreadsheet included "yes", "no", and "I don't know" responses to the questions, "After your patient's death, are you having unresolved feelings of stress from this experience?" along with corresponding open text entries and "Did you feel any distress from? (comments)."

Coding was performed in a two-step process using eclectic coding as defined by Saldana (2013), which "employs a select and compatible combination of two or more First Cycle coding methods" (p. 188). The first cycle coding methods included in this 
researcher's data analysis included: attribute, structural, and magnitude coding. Attribute coding was used in factoring in care area, HP role, and shift worked as part of the data analysis. Structural coding was employed as the data was collected in a highly structured manner (i.e. responses to specific survey questions) and the use of the spreadsheet facilitated grouping the data into focus areas aligning with the aims of the study. Magnitude coding was utilized to identify the number of times a certain concept was discussed among the participants. Although this is a qualitative study, it is possible to infer intensity of these concepts as they relate to the phenomena of study by taking note of how often the concept was identified among participants (Saldana, 2013).

Second level coding was achieved using two methods: code mapping and provisional coding. Code mapping was performed on preliminarily coded data for each aim. Additionally for the data from good death and bad death, provisional coding was applied using the second-generation framework of the QODD introduced by Downey et al. (2010).

\section{Use of Quality of Dying and Deatlı Questionnaire: Empirical Domains}

The data from this study were produced from a parent study attempting to demonstrate validity of an established instrument for use in the pediatric EOL setting. The QODD was originally created as an instrument for family members to complete after the death of an adult family member in hospice or acute care areas (Curtis et al., 2002). While the instrument demonstrated overall internal consistency (Cronbach's alpha $=.89$ ), exclusion criteria and homogeneity of sample significantly inhibited overall generalizability. Nevertheless, QODD has been the most frequently used instrument in assessing quality of dying and death (Hales et al., 2010), and has been modified for use in 
intensive care areas and among clinicians. The instrument's authors hypothesized six constructs, which included: Symptom and personal control, preparation, moment of death, family needs, preferences, and whole person concerns (Curtis et al., 2002). A recent article by Downey et al. (2010) argued a lack of theoretical foundation and rigor related to domain construction of the QODD. They used confirmatory factor analysis to demonstrate an overall weak fit of the six hypothesized domains $\left(x^{2}=274.296, \mathrm{df}=35\right.$, $\mathrm{p}<.001)$ and derived a four-factor model that demonstrated overall better fit $\left(\mathrm{x}^{2}=47.23\right.$, $\mathrm{df}=35, \mathrm{p}=.082$ ). This model includes "correlated, but distinct, latent variable domains" (p. 1): control of symptoms, being prepared, feeling connected, and transcendence. These domains, which constitute a second-generation framework, were employed in the thematic organization of the qualitative data related to good and bad deaths in this study. Although this factor analysis and subsequent framework were utilized in the family version, using it in this study provides a baseline framework from which to compare any differences between clinician and family member's perceptions of good and bad deaths.

\section{Trustworthiness}

As with all research, it is necessary to evaluate the rigor of this study in order to demonstrate its value for professional practice. Whereas there is general agreement to the types of validity assessed in quantitative studies (reliability, validity and generalizability), there is debate on how to best assess trustworthiness in qualitative studies (Holloway \& Wheeler, 2012). With deference to traditional qualitative researchers, measures of trustworthiness including dependability, credibility, and transferability in the context of this study will be discussed. 
Credibility alludes to how well the data and its analytic process address the research question (Polit \& Beck, 2012). Graneheim and Lundman (2004) recognize credibility first being established when the researcher determines the focus of the study, desired participants and data collection approaches. By including various HP working in multiple care areas, this study obtained varied and rich perspectives of the phenomena in question, resulting in increased credibility to the findings.

Credibility is also ascertained in data analysis techniques. In other words, how well did the researcher organize the data to ensure concise completeness? It is crucial for the researcher to select the appropriate unit for meaning of the themes. The process of coding down text, designated by Graneheim and Lundman (2004) as "condensation" (p. 106), characterizes this as a "process of shortening while still preserving the core" (p.106). In the current study, credibility in data analysis techniques was accomplished in two ways. First, the researcher utilized the theoretical framework for the QODD as proposed by Downey et al. (2010), which showed good overall fit of the model. Second, the researcher validated data analysis techniques with a methodologic expert to further establish credibility.

Dependability is another component of qualitative research trustworthiness. Graneheim and Lundman (2010) define it as "the degree to which data change over time and alterations made in the researcher's decisions during the analysis process. Since the data was submitted via online survey, the questions did not evolve as they often do when using other qualitative research methods. This contributes to high consistency; however, it inhibits the researcher's ability to change the questions as new data from participants emerge, thereby inhibiting exploration of novel themes that emerge from the data. 
Transferability is the final element in qualitative trustworthiness. Transferability alludes to the ability to anticipate a replication of the study's findings to other settings (Holloway \& Wheeler, 2010). It is important for a researcher to include " a clear and distinct description of culture and context, selection and characteristics of participants, data collection, and process of analysis" (Graneheim \& Lundman, 2004, p. 110) to allow the reader to critically analyze and make their own judgment regarding transferability to other situations. Consequently, transferability is best measured by critical analysis of the study by the reader.

\section{Summary}

This chapter detailed the methodology and method of this study. Directed content analysis with philosophic underpinnings of interpretive phenomenology was the stance upon which this post-modern, feminist researcher viewed this pre-collected data in an attempt to infer meaning. Constant, comparative analysis as a data analyzing technique was utilized in addition to conference with methodologic and content experts to promote epistemologic closeness to the findings. Finally, various measures to enhance trustworthiness were employed, including: seeking various perspectives of the phenomena under study, validation of data analysis techniques by employing a theoretical model, conference with method experts, strict adherence to the protocol through the use of an online survey, and full descriptions of the context of the study for critical analysis by the reader. The next chapter details the findings of the study. 


\section{CHAPTER 4}

\section{Findings}

Somebody should tell us, right at the start of our lives, that we are dying.

Then we might live life to the limit, every minute of every day.

Do it! I say. Whatever you want to do, do it now!

There are only so many tomorrows.

Pope Paul VI

The overall purpose of this study was to explore various factors of HP lived experience of a good or bad pediatric death in the hospital setting. Specifically, the aims were to:

1. Explore themes that HP associate with a good hospital death in the pediatric setting.

2. Explore themes that HP associate with a bad hospital death in the pediatric setting.

3. Explore concepts involving HP identification of their own needs being met when caring for a dying child in the hospital.

4. Explore concepts surrounding HP report of unresolved feelings or stress experienced after caring for a dying child in the hospital.

This chapter will define the participants in the study, including role and care area. For each aim, there will be a description of themes and subthemes derived from the data, including rich quotes to provide context and clarification to the reader. It will also include substantiation of the researcher's use of a second-generation framework to organize the data. Figures for each aim will be offered for further elucidation of the thematic analysis used. This researcher anticipates these analyses will enhance HP understanding of the phenomena under study. 


\section{Description of Participants}

There were a total of 309 surveys completed for analysis of the research question of the parent study. Of these, 187 participants included at least one open text entry that was analyzed as part of this study. Table 3 provides demographic data on the participants in this study.

\section{Table 3.}

Demographic Data

\begin{tabular}{lrr}
\hline $\mathrm{n}=187$ & $n$ & percent \\
\hline \multicolumn{1}{c}{ Role } & & \\
Registered Nurse (RN) & 114 & 61 \\
Social Worker (SW) & 21 & 11 \\
Respiratory Therapist (RT) & 14 & 7 \\
Pastor & 9 & 5 \\
Medical Doctor (MD) & 8 & 4 \\
Nurse Practitioner (NP) & 8 & 4 \\
Child Life Specialist (CL) & 5 & 3 \\
Supportive Care Staff & 4 & 2 \\
Children's Hospital Emergency Transport & 1 & $<1$ \\
(CHET) & & \\
Licensed Vocational Nurse (LVN) & 1 & $<1$ \\
Parent Liaison & 1 & $<1$ \\
Device Specialist & 1 & $<1$ \\
$\quad$ Care Area & & \\
Pediatric Intensive Care Unit (PICU) & 72 & 38 \\
Neonatal Intensive Care Unit (NICU) & 44 & 23 \\
Hematology/Oncology Unit (HO) & 30 & 16 \\
Cardiovascular Intensive Care Unit (CVICU) & 15 & 8 \\
Emergency Department (ED) & 11 & 6 \\
4 East & 7 & 4 \\
Convalescent Center & 5 & 3 \\
Computed Tomography Suite (CT) & 2 & 1 \\
Medical Unit & 2 & 1 \\
$\quad$ Shift Worked & & \\
Days & 112 & 60 \\
Nights & 51 & 27 \\
P.M. & 18 & 10 \\
No response & 7 & 4
\end{tabular}

As these data demonstrate, there was representation by various care areas and professions, adding to the richness of perspectives. 


\section{Good Death}

A total of 187 participants provided comments related to the quality of death. Of these, 122 classified the death as either good or best possible, 24 classified the death as either poor or worst possible, and 39 classified the death as neutral, don't know, or not applicable. An additional two participants did not quantify the quality of death, but provided comments, which were included in the analysis. Primary coding labels were nested under each of the four factors established by Downey et al. (2010). See Figure 1 for an illustration of data clustering. 
Figure 1: Good Death Data Clustering Using Downey et al. (2010) Constructs
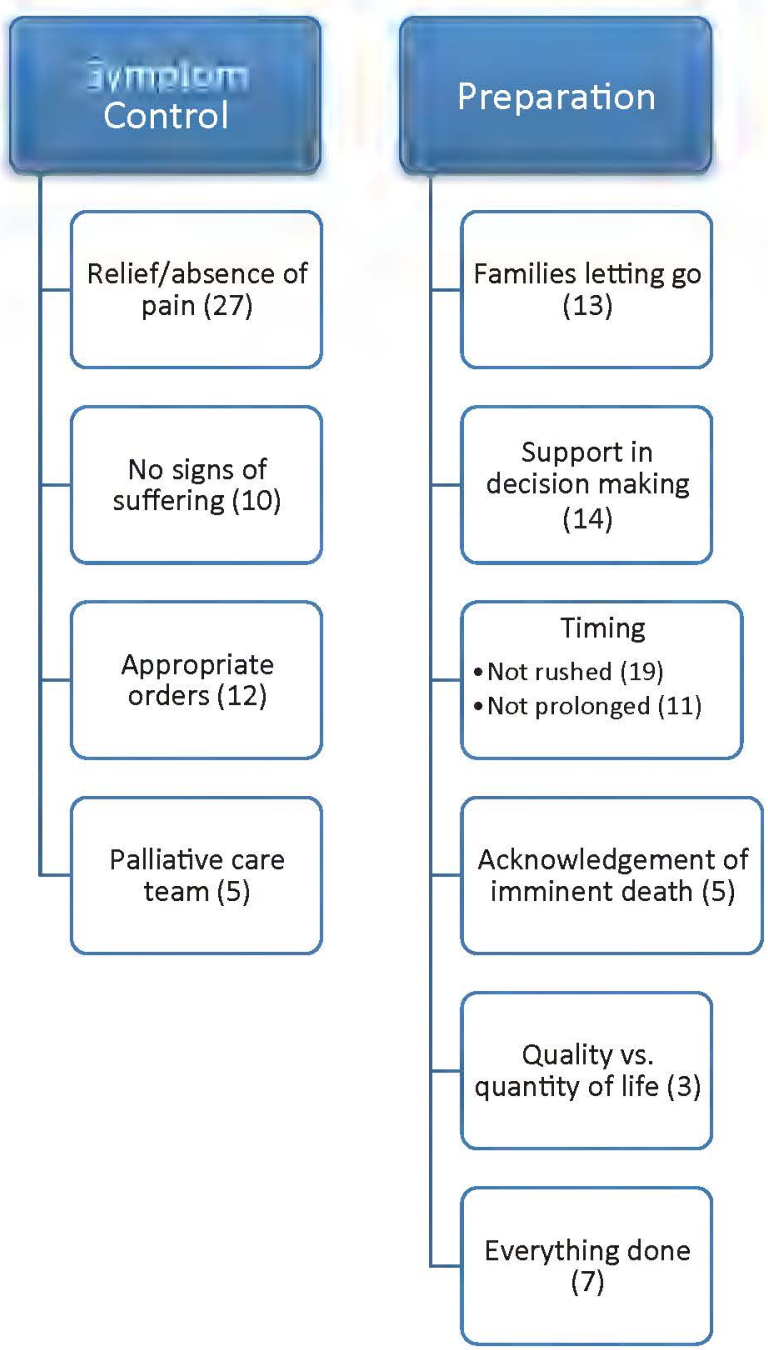
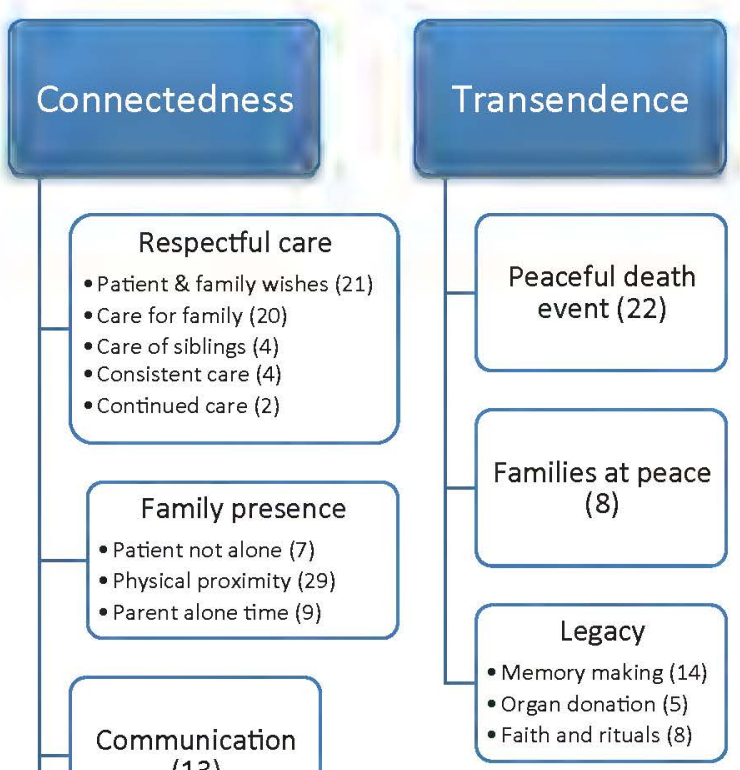

(13)

Specialized care team (30)

Symptom control. Adequate control of symptoms was frequently mentioned as an element related to a good death. Four subthemes were most closely aligned with symptom control in this study: relief and/or absence of pain, no signs of suffering, appropriate orders, and utilization of the palliative care team. 
Relief and/or absence of pain. Pain control was often discussed in describing quality of death, including participants representing nearly every care area and role, indicating inclusive agreement. Several variations of ensuring pain control were mentioned. A RN working in the ED stated: "[Patient] was unresponsive but pain management was still discussed." A nurse working in the NICU recalled: "we tried to optimize comfort and the bedside RN and MD worked to achieve this." Another RN working on the surgical floor discussed parent concern regarding orders for pain medication in order to achieve pain control: "mom had refused pain meds for fear of 'killing the patient', once the meds were resumed [the patient] was very comfortable and peaceful in moms arms."

No signs of suffering. Closely tied to pain relief, the absence of signs of suffering was identified as an indicator of a good death. A CL specialist working in the HO unit wrote: "It was peaceful. She did not suffer and appeared comfortable." A RN working in the HO unit reported, "It was peaceful and did not look like he was suffering." The majority of respondents identifying relief of suffering were registered nurses (RNs), representing many care areas.

Appropriate orders. Several participants reported having appropriate orders for EOL care to be an indicator of achieving a good death. The statements related to appropriate orders were offered primarily by RNs, but a RT and SW mentioned this as well. A few respondents relayed the need for getting appropriate orders as a form of patient advocacy, highlighted by this NICU RN: "[Patient] had no pain meds/ sedation ordered when I first cared for her. I obtained pain med orders and [patient] appeared to be pain free after receiving meds." And again by this PICU RN: "I am a strong advocate for 
families and patients under these stressful circumstances, and I think it is so important to make both the family and patient as comfortable as possible." From the perspective of prescriber, a NP wrote: "As the NP, I felt he had adequate orders for [as needed] pain and continuous sedation. A MD trainee seemed less confident: "I looked to the palliative care specialist to help decide which medications to use to keep the patient comfortable.

Without her I would not have been as comfortable ordering medications."

Palliative care team. Collaboration with pain and palliative care services supported symptom control. Several respondents- including various HP in multiple areas identified the addition of palliative care services to be an important factor in achieving a good death. As a RN in the PICU so eloquently wrote: "When we withdrew his ventilator support, he breathed like he had never struggled a day in his life. He never regained consciousness, because his pain, anxiety, and trauma of what he had been through were managed by adequate medications through a pain service consult." Preparation. Preparedness as it relates to patient, family, and HP were reported as elements of a good death among participants in this study. A total of six subthemes, one of which contained additional subthemes, were grouped into the following major themes: families letting go, support in decision making, timing, acknowledging imminent death, quality vs. quantity, and "everything done".

Families letting go. In this study, HP reported the concept of "letting go" as important in achieving a good death. Letting go is a concept defined by Lowey (2008) as containing four core attributes: a shift in thinking, recognition of death, acknowledging the loss that will come as a result, and allowing death to occur without prolongation. Registered nurses and social workers (SWs) were likely to identify letting go as a factor 
of good death in many care areas, including, PICU, CVICU, and HO. A RN working with a patient in $\mathrm{HO}$ unit wrote: "Dad was ready and told him it was Ok to go." Another RN working in the PICU alluded to the process of this concept, stating, "Parent learned to let go [of] their child."

Support in decision-making. Closely related to letting go, HP discussed providing support to parents during the excruciating decision-making process that ultimately results in the death of a child as being helpful in achieving a good death. Eleven participants mentioned providing assistance in decision-making, including pastors, SWs and several RNs working in various care areas. A wonderfully rich description of this was provided by a NICU RN:

I received in report that the parents were having difficulty in making the decision to withdraw support. They both agreed that it was necessary, but were appropriately reluctant to actually do so. They stated, "It didn't feel right". Although it was a delicate situation, I was able to bring about conversations that helped them express their feelings, hopes and dreams, and ultimately bring closure to the process. Afterward, dad made the statement "she looks so peaceful now. We're ashamed we waited so long to do this. This was so beautiful. This is the way it should be."

Timing. Health professionals in this study frequently mentioned timing as a crucial factor in achieving a good death. Timing as it relates to a good death is described in two subheadings: not rushed, and not prolonged.

Not rushed. Participants recognized the need for time to allow the parents to come to terms with the situation and make decisions as well as time after death. A SW reports: 
"Parents were allowed ample time to grieve and hold patient and participated in memory making."

Not prolonged. In addition to allowing for ample time to process the impending loss, avoiding prolongation of dying was attributed to a good death among participants in the study in several roles and several care areas. A RT working in the ED provides evidence of this concept: "Was not drawn out code, but called after around 30 to 45 [minutes]."

Acknowledgement of imminent death. A key element in being prepared for death is recognizing death is near. In this study, HP report this concept is important for both family and HP in order to achieve a good death. A pastor on the Medical unit reflected: "Once it was known he would die, things went very well."

Quality vs. quantity. A few HP in this study qualified a good death in context of the alternative. An example of this includes comments from a RT in the ED, "If [patient] lived it would be a terrible life." This may be attributed to quality of life in a global sense or prolonged suffering as inferred by this respondent, a RN in the CVICU who wrote, "It was torture to watch him suffer... It was good that [the death] happened."

Everything done. An interesting finding related to achieving a good death was the concept of having everything done. Various HP reported this, many of whom provided care in the ED, as this RN who wrote: "It was difficult to see, however, [because] I saw the entire process, I knew that we had tried absolutely everything to revive the child before pronouncing him dead." This is an important finding; in other contexts everything being done to save a patient is associated with futility and unpreparedness, as this PICU RN wrote under challenges about this child's EOL care: "Worsening BGAPs, 
[desaturations], [blood pressure] lability and ventricular arrhythmias despite treatment with family wanting "everything done."”

Connectedness. Connectedness refers to spending time with loved ones and sharing affection with the dying person. Communication is central to this concept. Subthemes situated under connectedness in this study include: respectful care, family presence, honest and ongoing communication, and presence of the specialized care team. Respectful care. Health professionals universally recognized providing respectful, individualized care to the patient and family as being an integral part of achieving a good death. Nested under this theme were five subthemes- patient and family wishes, care for family, care of siblings, consistent care, and continued care.

Patient and family wishes. Honoring the families' wishes was frequently mentioned in the context of a good hospital death. A RN on the $\mathrm{HO}$ unit exemplifies this: "We were able to honor the patient and family's wishes by keeping him on the floor on a low dose of dopamine for EOL care."

Honoring patient wishes was only mentioned once in the data; which is an interesting finding. In response to the question, "What were good things about this child's EOL care? a RT in the PICU wrote, "[The patient's] wish to end it was honored." Another respondent, a device specialist desired patient input, commenting under challenges to this child's EOL care, "Patient was not able to participate in the final decisions".

Care for the family. Several respondents spoke about providing care and support for the family. A RN in the HO unit wrote, " $[\mathrm{He}]$ and his family had all the support they 
could have possibly needed." Another RN in the HO unit affirmed, "the parents knew what to expect, and seemed grateful for the care they received."

Care of siblings. Unique to caring for dying children is the focus on the sibling. Child Life specialists were often credited by respondents as providing this valuable service during a patient's EOL. A RN working in the PICU appreciated the support from $\mathrm{CL}$, stating, "[a member] from Child Life was amazing at working with the siblings before her death". Another RN on the surgical floor wrote, "Child Life helped with the child's sibling with memory making and discussions."

Consistent care. Participants in this study substantiated the benefit of relationships with dying patients and their families. This could be found in responses from various $\mathrm{HP}$ in several care areas. A supportive care staff member working in the PICU wrote, "I think he was so well cared for-one of his primary RNs was on his last shift-his primary oncologist was also on". A RN in the PICU also mentioned consistency in care:

I feel it was very good for and important to the family to have his primary nurses with the patient and family the last two shifts of his life. I think it was also great that Dr. $[\mathrm{X}]$ was there to compassionately extubate, as the family had a [very] good rapport with him.

Continued care. A few participants specifically mentioned providing continued care to the families after their child died. A pastor in the PICU expressed ongoing support to the family: "Parents with [patient] until expiration. - Parents educated on what to do next with mortuaries and funeral arrangements." Another example provided by a RN working in the PICU: "total time once withdraw of care to cardiac death was 3 hours. 
Parents were ready to leave after this. We had arranged for family member to take them home."

Family presence. Having family present at the time of death was often mentioned when discussing qualities of a good death. All forms of HP in nearly all care areas reported this. A RN working in the PICU wrote: "He died peacefully in grandmothers arms. He was surrounded by the people who loved him."

Patient not alone. Closely related to family presence, was the concept of not dying alone. A few respondents alluded to HP acting as family proxy during EOL if the family could not be present so as to avoid the patient dying alone. A LVN working at the convalescent center explained: "With knowing that staff took turns holding the patient as the family was not available during her last moments I can rate it good overall because at that point it would truly have been best possible." A RN in the PICU also wrote:

"Although her family was not present for many days prior to her death, or on the morning of her death, she had many staff members from PICU and [HO unit] that knew her well and cared for her, that kept her company during her final hours and days."

Physical proximity. Two concepts related to physical proximity were often mentioned when describing a good death: family members holding the child as they died and use of a family bed. A RT working in the PICU eloquently illustrates both of these: I advocated for a "family bed" and luckily, the nurse taking care of the baby was supportive of this. Also, I advocated for proning the baby on his Mommy's chest so she could spend her remaining time with him as close as possible. She took off her sweatshirt, and just had a thin top on, so, as she said, she could feel him close to her. And since it was a family bed, Dad laid next to them. 
Parent alone time. A few respondents specified allowing parents time alone with their child as he or she died was important in achieving a good death. A RN in HO unit provided a wonderful exemplar: "[the extended family] came in a few at a time, and left the parents alone with her towards the end so the parents were not overwhelmed by the extended family members' grief."

Communication. Communication was globally recognized among participants as a key factor in attaining a good death. There were several different qualities of communication identified, including, honest, ongoing, and consistent. In this data rich response, a RN working in the PICU describes all of these elements, and implies how challenging this can be for HP:

In the end, his mother asked the hard questions, Will he recover? Will he come home? Will he ever not be in pain? Will the treatment work? If not, what are we doing? And why? If he can't live the life he was meant to then I want him to stop suffering? Will you help me? And we did. The nurses and staff in the PICU, social workers, support liaison, doctors, supported this decision and worked together.

An additional comment by a RN working in the NICU provides further clarity of these concepts. "The parents were updated by everyone on the disciplinary team. Everyone was 'on the same page' giving them consistent information."

Specialized care team. Participants claimed having access to a full compliment of specialized professionals was integral for providing a good death. This concept was almost exclusively mentioned by RNs. The reason for this may be related to the RN acting as the hub of patient care for a dying child, and would have the global view due to 
their proximity to the patient. While many of these comments were not specific, occasionally a participant would mention specific team members or roles. One participant mentioned this who was not a RN. This participant was a parent liaison, who provided an account of the benefits of this role specifically: "When parents of this child asked for someone who had suffered a loss of a child, I was asked to be present to support the parents. Being present with them, comforting them, validating their feelings [was] welcomed by the parents."

Transcendence. Downey et al. (2011) defined this domain as being "unafraid of and at peace with dying, and being untroubled about strain on loved ones" (p.5). The results of this study have been categorized into four subcategories: a peaceful death event, families at peace, legacy, and faith.

Peaceful death event. One of the most frequently captured codes within this dataset associated a peaceful death event with achieving a good death overall. A RN on the surgical floor richly describes this: "[Patient] was comfortable and peaceful at the time of passing. The entire family was able to be with the [patient], holding him and without any medical intervention at the time of passing."

Families at peace. This concept, which is closely related to families being prepared, was also reported among participants of this study. There were internal and external factors influencing peace among the family. Internal factors included being prepared, having wishes honored, and faith. Being prepared and having wishes honored have already been explored; faith will be discussed as its own subtheme within transcendence. External factors included providing a calm setting, extended families 
providing support, and family consensus regarding care plan. A RT working in the PICU illustrates a touching example of providing a calm setting:

Then I asked if they wanted [lullabies] on the radio, and they got out their cell phone, and listened to their own [lullabies], which I thought was even better. And so as not to hear the apnea alarm go off on the vent, I put him on the [continuous positive airway pressure] bag, which has no alarms... as I thought that would be sooo distracting to them and bring them harmful memories.

While having extended family present was identified throughout the data as being associated with a good death, a pastor and a nurse specified having them present as a means of support. This NICU RN stated, "both sets of grandparents were at the bedside to support the parents." Another NICU RN explained family consensus, "The parents were in complete control of the situation, which I think greatly aids in their emotions and coping."

Legacy. For the purposes of this study, legacy as defined by Duggleby and Wright (2004) was used: "Leaving something behind of value to others...it contributes to your hope to know that those will live on" (p. 364). In this study, legacy was often described by the parents' activities and statements, rather than the patient themselves. Two subthemes related to legacy were identified- memory making and organ donation.

Organ donation. A few participants mentioned being able to donate organs of the child after death was a factor in achieving a good death. Most of the participants mentioning this were RNs, and all worked within a critical care area. It would be interesting to better understand if this was a product of the unit culture, or if children cared for in other units were not eligible. A RN working in the PICU provided this 
empathetic reflection: "The family felt that although their son had died...he would give life to others through his organs being [donated]."

Memory making activities. While not specified, participation in memory making activities was noted to be a component of a good death. A SW working in the PICU provides an example of this, "I thought things went as well as possible with the parents and the brother in the room assisting with memory making."

Faith and rituals. Interestingly, only one respondent specifically mentioned faith as a factor associated with a good death. However, there were a few others who mentioned several faith-based activities (praying and baptism) in comments associated with good things about child's EOL care. Pastors and RNs were the only two professions that remarked on matters of faith or faith-based activities. A RN working in the PICU gave praise to the pastor providing religious support, "Chaplain came to pray and baptize the child (which I thought was awesome for the parents)."

Additional post mortem rituals were recognized. This NICU RN provided a beautiful illustration:

I was happy to carry out the bathing of the infant with mom ... we shared so many fun memories as we got her ready for the mortuary. We dressed her up, fixed her hair in ribbons, sang to her...

\section{Bad Death}

A total of 24 participants classified the death as either poor or worst possible and provided comments related to the quality of death. An additional 39 classified the death as neutral, don't know or not applicable and two participants did not enter any information related to the quality of death, but provided comments, all of which were 
included in the analysis. Primary coding labels were nested under each of the four factors.

See Figure 2 for a representation of data clustering.

Figure 2: Bad Death Data Clustering Using Downey et al. (2010) Constructs
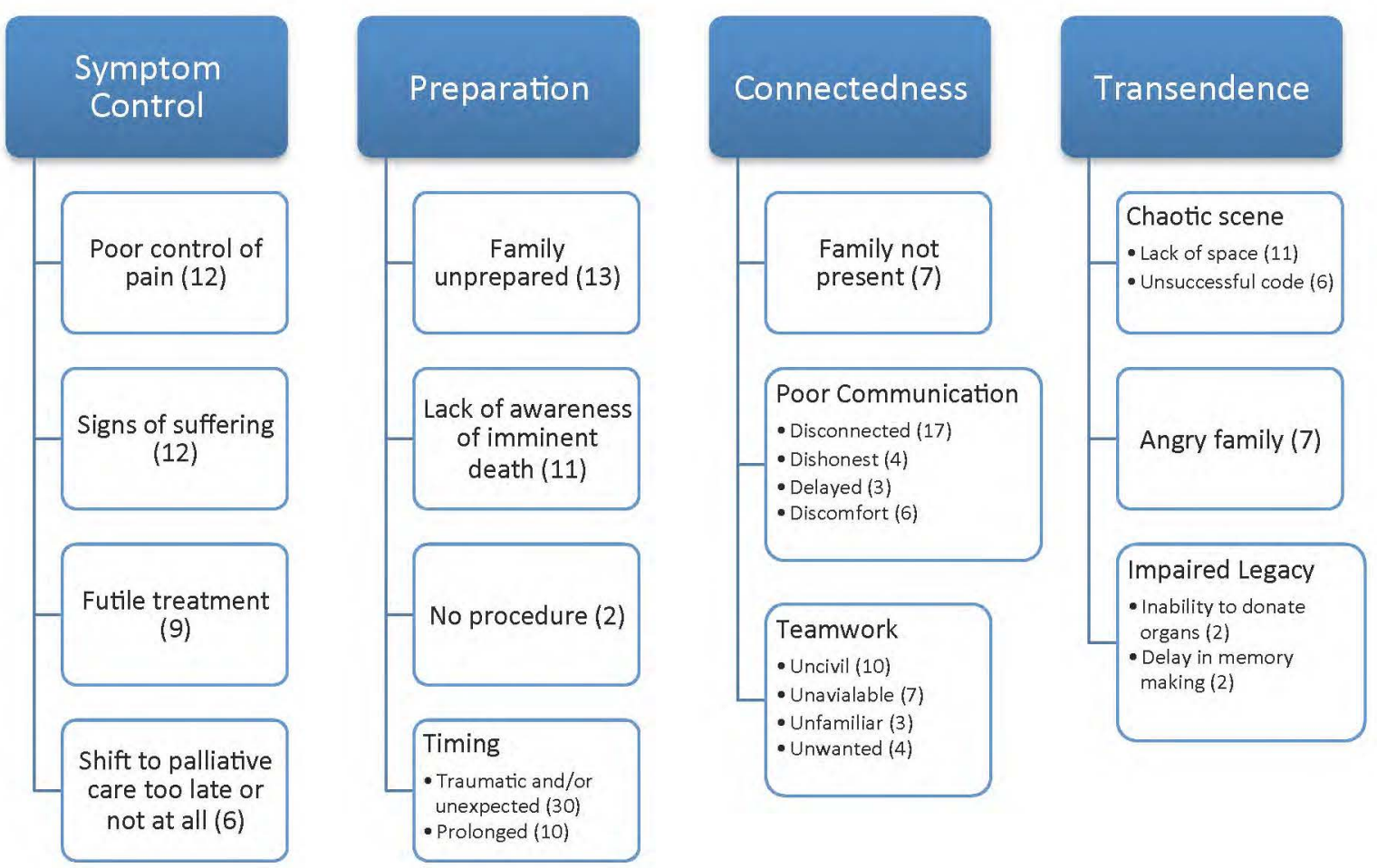
Symptom control. Poor symptom control was frequently identified within the context of a bad hospital death. Four subthemes arranged under this heading: poor control of pain, signs of suffering, futile treatment, and shift to palliative care too late or not at all.

Poor control of pain. Inadequate pain control was frequently associated with a bad death. Participants identified several reasons for this, including lack of availability of orders, lack of providing ordered medications, and parental refusal. A RN in the CVICU implied unavailability of proper orders, "the parents did not make the baby a [do not resuscitate] so we could not give meds that would further lower his [heart rate] and [blood pressure]." A RT in the convalescent center described a child not being given ordered medications:

Some nurses did not give her medication to make her comfortable. They felt that she didn't need it. So the night I worked with her I was told that her last dose of morphine was at $2 \mathrm{pm}$. [At] $11 \mathrm{pm}$ she was crying and moaning in pain.

A NP on the surgical unit mentioned parental refusal as a limiting factor in providing adequate pain control, stating, "not being able to allow him to be as comfortable as Mom worried about too much medication."

Signs of suffering. Pain and suffering are closely related and the presence of signs of suffering was mentioned in the context of a bad death. A RN in the CVICU reflected, "It was torture to watch him suffer all night." An NP on the surgical floor wrote: "We were titrating up doses of Morphine and Valium the shift I was on, but still had difficulty controlling the dyspnea and agitation." 
Futile treatment. Futility was a common theme among bad death responses regardless of care area or role. A MD in the NICU reflected, "difficult to make determination of futility; required two painful surgeries". This participant went on to identify ethical concerns surrounding this concept: "I think the ECMO run was longer than some of the bedside staff thought was appropriate; the patient had a pretty poor prognosis for a period of time prior to withdrawal."

Shift to palliative care too late or not at all. Nurses, especially those working in critical care areas were most likely to identify a prolonged or lack of transition to palliative care as a challenge to providing a good death. A RN working in the CVICU reported: "I wish we were better at getting DNR status so children could die with better pain management. The parents did finally allow the baby to be extubated and held but I feel we could have done more earlier on."

Preparation. Preparedness, or more specifically a lack or preparedness of impending death was identified as an important concept of a bad death. A total of three subthemes, one of which contains an additional two subthemes are within this category: Family unpreparedness, lack of awareness of imminent death, and timing.

Family unprepared. Health professionals in various roles commented on the family being unprepared as a factor in a bad death. Although this was most frequently reported in the context of a sudden or traumatic death, it was also discussed in a prolonged death, implying denial among the family members, as highlighted by this PICU RN: "there was nothing good. The parents were not aware he was dying until the last 30 minutes. They did not have time to call family members in to say good-bye..." 
Lack of awareness of imminent death. In addition to the families being unprepared, HP can also have difficulty knowing a child is nearing death. This can include some or all HP providing care. A PICU RN provided an example of a situation where some HP were not able to recognize imminent death: "Delay of providers to "see the signs' and have the conversations. They tend to not want to 'give up' on their [patients] as much as the families don't want to give up." A supportive care staff member poignantly recalled an instance where all HP could not "see the signs": "mother really led the team to recognize futility." This participant goes on to describe a challenge specific to this child's EOL care, "difficult decision to make to switch gears and let go of the slimmest whisper of hope that he might get better."

No procedure. Of note, two respondents, a SW and supportive care member provided information related to a sudden death of an outpatient child. They both identified challenges to providing EOL care related to the child's outpatient status. The SW lamented a lack of an appropriate "space to go with the patient and family in an unusual situation like this, as he was not inpatient." The supportive care member offered as a suggestion: "Having a more definitive plan in place for scenarios like this one."

A LVN working in the convalescent care setting illustrated another aspect related to lack of procedure. The comments reflected a lack of process for enabling hospice care. Under suggestions for improving EOL care, this LVN wrote:

Once the parents changed the code from full code to AND to have tried to work out hospice services at that point... [Have] pain medication orders for palliative care in place upon admission from the PICU.... 
This respondent went on to suggest the following to improve this child's EOL care- "If the hospital offered their own hospice services to patients."

Finally, a RN working in the CVICU relayed uncertainty in how to provide EOL care in this response:

Unclear what monitors we wanted to leave on, how much privacy to give the family, explaining to the family how long the [patient] would live after we pulled the [endotracheal tube], how much family should be outside of the room, weeping... I should have removed the monitors, wrapped the baby in a baby blanket and allowed the parents to have the feeling that they are not in a hospitalas best as I could.

Timing. Similar to concepts related to a good death, health professionals mentioned timing as an important facet of a bad death. Timing as it relates to a bad death falls under one of two subheadings: Traumatic and/or unexpected, or prolonged.

Traumatic and/or unexpected. Of the 24 participants who qualified the specific death event as poor or worst possible, 10 indicated the death event was traumatic and/or unexpected. This is an important finding- of those participants who reported a good or best possible death event; only one defined the death as sudden. This respondent, a pastor working in the NICU, goes on to contextualize the death event as best possible given the "speed of the decline."

Participants who associated traumatic or unexpected death as a factor in a bad death varied in terms of both role and care area. A SW working in the NICU sympathetically recalled, "Although the baby's prognosis wasn't the best, nobody expected the baby to die when/how he did, especially the parents! I felt so bad for them." 
A PICU RN also wrote: "it was a very sudden illness and the [patient] died very fast within two days of being healthy. The parents were in shock and were [devastated]. They didn't know what was happening." As evident in these passages and in all the comments, unexpected deaths were highly associated with a lack of preparedness.

Prolonged. Of the participants in this study, RNs were the only HP who identified prolonged dying process as an element of a bad death. A RN in the PICU wrote, "Here was a [patient] that was here for months intubated that the doctors would not give up on. They tortured the child and his family and gave them false hope." An associated concept, prolonged resuscitative efforts were also reported by a RN and a RT. The RT, who worked in the CVICU explained, "[Patient] had no [heart] rate for two hours... did not follow PALS to stop CPR, with[in] a reasonable time, and staff was not asked for suggestions or should CPR stop prior to [patient] going on ECMO."

Connectedness. Several respondents in this study identified a lack of connectedness in the context of a bad pediatric hospital death. Subthemes of disconnectedness included: family not being present, various forms of poor communication, and teamwork concerns.

Family not present. Health professionals identified family not being present as a barrier to achieving a good death. Similarly, family not being present during resuscitation efforts was mentioned as detracting from the quality of death. A RN working in the CVICU implies frustration in the case of family absence with a dying child under his or her care: "We needed someone to step up and say, 'get in here lady and see your son dying." A MD working in the ED identified a possible improvement to the child's EOL care to be, "Perhaps having family witness efforts in the trauma bay." 
Communication issues. Poor communication was frequently mentioned as an element of a poor quality death. Subthemes related to communication within this dataset include: disconnected, dishonest, delayed, and discomfort.

Disconnected. Many HP in this study reported disconnected communication concerns. These included a lack of communication between HP and families, poorly understood communication between HP and families, and language barriers. An example of lack of communication was illustrated by a RN working in the PICU, who wrote, "The patient has life sustaining treatment for days without the discussion of end of life coming up." A pastor in the NICU explained poor understanding of attempted communication: "Family was very angry and confused about how the patient could have died despite the medical team's efforts to help them understand the severity of the patient's illness and that he may not survive." Another example was provided by a HO unit RN, who wrote, "Mom did not wish to hear any information about patient regarding deterioration in status, which posed a problem and issues when he was becoming very close to passing away." Nurses (RN and LVN) were the only participants who reported language barriers as being a challenge to providing a good death. A RN working in the NICU acknowledged, "Not speaking Spanish I felt disconnected with the family and couldn't offer a much support as I would have liked."

Dishonest. Registered nurses working in the PICU or NICU reported a lack of honest communication as being contributory to a bad death. Most of the comments related to dishonest communication revolved around the concept of false hope. One NICU RN expressed how ethically distressing this can be: 
I had to advocate more than I felt comfortable with. I even pulled in another doctor to talk with parents because I was not happy with the false hope that another doctor was giving mom. I had to push really hard for the doctors to be honest and not give false hope. If I had not pushed for them to be honest the infant would be hooked up to life support today and would struggle for months then eventually die from her condition in a worse state than she was in now.

Delayed. Initiating EOL care conversations was frequently reported as occurring too late in the dying process. Most of the responses were describing communications between HP, patients and families, as this PICU RN, who wrote, "It was a foreseeable death, and yet nothing was mentioned to the family until the morning of, giving them very little time to grasp the circumstances...." Another HP discussed delayed communication between HP as a component of a bad death. This RT, working in the convalescent center described this well, expressing "The doctors only really did anything the day before her death. You can't really blame the doctors for that. The day/pm shift nurses took too long to get the doctors involved."

Discomfort. One possible explanation for all the identified communication problems is related to HP discomfort in communicating with families of dying children. While not necessarily associated with a bad death, a NP, RNs and SWs in this study relate apprehension in talking to families about their dying children as a challenge in the child's EOL care, as in the case of this CVICU NP, who wrote, "I would like more information on talking to families regarding bad tests and end of life care. It's hard to balance being realistic with not removing all hope". 
Teamwork. Concerns related to teamwork were frequently mentioned in context of a bad death event. These fell into one of three subthemes: uncivil, unavailable, and unwanted.

Uncivil. Many HP reported discord among the HP team when describing a bad death. Several different types of HP reported this, all of whom provided care in the critical care areas (CVICU and PICU). A RN working in the CVICU, implied team disagreement in these comments: "Both the day nurse and myself advocated for a "plan change' but the patient ended up responding to increased doses of Ativan and Presedex."

Unavailable. Several HP working on night shifts or weekends lamented the absence of valuable team members. Social workers and RNs in various care areas provided rich data on this subject. A RN working in HO unit wrote, "Although I had to stand in to help explain, pray, I do not think it made the family's experience any worse. The chaplain was able to come after the death, and the family was happy with my explanation to the cousins."

Unfamiliar. Related to unavailable team members, the team members asked to fill in during a primary team member's absence reported challenges in their ability to provide a good death. A SW who was filling in for a colleague conceded this struggle

Because I was filling in for primary SW, I did not have full background on family. Patient was not anticipated to pass so soon. Family had wanted to do body donation but there isn't a program that would accept such a young child. I'm not sure if this was discussed prior to his passing.

Unwanted. A few respondents mentioned family members refusal of support from specialized team members. A SW on the surgical floor mentioned "family somewhat 
hesitant to additional support from SW, Child Life, [and] Chaplain". A pastor in the PICU also wrote: "Family had a difficult time listening to psych/social team and allowing us to guide them through the end of life process."

Transcendence. In this study, respondents identified concepts revolving around three subthemes related to transcendence: Chaotic scene, angry family, and impaired legacy. Two of these contained additional subthemes.

Chaotic scene. Several HP reported a chaotic scene as part of a bad death event. These HP represented various care areas, including, ED, CT scan, PICU, HO, unit and NICU. Two subthemes were nested under chaotic scene, including lack of space and unsuccessful code.

Lack of space. Respondents in this study identified a lack of space for EOL care in two contexts, lack of any space or insufficient space for visitors. In the ED and CT scan, HP reported no space was available for EOL care conversations, or continued care of family after the death of a child. A SW working in the ED described this, stating, "Having a separate meeting/waiting room for parents and their family members would have been helpful."

Registered nurses in several care areas reported insufficient space as a challenge in the child's EOL care. A RN in the NICU reported a challenge in providing EOL care on the unit, "Way too many visitors, it disrupted the whole unit." This respondent also offered a suggestion for improving EOL care, "Having the infant moved to a larger room. It would be great if we had a special room to take end of life events to that was not in the unit...one with comfy chairs, refreshments, music". 
Unsuccessful code. Some respondents in this study contextualized a bad death as occurring after an unsuccessful code. While often associated with a sudden death, there is a subtle difference between the two. A bad death as the result of a failed code lends credibility to the concept of "death as failure", which is well documented in the literature (Buckman, 1990; Chapple, 2010). A pastor in the NICU qualified a poor death by writing, "code blue with failed CPR and attempted intubation." A RT working in the PICU also provided comments related to a reported worst possible death, "[patient] died during a code."

Angry family. A few respondents mentioned family members being angry after the child had died as a being a challenge related to providing EOL care. This was exemplified in the comments by a SW working in CT scan: "parents grief process initially expressed in extreme anger, made difficult accusations "you killed him: to various staff/[medical doctors])..." Conflict between family members during the death event was also reported. A RN on the surgical unit illustrated this concept: "Disagreement between mom... and dad... on careplan. Dad accused mom of trying to "kill" the patient...."

Impaired legacy. In a few respondents, challenges related to providing EOL care were related to legacy. Two subthemes were identified: inability to donate organs and lack of memory making activities.

Inability to donate organs. Two respondents reported inability to donate organs as challenges to EOL care. A RN working in the PICU reported, "Parents wanted life sharing but the baby wasn't eligible". 
Delay in memory making. Two respondents also reported inhibiting factors to allowing memory-making activities as a challenge to EOL care. A SW in the CT scan wrote, "[Medical examiner] involvement, unable to complete the memory making activities or move patient without their permission."

\section{Meeting the Needs of the HP.}

In the parent study, a total of 46 participants provided open text data in response to questions related to their own needs being met when caring for a child at EOL. Of these respondents, 24 reported their own needs were met, 19 reported their needs were not met; nine stated they did not know, and four replied not applicable. Registered nurses provided the majority of responses $(n=35)$, but SWs, RTs, a NP, parent liaison, and supportive care team member also gave responses. All open text data were analyzed. The findings were then categorized into two categories, HP needs being met, and HP needs not being met. Figure 3 provides a visual representation of themes related to HP needs being met. 
Figure 3. Meeting the Needs of the HP

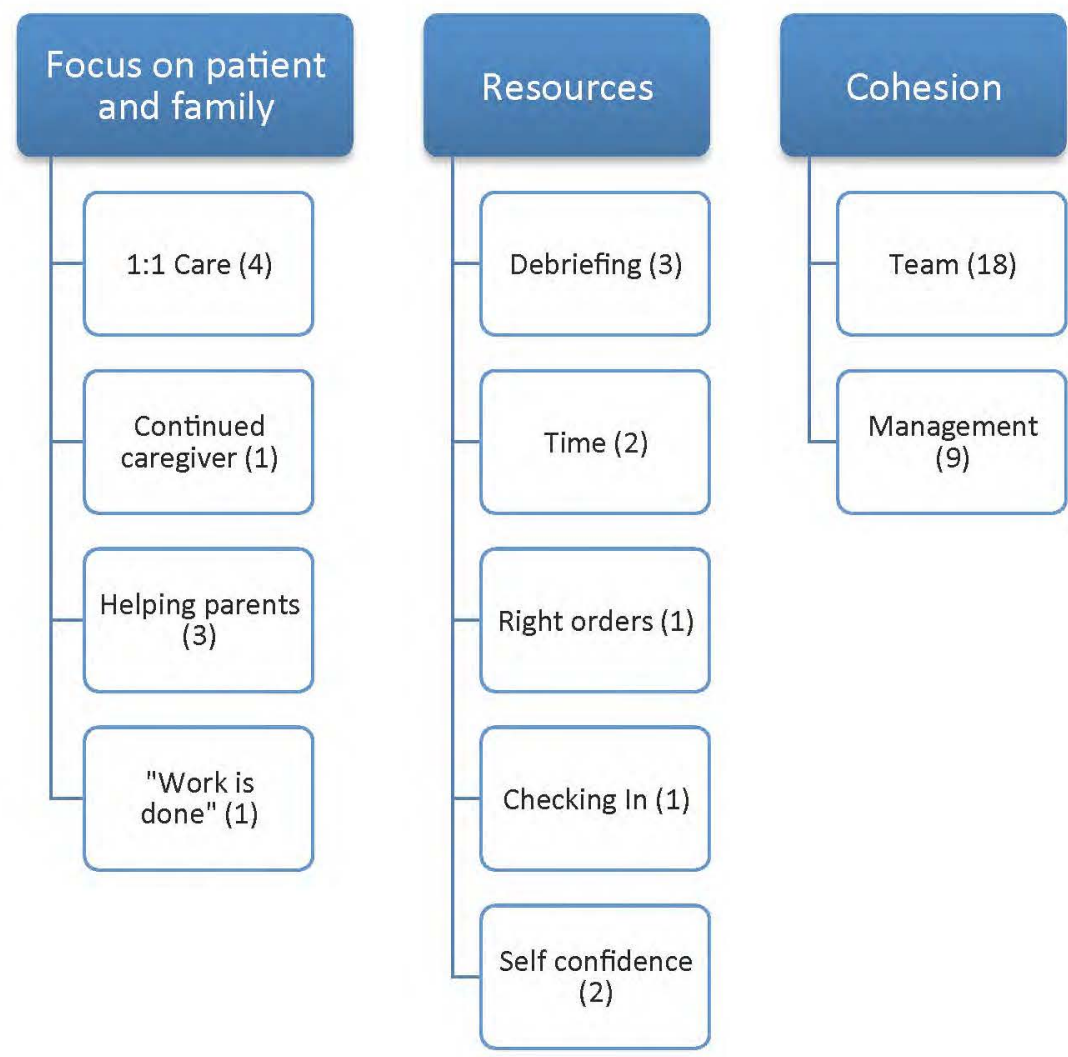

Focus on patient and family. Participants in this study provided evidence to suggest focusing on caring for the patient and their family helped meet their own care needs. Subthemes under this heading include: one-to-one care, helping the parents, continued caregiver, and "work is done." Each of these subthemes will be highlighted.

One to one care. Of the participants providing comments regarding their own needs being met, only RNs indicated being able to give care only to this patient and family as a factor. One respondent, who provided care in the NICU, wrote, "I was assigned only to this patient. I had the freedom to devote as much time and attention to the parents and their baby, as I felt they needed". 
Continued caregiver. A RN described having an established relationship with a patient and their family as being helpful in meeting his or her own care needs. This participant who works in the PICU observed, "She was to be compassionately extubated the next day and I was a consistent caregiver."

Helping parents. Both RNs and SWs report being able to help parents as a source of meeting their own care needs. A RN working in the ED recounted, "...got to help the parents make the memory box."

"Work is done". One RN reported being able to go home after completing her work caring for the dying child and family as being a source of meeting his or her own care needs. This RN, who cared for this child and family in the PICU, remarked, "I was able to go home after the [medical examiner] arrived for my patient."

Resources. Respondents in this study offered several beneficial resources related to meeting their own care needs. The four subthemes that emerged from data analysis as related to resources include, debriefing, right orders, time, and checking in.

Debriefing. A few respondents mentioned debriefing as an important resource for meeting their own care needs. A RN working in the CVICU exemplified this sentiment, "our manager provided a debriefing for this case. Applause...Applause!"

Right orders. One respondent, a RN working in the $\mathrm{HO}$ unit, identified having the proper orders as a means of having her own needs met. Under the question "Were your needs as a caregiver to a dying child met?" one RN wrote, "with regards to medical orders, yes." 
Time. Two respondents discussed taking time after the death event as being helpful in meeting HP care needs. One participant, a RT working in the PICU warmly described this in the context of helping meet a colleague's care needs:

...in this case...all went well, and I could tell it was tough for the nurse, so I hugged her, and asked her to go on break to collect her thoughts. She came back renewed and that made me feel better too. I like to take care of "my nurses" in these situations, because I have been here so long, and seen so much.

Checking in. Two RN participants suggested having continued support after the death event as being a method of having their own care needs met. A RN in the PICU acknowledged, "Charge RN and fellow staff members were extremely supportive and kind throughout the night and in the days to come."

Self-Confidence. A final resource related to meeting self-care needs while caring for a dying child was one of self-confidence, reported by two respondents. One participant, a RT caring for a dying child in the PICU remarked, "My needs were met because I knew as a team we did the best we could to make a horrible situation as best as it possibly could." This finding in an important consideration in juxtaposition of HP report of care needs not being met.

Cohesion. Several respondents acknowledged receiving support from other HP as important for meeting their own care needs after caring for a dying child. These responses were collapsed into two subthemes: team and management.

Team. Various HP mentioned their team members were invaluable in meeting their own care needs. The responses often included specific individuals and HP roles, 
including MDs, chaplains, SWs, supportive care staff, RNs, RTs, and CNA. A RN working in $\mathrm{HO}$ unit provides a touching description of this

The medical needs were met by the physicians and [pharmacists].... My charge nurse took away my other patients so I could focus on [the patient], other RNs were constantly checking on me to see if I was ok. And after the passing multiple RNs quickly paged who needed to be paged, and brought me all the necessary supplies. Also more experienced nurses gave me guidance throughout the entire process.

Management. Having supportive leaders was frequently mentioned in the context of supportive resources in caring for a child at EOL. Eight RNs specifically mentioned charge nurses. An additional participant mentioned management in general. A RN in the CVICU affirmed: "My charge, fellow staff RNs and MDs were quick to offer condolence and support for me, asking if I was ok, or coping well."

\section{Not Meeting the Care Needs}

In order to further understand the concept of HP needs being met, it is also important to understand factors related to HP care needs not being met. In analyzing this data, themes negatively related to needs being met were identified, which helps to further substantiate the themes found in the affirmative responses. However, additional themes were discovered, which may provide further insight into how to support care needs among those who reported difficulty. Figure 4 provides a visual representation of the four themes and their associated subthemes. 
Figure 4. Not Meeting the Needs of the HP
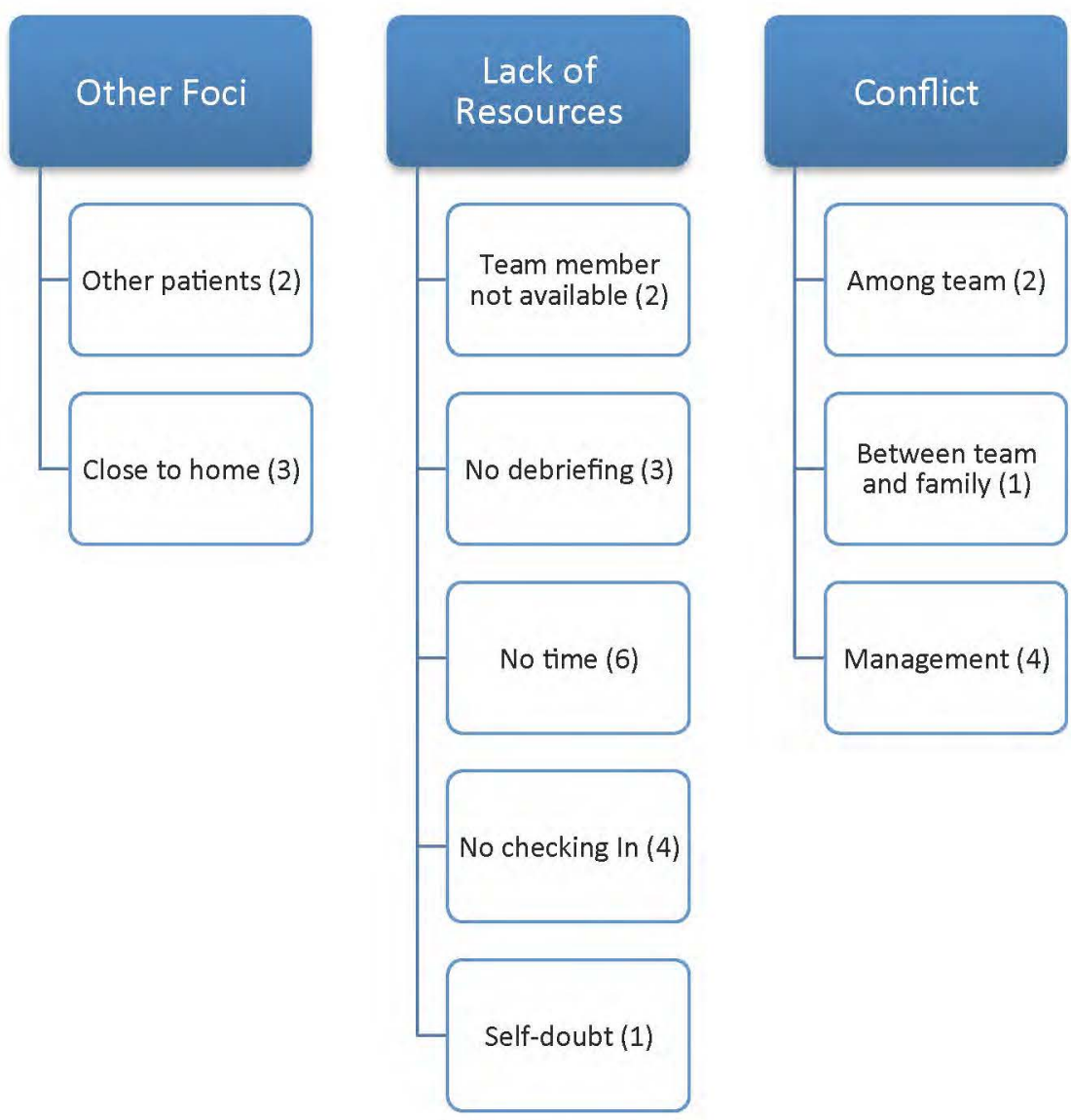

Other foci. Not being able to focus solely on the dying child and his or her family was an element respondents claimed impaired their ability to have their needs met. Subthemes associated with other foci include other patients, and close to home.

Other patients. Two respondents reported having other patients impacted their ability to adequately provide EOL care, which resulted in their own needs not being met. These respondents were RNs, working in the ED and CVICU. The CVICU RN wrote, "I had [three] patients total that night and could not be as present for the patient or the family as I thought was appropriate."

Close to home. Two subthemes involving other foci were related to the concept of "close to home", taking a new admission in the room where the previous patient died, as 
well as identification with the HP own children. Two RNs working in the NICU described having to take an admission in the same room where their patient just died affected their ability to meet their needs. One of the RN wrote: "After post [mortem] care was finished I picked up a patient. That was fine but then I had to admit a [patient] into the same room my [patient] died in. That made for a difficult shift."

Another nurse implied associating the dying patient with his or her own child as interfering with being able to meet self-care needs. This RN who worked in the PICU commented under were your own care needs met, "I have a child the same age." These are interesting findings, which were not previously identified in the literature review.

Resources. Just as having resources aided in HP being able to meet their own needs, a lack of these resources was implicated in HP inability to meet their needs. Subthemes under resources include, team member not available, no debriefing, no time, and no checking in.

Team member not available. Two RNs reported the absence of a key team member impeded their care needs being met. One RN, working in the $\mathrm{HO}$ unit, wrote, "The on call social worker was called after the patient had passed away, and took an hour to get here. I felt a little bit lost during this time of what I should have been doing for the family." Another RN, who provided care in the NICU lamented the absence of key team members on the night shift, writing "No social workers available on nights, barely even on day shift. Managers not present to support staff."

No debriefing. Just as having a debrief was reported to aid in HP needs being met, the lack of a debrief was frequently identified in association with HP care needs not being able to be met. Registered nurses working in diverse care areas reported this. One 
NICU RN mentioned, "I am hopeful that we will have a more in-depth debriefing about this patient situation in the next week or two."

No time. While RNs in critical care areas comprised the majority of respondents reporting a lack of time to grieve, a supportive care team member also mentioned this as an inhibitor to meeting HP needs for caring for a dying child. This respondent, who provided EOL care in the CT scanner reflected, "After providing care to the family, I immediately went back to the CVICU to admit the new Open Heart case while training another nurse." A RN working in the NICU provided another powerful exemplar:

[I] was the nurse caring for the dying patient, after the patient passed within an hour I had to admit a patient. I don't think this is appropriate and there should be some sort of other way to do that if a patient [dies] on your shift and you're the nurse. The experience of the patient dying and the post mortem care is draining not only for the family but the nurse taking care of that child.

No checking in. Similar to debriefing, providing ongoing support to HP was seen as a support for HP meeting their needs. The opposite also holds true. In this study RNs were the only participants that mentioned a lack of follow up as an impediment in meeting their own needs. A NICU RN provided a rich description of this

In the moment it was obviously about the baby, but when I came back to work the next night and saw that she had died, I cried (for many reasons) in the bathroom before report, trying to compose myself. The whole rest of my night was off-kilter and I felt like I didn't really have anybody to talk to.

Another RN working in the PICU wrote, "SO many sad cases in PICU that day. People were supportive during the shift but it's the follow up support that's lacking..." 
Self-doubt. One participant implied a lack of self-confidence in caring for EOL children and families. This participant, a RN who provided care in the ED, reported "Would like to have more resources or better ways to communicate with families of a lost loved one." This was also found in thematic analyses of bad death in this dataset.

Conflict. Conflict was a theme emerging from the open-text comments related to HP meeting their own needs when providing care to a dying child. Conflict was described in three areas, among team, with family, and with management.

Among team. Two participants in this study communicated their own care needs were not met as a result of conflict between HP. One respondent expressed distress after a perceived usurping of his or her role in the following excerpt

The death was very sudden (during operation) and unexpected, and with an unfortunate chain of events where much of my role as social worker was unable to be done (the staff did not wait to tell the family until I was present and we could not do memory making as it was medical examiner case. Therefore, I did not feel much like I could appropriately act as caregiver in the usual way we can as social worker in these events for this particular death.

With family. Two respondents related care plan conflicts with family were associated with not being able to meet their own care needs. A participant who works as a $\mathrm{RN}$ in the CVICU conceded

This was a frustrating patient for both RN's and MD's alike as the mother refused to visit or change the patient's code status. I would have preferred to have him intubated and sedated versus what he had which was no support and little pain medication. 
With management. A few respondents identified a lack of support from or conflicting priorities with management negatively affecting their ability to meet their own care needs. This RN details a lack of support from management

PICU is always so busy that's there's no time to process a death - you may be admitting a pt. right after taking the one who died to the morgue... I experienced 2 gruesome codes and a then a death all within about a 1 month period earlier this year when there was no policy in place. My colleagues are always supportive but it definitely was awful to not get any relief from the bedside after these events. In fact, the charge nurse asked me if I would stay 4 hours over my 12 hour shift because we were short staffed and I had already been with the patient all day - this way I would be there when they withdrew care! Not acceptable and careless to put me in that position.

Another RN from the NICU explained an incident related to conflicting priorities between staff nurse and management and its deleterious effects,

The Charge RN and supervisor asked the family member's only support person to leave after the bedside $\mathrm{RN}$ allowed the friend to come to the bedside. This makes the bedside RN look bad and it's horrible to take away the family members support during this difficult time.

\section{Lingering Distress}

In the parent study, a total of 79 participants provided open text data in response to questions asking about distress related to their experience of caring for a child at EOL. Of these respondents, 39 reported unresolved feelings or stress, 34 denied these feelings, and six stated they did not know. A curious finding: of those who replied not having 
unresolved feelings, 21 respondents went on to contextualize this, often implying some element of lingering feelings. Registered nurses provided the majority of responses $(\mathrm{n}=35)$, but MD, SWs, RTs, NPs, pastors, child life specialists, supportive care team members, CHET team member, and parent liaison also gave responses. All open text data were analyzed. The findings were then categorized into two classes: HP reporting unresolved feelings, and HP not reporting unresolved feelings. Three themes emerged from the data of both groups, and each theme had additional subthemes. Figure 5 shows the themes identified related to reports of unresolved feelings. 
Figure 5. HP report of unresolved feelings
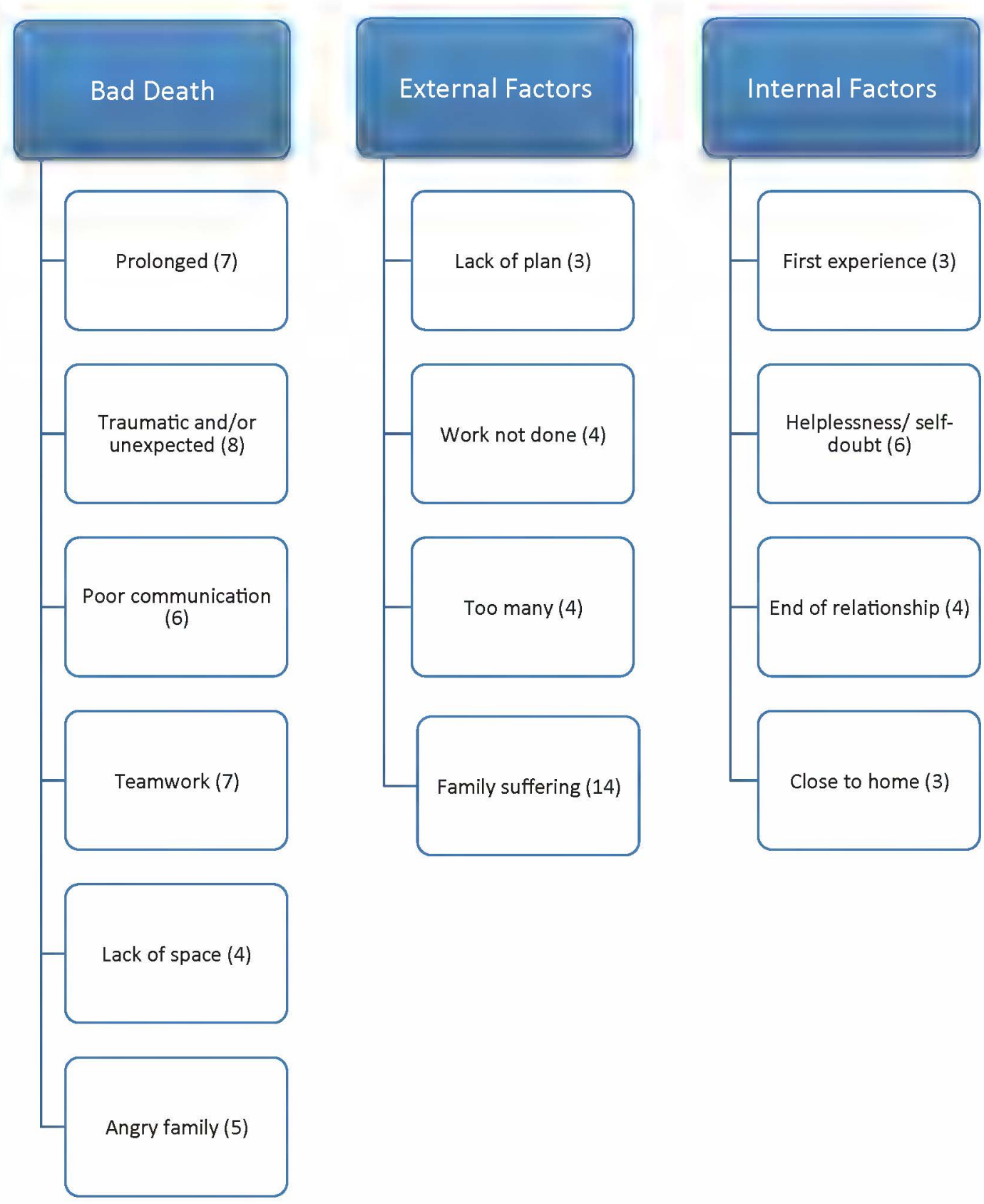

Bad death. Several respondents associated lingering stress with components of a bad death. Subthemes of a bad death that were identified by respondents in this study include: prolonged, traumatic and/or unexpected death, communication barriers, staff discord, lack of space, and family strife. 
Prolonged. Several HP recognized lingering feelings after caring for a child whose death or suffering appeared prolonged. A RN working in the CVICU expressed anguish over prolonged suffering in a dying patient,

I feel like we will keep anyone alive for the sake of keeping them alive. When a patient has a poor social situation, a life altering heart condition and neurological condition, we should stop sooner and have a stronger voice for the patient even if the parents aren't sure.

Traumatic and/or unexpected. Many respondents reported feelings of stress related to a sudden death. Several types of HP working in the critical care areas and ED presented this view. A MD working in the CVICU offered: "The sudden decompensation and her eventual death left me extremely saddened about the circumstances and for the parents." Another reflection provided by a RN in the NICU, "It was a traumatic, rapid, unexpected death in an otherwise seemingly healthy newborn."

Poor communication. Communication issues were also reported among respondents in this study. Problems with communication were identified as delayed, dishonest, or disconnected. A RT in the convalescent center provided an example of delayed communication causing stress,

It upset me that it took so long for the nurses to contact the doctor and let them know her condition. When I asked [on a previous shift] if they had contacted the doctor for an order for something to make her comfortable they told me no. At that point she had already been on a non-rebreather for 4-5 days and already was having difficulty breathing prior to that. 
Another participant discussed dishonest communication as creating distress. A RN who works in the PICU described:

Because false hope was given mom kept on grabbing on to small words and phrases ... this made her not want to [choose] what was best for the baby. We really need to educate our medical team on how to give bad news without giving false hope!!!

Disconnected communication that caused lingering stress was mentioned in the context of both language barrier and communication breakdown. Two participants acknowledged a language barrier with non-English speaking patients and families was a cause of lingering stress, as highlighted by this NICU RN, "Miscommunications with a Spanish speaking family only after the patient passed they asked for a place to stay. This should have been discussed earlier in the day with the social worker." A RT wrote about communication breakdown contributing to feelings of stress, "...it would be nice to be notified if there is any change in [patient's] status while I have been off for a stretch. It's a real blow if you walk into something that was not anticipated."

Teamwork. Another theme associated with both a bad death and lingering distress was dysfunction among the team. Absence of team members, disagreement among team members, and discomfort working with team members were all associated with team dysfunction. A total of seven respondents discussed poor teamwork as a factor in lingering distress, three of which denied having lingering distress. For example, a pastor working in the PICU denied having unresolved feelings, yet goes on to provide evidence of distress resulting from the absence of a key team member 
Parents of the patient decided to have a "tea party" in the patient's room in CCU without consulting staff. Mom invited the [patient's] 7-year-old friends to be at bedside and, essentially, forced them to do memory-making activities that they voiced being "scared" to do. These things were done after hours when $\mathrm{psych} / \mathrm{social}$ support was limited or not present.

Team disagreement was mentioned by one participant, a RN who provided care in the CVICU, "Social work did not want to give us the fingerprints kit. Stated it was a process and that they should do it later in order to do it properly. This baby was dying and it [didn't] fit into their timeline." A parent liaison implied feeling less than welcome in EOL care situations, reporting distress as a result of "[psychosocial] staff unfamiliar with a caring parent liaison with this experience."

Lack of space. Having no private space for a death event was mentioned specifically by RNs as causing lingering feelings or stress. One wrote, [In] the ED it frequently happens in the halls or other places while other families are watching. We are unique in the sense that our deaths are usually completely unexpected so we need a gathering place for the family during this process.

Angry family. Participants also mentioned family anger as a factor in unresolved feelings after caring for a dying child. This anger could be directed toward HP or toward each other. One HP, a RN in the PICU described family anger as "normal stage of grief." A supportive care team member also reported, "some family members were difficult", but provided no context to fully explain this. Family disagreement was mentioned more often. A SW in the PICU reported distress as a result of "Uncle [struggling] with the [patient's] death as it shed light on how his relationship with parents is poor." Another 
respondent, a RN in the NICU reported, "there was a lot of conflict leading up to final decision. Parents were not on same page until just before extubation."

External factors. In addition to concepts related to bad death, other themes emerged from analyzing the comments regarding unresolved feelings. These were organized into internal and external factors. Subthemes associated with external factors include, lack of plan, work not done, too many, and family suffering.

Lack of plan. Three respondents identified unresolved feelings due to an unclear or lack of plan. One respondent, who identified the lack of a plan as a component of a bad death in the outpatient setting, also reported distress, asking the question, "How could we [better] care for families who came in as outpatient clients?" Another respondent, a RN working in the NICU denied unresolved feelings, but went on to acknowledge distress resulting from the child being "on ECMO for five weeks with no improvement and it was difficult at times to find out a plan or if there was a plan."

Work not done. Continued work responsibilities contributed to lingering stress among four participants, a child life specialist, and three RNs. In a touching entry, a RN working in the NICU lamented

I just feel like because I haven't had a night off since, I haven't had a chance to really recoup. Haven't felt like myself, stumbling a bit over simple every day things at work, especially when interacting with parents. I feel like, "Am I overreacting? Am I being weak?" but also that it's normal and okay to feel more emotional than usual after an event like this. I'm not normally a big crier, but I've just been very emotional since and holding a lot in. 
A child life specialist working in the PICU felt a lack of support from management to be able to complete the work needed, writing, "I feel the hospital does not always support [over time] that is necessary to support the dying and work with siblings in crisis."

Too many. A few RNs working in critical care areas mentioned taking care of too many dying children produced unresolved feelings. A PICU RN reflected, "Just emotional from all of the horrible cases we have experienced on the unit in the past few months. Feel worn down emotionally." Another RN in the NICU simply stated, "I believe I have compassion fatigue syndrome."

Family suffering. Observing family suffering was a widely reported consideration for experiencing unresolved feelings after caring for a dying child. Health professionals in various roles and care areas reported this. Many respondents provided general comments, as in the case of this SW working in the NICU who reported unresolved feelings, "because the family was traumatized from the experience." Two respondents identified an inability for parents to have time alone with their child during EOL as a factor in family suffering. A RN working in the PICU provided: "grandparents were hard to get out of the room to allow the parents to be alone with their child for a period of time, I have always felt that is something all parents need to do..."

A few participants mentioned specific explanations related to family suffering in these death events. A NP working on the surgical floor wrote about the anguish observed when a parent loses a second child,

There is nothing more difficult than to watch a mother lose her child, this mother also lost her daughter to the same terrible neurodegenerative condition. It was 
very difficult to watch the mother feeling so desperate and having to endure this all over again. I still grieve for the mother's losses.

Another participant highlighted the distress experienced when caring for a dying twin. While this respondent, a NP working on the surgical unit, denied unresolved feelings, he or she went on to describe challenges in this child's EOL care, "Patient had a twin brother who was coming home from the hospital at the same time this baby was having care withdrawn. This was one of the hardest emotional aspects of participating in this baby's end of life care."

Internal factors. Respondents in this study also discussed lingering feelings of stress related to internal factors. These factors were categorized into four subthemes- first experience, helplessness/ self-doubt, end of relationship, and close to home.

First experience. A total of three respondents identified a lack of previous experience in caring for a dying child as a cause for distress, two RNs and one MD. A RN working in the HO unit recalled of this difficult event, It was my first patient to pass away. And despite sufficient self-care and debriefing, I still replay things I could have done better, or ways I could have said other things. I think it is a hurt that will simply take some time to recover from.

Helplessness/self-doubt. Some HP in this study reported sadness as a result of being unable to save the patient, or uncertainty related to the plan of care as being significant factors in having lingering feelings. A RT provided an example of feeling helpless, reflecting, "It is not easy to see your [patient] is dying and you can not do anything." Self-doubt was implied by this RN in the NICU, who wrote, "I just wish I knew if withdrawing support was the right thing to do. I would like to know the autopsy 
results." A second RN also provided evidence to support this, acknowledging, "Every time I go through this process, I am kept awake for nights thinking about what I could have/should have done to make it better for the family." Interestingly, two of the three participants who reported lingering distress as a result of self-doubt specifically mentioned withdrawing of support.

End of relationship. Four RNs reported mourning the loss of the relationship with the family as a cause for lingering distress. These RNs provided care either in the PICU or NICU. One PICU RN recounted, “The mom contacted me on facebook but I couldn't allow her to be my friend.... Felt wrong. But I bonded with this family!"

Close to home. As in the category of support, HP in this study reported identifying their dying patients with their own loved ones as a cause for lingering stress. Three participants described this phenomenon, all of whom were RNs providing care in a critical care area. One RN who provided EOL care in the NICU, wrote

I keep rethinking the scenario in my head and it's been almost a week since that shift. It was a traumatic, rapid, unexpected death in an otherwise seemingly healthy newborn. It hit me very hard. I have 3 little ones of my own.

\section{No Lingering Distress}

Despite having less data, there were still themes that emerged from the data of respondents who denied having unresolved feelings after providing care to a dying child. Figure six provides a visual representation of the themes, factors related to a good death, as well as external and internal factors. 
Figure 6. HP not reporting unresolved feelings
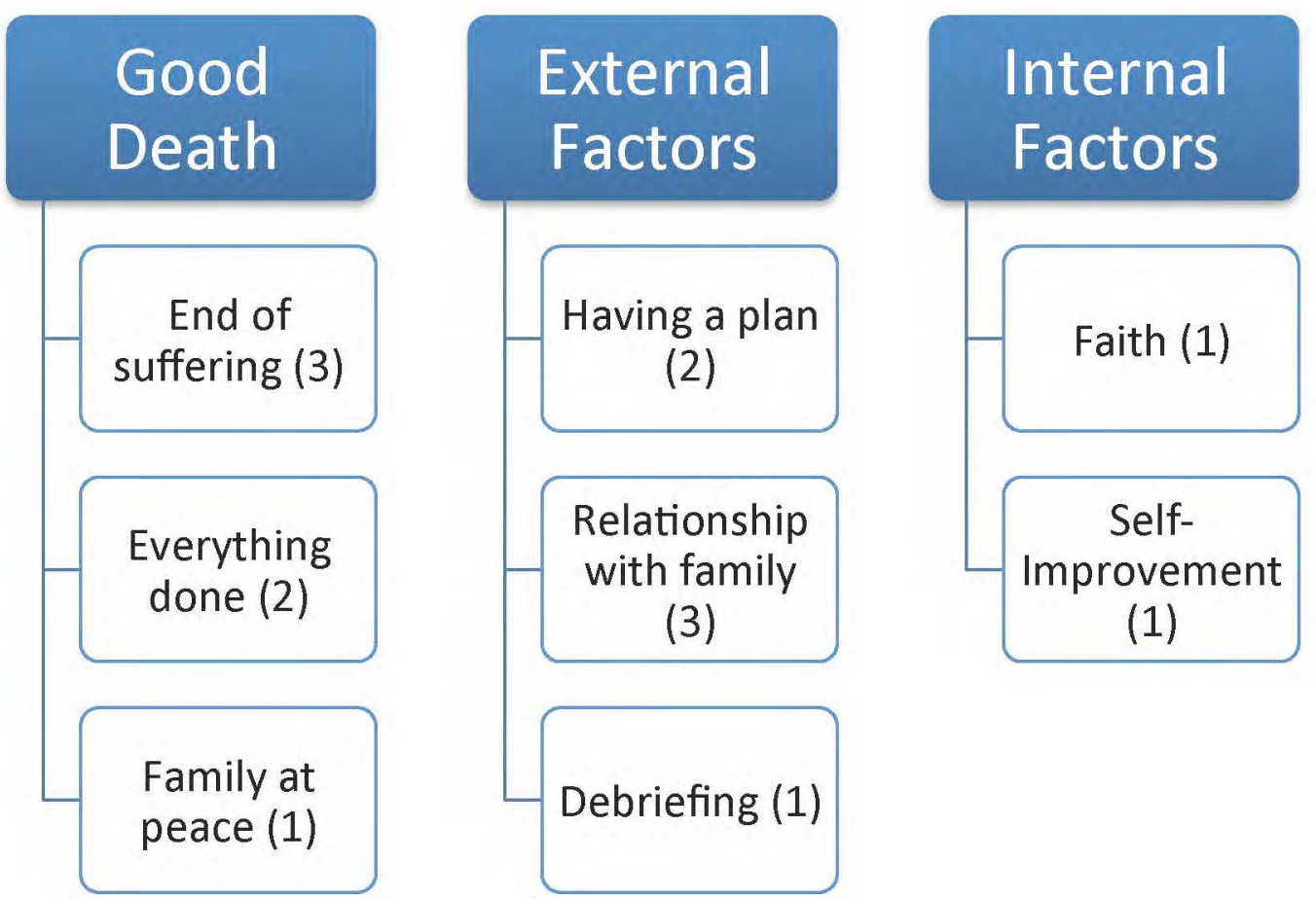

Good death. Participants in this study who denied lingering feelings occasionally contextualized this with themes associated with a good death. Specifically, respondents mentioned themes associated with ending suffering, doing everything, and seeing families at peace as assisting HP with their grief resolution.

End of suffering. Registered nurses in this study associate being able to see their patient is no longer suffering as a promoter of easing their own grief. As a RN who cared for a dying patient in the NICU, observed, "I feel the baby is not suffering any more and that is enough for me."

Everything done. Two respondents, a RT and a RN felt satisfaction in the knowledge that everything possible had been done to save their patient, which aided in their grief resolution. The RN, who provided care in the ED, wrote, "It was difficult to 
see, however, [because] I saw the entire process, I knew that we had tried absolutely everything to revive the child before pronouncing him dead."

Family at peace. One participant, a RN working in the PICU, lovingly explained how facilitating family peace during the death of their child aided him or her in the grieving process,

I was emotional at times with the family, i.e. prayer, baptism. So I was emotionally exhausted at the end of the day, but family said the whole process left them at peace. We allowed natural death in family bed with mom holding patient, I think that made all the difference.

External factors. In addition to concepts related to good death, other themes were found in HP description of not having lingering feelings. These were separated into external factors and internal factors, similar to those of HP reporting lingering stress. External factors associated with HP denying lingering feelings include, having a plan, relationship with family, and debriefing.

Having a plan. Achieving a consensus among team members regarding EOL care aided in grief resolution in two HP respondents in this study, both of whom were RNs. As one RN who cared for a child in the HO unit reflected, "... everyone seemed to be on the same page when it came to the plan for his end of life."

Relationship with family. Three respondents mentioned having a relationship with the family supported their ability to process grief. One participant, a RN working in the HO unit said, "I was comfortable with the parents which helped tremendously, and they were open with me and respected my opinions and medical actions." 
Debriefing. While debriefing was mentioned frequently by participants in this study as a resource for caring for HP needs when providing care to dying children, one respondent recognized that the debriefing session was beneficial to resolving feelings. This SW provided care in the CT scan during a sudden, unexpected death event, but denied lingering feelings, granting, "attended debriefing" assisted in his or her grief resolution.

Internal factors. Two HP mentioned internal factors as being important in preventing lingering feelings-faith and continuous self-improvement.

Faith. Only one respondent mentioned his or her faith as a support in resolving feelings after caring for a child at their EOL. This RT who provided care in the PICU, poignantly wrote,

I love taking care of patients at the end of life, as it leaves me feeling so grateful for all God has blessed me with in life. It's the least I can do to thank Him by helping these families in need. If I ever lose this compassion, it's time to quit.

Continuous self-improvement. Another participant, a RN working in the NICU denied having lingering feelings, but went on to contextualize "Every time I care for a dying patient, I have unresolved feelings and stress." However, this participant also one way this is resolved, "Of all the dying patients I've cared for, I've never performed perfectly, but I have learned tons to make the process better."

\section{Summary}

This chapter presented information regarding the participants of the parent study, as well as participants of this secondary data analysis. It substantiated the researcher's use of a second-generation framework related to the instrument employed in the parent study 
to organize the themes of good death and bad death data to fulfill aims one and two. These four themes were, symptom control, preparedness, connectedness, and transcendence. Several themes were nested under each of these main themes. Data related to meeting the needs of HP caring for dying patients were organized into three themes; focus on patient and family, resources, and cohesion. Data provided surrounding lack of support were organized into three similar but opposite themes; other foci, lack of resources, and conflict. Themes that emerged from HP report of ongoing distress fell into one of three categories, bad death, external factors, and internal factors. Themes emerging from HP report of no ongoing distress fell into similar categories, being good death, external factors, and internal factors. The following chapter will discuss these findings in relation to current understanding of each of these aims, describe limitations, and provide guidance on future research possibilities. 


\section{CHAPTER 5}

\section{Discussion}

You're going to be there when a lot of people are born, and when a lot of people die.

In most every culture, such moments are regarded as sacred and private, made special by a divine presence.

No one on Earth would be welcomed, but you're personally invited. What an honor that is.

Thom Dick

This study analyzed pre-collected, open text data from HP reporting good and bad pediatric hospital deaths, sources for meeting self-care needs when caring for a dying child, and concepts surrounding lingering feelings resulting from caring for a dying child and their family. In this chapter findings are compared and contrasted to current literature on these subjects. The researcher will provide credence for future development of a midrange theory and will also discuss limitations of the study and provide guidance for practice implications and future research.

\section{Good and Bad Death Data}

Most of the findings related to good and bad pediatric hospital deaths within this study are identified within the literature. The use of Downey et al.'s (2010) empirical domains aided in categorizing the data into a model of good fit, however, was not fully able to account for all themes identified due to the qualitative nature of this study. Because of this, the researcher placed the additional themes identified under the four 
domains most relevant to the data provided. For example, Downey et al. (2010) define pain relief and absence of suffering as factors related to symptom control, but from the HP perspective, having appropriate orders and working with a palliative care team would also influence symptom control. Consequently, these were added to this domain. Because the QODD was originally created for patients and their families, this instrument may not capture many factors important to HP. It is important to note the survey in the parent study was modified from the previously validated instrument, in an attempt to establish validity of this new instrument in this particular population. Therefore, in addition to using the empirical domains put forth by Downey et al. (2010), the researcher reviewed the literature to confirm current knowledge and identify new findings as a result of this research.

Good death. Most of the findings related to HP report of good death in this study have precedence within existing research. Each theme of good death in this study will be briefly discussed in the context of current knowledge.

Symptom control. Relief or absence of pain and suffering are universally associated with a good death in the literature (Beckstrand, Callister \& Kirchhoff, 2005; Contro et al., 2004; Downey et al. 2010; Farrell, 2005; Hendrickson \& McCorkle, 2008; Luxardo, Padros \& Tripodoro, 2014; Price, Jordan \& Prior, 2013; Sellers et al., 2014). Additionally, utilization of a palliative care team was identified as a promoter of providing a good death by Beckstrand et al. (2005). Having appropriate orders was only mentioned in one pediatric study as facilitating EOL care within the NICU (Wright, Prasun, \& Hilgenberg, 2011). However, a literature search on EOL order sets resulted in a few articles that associated EOL order sets with HP report of satisfaction in caring for 
adult patients at EOL (Kuschner, Gruenwald, Clum, Beal, \& Ezeji-Okoye, 2009; Treece, 2007).

Preparation. Support in decision making, timing, and acknowledgement of imminent death have all been substantiated in the literature as being integral in achieving a good hospital death among HP and parents (Beckstrand et al., 2005; DelVecchio Good et al., 2004; Gilmer, Foster, Bell, Mulder, \& Carter, 2012; Poles \& Bousso, 2009, 2011). New findings relative to HP perception of a good pediatric hospital death emerging from this study include, families letting go, and everything done.

Families letting go. While most of the adult EOL research described letting go from a patient perspective as important for achieving a good death, there was not a previously identified study which identified parental ability to let go was related to a good pediatric hospital death. Given the unnatural idea of outliving their child, and their desire to protect their child, as well as being the child's medical decision maker, being able to let go of a dying child would likely present more difficulty than letting go of other dying loved ones. One qualitative study identified factors that support parents' ability to let go of a child dying from cancer to include: certainty of inability to cure, postponed grief, witnessed suffering, disentangling their needs, and meaningful parenting (Kars, Grypdonck, Beishuizen, Meijer-van den Bergh, \& van Delden, 2010). However, this has not previously been associated in the literature by HP as important for achieving a good pediatric hospital death.

Everything done. The concept of doing everything possible to save a child has not been previously described in a good pediatric hospital death. In fact, most of the research describing a good death purports the opposite is true (Beckstrand et al., 2006, DelVecchio 
Good et al., 2004; Poles \& Bousso, 2009). Most of the research on EOL excludes sudden deaths, focusing instead on patients with terminal disease processes. Of the respondents reporting "doing everything" for the patient in this study to be a component of a good death, $57 \%$ were describing a sudden death event. The concept of doing everything to save a patient has been described by Timmermans (2005) as "resuscitated death". According to Timmermans, this is done in an attempt to "broker death"; that is to create an illusion of a culturally appropriate death. Considering this, it stands to reason that HP describing sudden death would identify this as an antecedent to a good death.

Connectedness. Findings related to connectedness in this study have been well documented in the good death literature. Components of respectful care were mentioned in all of the articles within the literature review (Beckstrand, Callister \& Kirchhoff, 2005; Contro et al., 2004; Georges, Grypdonck, Dierckx de Caterle, 2002; Kehl, 2006; Luxardo, Padros \& Tripodoro, 2014; Price, Jordan \& Prior, 2013; Sellers et al., 2014). Family presence and associated subthemes were identified in a previous study by Beckstrand, Rawle, Callister, and Mandleco, (2010) and in a concept analysis by Hendrickson and McCorkle (2008). Honest, ongoing, consistent communication is described as critical for achieving a good death throughout the literature (Beckstrand, Callister \& Kirchhoff, 2005; Beckstrand Rawle, Callister, and Mandleco, 2010; Contro et al., 2004; Price, Jordan \& Prior, 2013; Sellers et al., 2014). Access to a specialized care team was not previously identified as a component of a good death. However, Poles and Bousso (2011) acknowledged this to be an antecedent of a dignified death, a related concept. 
Transcendence. Findings in this study related to transcendence have been previously identified in the literature. A peaceful death event is identified as a component of a good or dignified pediatric death by DelVecchio Good et al. (2004), Poles and Bousso (2011), and Welch (2008). Family members at peace have been connected to good death as well (Poles \& Bousso, 2011; Welch, 2008). Hendrickson and McCorkle (2008) identify the concept of legacy specific to the good death of a child is.

Bad death. Similar to the findings related to good death, the majority of the findings in this study related to a bad pediatric hospital death have been described in the literature. Each theme will be reviewed in context with existing evidence to confirm, refute or add to the science.

Symptom control. Most of the studies looking at challenges to providing a good hospital death included concerns about inadequate pain control and suffering (Beckstrand et al., 2010; Contro et al., 2004; Gilmer et al., 2012; Liben, Papadatou \& Wolfe, 2008; Longden, 2011; Price, Jordan \& Prior, 2013). Concerns related to futility also appear in the literature (Beckstrand et al., 2010). While not described by HP, parents of terminally ill children indicated delayed referral to palliative care/ hospice was an issue related to their child's EOL care (Price, Jordan \& Prior, 2013).

Preparation. Lack of preparation among HP and family members is well described in the literature as being a barrier to achieving a good death. Families being unprepared related to lack of understanding resulted in distress to HP and families (Beckstrand et al., 2010; Gilmer et al., 2012; Liben, Papadatou, \& Wolfe, 2008; Price, Jordan \& Prior, 2013). While not addressed as a theme, one study by Contro et al. (2004) anecdotally described a parent's challenge to providing EOL care to his or her child 
outside of hospitalization due to a lack of procedure. This study appears to be the first to discuss HP frustrations with a lack of procedure for outpatients at EOL. Only one study (Price, Jordan \& Prior, 2013) mentioned prolonged dying phase as an "issue" reported to be a challenge among HP providing EOL care to children.

Several respondents in this study indicated a bad hospital death was related to the sudden, unexpected nature of the death. This has implications in preparedness among both HP and parents, which are also components of a bad death. Current research is limited to studies related to HP perceptions of children dying from a life limiting disease process or who were receiving palliative care. There are no current studies evaluating HP perceived quality of a sudden or unexpected death in the pediatric hospital setting. A literature search specific to HP perception of sudden pediatric deaths produced no pertinent articles. There was a 2014 technical report, which provided guidance on handling a death of a child in the emergency department ( $\mathrm{O}^{\prime}$ Malley, Barata, \& Snow). It included a section discussing the concept of a "good death". It acknowledges "the culture of the ED is perhaps most particularly vulnerable" to the "unspoken belief that death is a failure on the part of the medical system" (p. e321). Further research should focus on this unique population: HP caring for sudden or unexpectedly dying children in the ED.

Connectedness. Study findings are consistent with the literature on communication problems detracting from a good death event (Beckstrand et al., 2010; Gilmer et al., 2012; Liben, Papadatou, \& Wolfe, 2008; Price, Jordan \& Prior, 2013). Dysfunctional teamwork between various HP, and HP and family also has been previously discussed as a barrier to achieving a good death (Beckstrand et al., 2010; Price, Jordan \& Prior, 2013). While research suggests having family present during the 
death event a factor related to a good death, there is no research indicating the opposite is true. This constitutes a new finding related to this study.

Transcendence. Many of the themes associated with transcendence in this study are described in previous studies. In a study by Beckstrand et al. (2010), concepts related to lack of space, anger among family members, and anger directed to the HP were identified as obstacles in EOL care. While Price, Jordan and Prior (2013) identified "organ donation" (p. 76) as a challenge to providing EOL care to a child, it provides no context to clarify whether or not inability to donate organs impacts the quality of death as it relates to legacy. It is more likely participants are describing HP discomfort with asking parents about organ donation. The association of a bad death with the inability to donate organs constitutes a new finding.

\section{Meeting the Needs of HP}

While many of the findings of this research corroborate findings in the literature, there are new findings specific to this study that add to the understanding of providing adequate support for HP caring for dying children. These findings are provided in order of themes previously organized.

Focus on patient and family. Previous studies looking at HP providing care for dying children have highlighted the benefit of nurses being able to focus their attention on this situation (Conte, 2013; Davies et al., 1996). Helping parents, as a method to enable HP needs being met was identified among a group of obstetric nurses caring for a fetal demise couplet (Puia, Lewis, \& Beck, 2013). The current study expands on this idea. Providing a consistent presence for patients and families has been previously suggested as both facilitating a best possible death (Beckstrand et al., 2010) and ameliorating 
nurses' grief (Conte, 2014), but does not specifically suggest this to be a source of meeting their own care needs. It should be noted, however, these two concepts are closely related.

The idea of being able to go home after the "work was done" was mentioned as a support to HP meeting his or her own needs by one participant in this study. While related to having time away, there is a significant difference. Many respondents in this study expressed having to go back to work even with an hour break as negatively affecting their ability to meet their own needs as well as being able to resolve lingering feelings. Within the existing literature, having time after providing EOL care is suggested to be supportive of HP self-care needs (Clements \& Bradley, 2005; Rourke, 2005; Wenzel, Shah, Klimmek, \& Krumm, 2011) and a lack of time is not (Puia, Lewis, \& Beck, 2013). A HP being able to go home after providing care to a dying child and their family is not found within the existing literature.

Resources. Resources previously identified as being supportive of HP meeting their own care needs in the context with caring for a dying child include: debriefing (Beckstrand et al., 2010; Clements \& Bradley, 2005; Puia, Lewis, \& Beck, 2013), and time away as previously discussed. While not specific to HP meeting their own needs, one study by Wright, Prasun and Hilgenberg (2011) suggested having order sets for EOL care as a facilitator to EOL care. "Checking in", the concept of team members ensuring HP that have recently cared for dying children and their families are not suffering from lingering distress several days to weeks afterward is a new finding related to resources for meeting HP needs identified in this study. 
Cohesion. The findings of support from the team as being important in meeting their own care needs for HP caring for dying is supported in the research literature (Davies et al., 1996; Morgan, 2009; Pearson, 2010). Other research also suggests support from management aids in HP caring for dying children in meeting their own care needs (Morgan, 2009; Price, Jordan, \& Prior, 2013).

\section{Lingering Distress}

Caring for dying children is well known to create feelings of grief (Davies et al., 1996; Morgan, 2009; Pearson, 2010). The findings of this study reinforce much of the current literature on this topic, and add some new data for consideration. Data will be reviewed as thematically organized for this study.

Bad death. Several participants who identified lingering feelings provided comments that were aligned with bad death themes. This finding is supported by other studies, which have correlated prolonged suffering and futility with moral distress and grief (Keene, Hutton, Hall, \& Rushton, 2010; Lazzarin, Biondi \& Di Mauro, 2012; Morgan, 2009; Wenzel, Shaha, Klimmek, \& Krumm, 2011). There is limited research surrounding lingering distress among HP surrounding the sudden death of a child. There was one study published by Keene et al. (2010) that associated sudden deaths with HP request for debriefing sessions, and also recognized unexpected deaths to be among the most distressing aspects of a child's death.

Communication issues causing distress in pediatric EOL care is well documented (Keene, Hutton, Hall, \& Rushton, 2010; Lazzarin, Biondi, \& Di Mauro, 2012; McCloskey \& Taggart, 2010; Morgan, 2009; Price, Jordan, \& Prior, 2013; Puia, Lewis, \& Beck, 2013) as is team member conflict and/or unavailability (McCloskey \& Taggart, 
2010; Morgan, 2009; Puia, Lewis, \& Beck, 2013). Lack of an appropriate space has not previously been identified as being a factor in HP lingering feelings; this constitutes a new finding. This was found in various care areas (ED, PICU, HO unit), which indicates this is not geographically limited. Feelings of distress reported as a result of family anger have been previously identified (Keene, Hutton, Hall, \& Rushton, 2010; McCloskey \& Taggart, 2010).

External factors. Participants in this study bemoaned the lack of a plan as creating feelings of lingering distress. This may influence HP feelings of helplessness and self-doubt, but the participants also described not having appropriate orders or processes in place specific to the patient's outpatient status as being emotionally distressing. Only one study, which focused on adults, mentions this (Luxardo et al., 2014). Studies by Conte, (2014), Puia, Lewis, and Beck (2013), and Wenzel et al, (2011) have identified themes related to HP work not being done as significant barriers to resolving feelings subsequent to caring for a child at EOL. Another new finding in this study is related to the concept of "too many". Nurses working in the critical care areas seemed particularly affected by this concept. This has not been previously identified in studies surrounding lingering distress among HP, nor has HP feelings of distress related to observing family suffering as described in the current study.

Internal factors. Evidence exists in the literature to support HP acknowledgement of emotional distress related to helplessness when caring for a child at EOL (Conte, 2014; Morgan, 2009; Price, Jordan, \& Prior, 2013; Sarwar, Mangewala, \& Baron, 2013). Grieving for the end of the relationship between HP and family is also discussed in existing studies (Conte, 2014; Keene et al., 2010; McCloskey \& Taggart, 
2010; Morgan, 2009; Price, Jordan, \& Prior, 2013; Rourke, 2007). Unresolved feelings attached to an HP first experience with caring for a child at EOL was not found in the original literature search. A separate search for first time death experiences among HP resulted in one article discussing the association between first time adult patient death experiences and emotional distress among nurses (Kent, Anderson, \& Owens, 2012). Another study, which looked at nurses caring for a dying child in the hospital, identified first experience caring for a dying child to be contextual factor influencing their ability to cope (Cook et al., 2012). Further exploration of this concept is needed.

A final theme from the current study identified a concept considered "close to home", or identification of a dying child to a loved one, as influential on HP, specifically RN grief resolution. There are only a few anecdotal findings regarding this concept within existing research (Morgan, 2009; Puia, Lewis, \& Beck, 2013). Further study on this unique phenomenon is recommended.

\section{Other interesting findings}

In addition to themes identified, there were two unique cases that were discussed in the open text data regarding challenges to EOL care or unresolved stress that deserve further exploration. Two poignant stories mentioned deserve further exploration. The first is described by a NP who wrote: "Patient had a twin brother who was coming home from the hospital at the same time this baby was having care withdrawn. This was one of the hardest emotional aspects of participating in this baby's end of life care." Another case reported by a $\mathrm{RN}$ on the surgical floor:

There is nothing more difficult than to watch a mother lose her child, this mother also lost her daughter to the same terrible neurodegenerative condition. It was 
very difficult to watch the mother feeling so desperate and having to endure this all over again. I still grieve for the mother's losses.

The concept of having "everything done" is an interesting finding in this study. Many times, this concept was related to a sudden death, which may have supported HP report of good things about the child's death. However, four respondents described having "everything done" in context with futility and prolonged suffering. A further exploration of this concept- as it relates to type of death- is needed.

\section{Missing findings}

Of interest, there were two findings mentioned in previous research that were only minimally described in this study. The first was the concept of honoring patient wishes. Although many respondents described honoring the parent wishes as supportive of a good death, only two respondents mentioned honoring the child's wishes, one who felt satisfied the patient's wishes were honored, the other reporting the patient's inability to participate in final decisions as a challenge to EOL care. Due to the de-identified nature of the data, it is unclear whether or not children in this study were at an age or possessed the cognitive ability to make their wishes known. However, it could be the patient's wishes are not considered due to the desire to protect children from knowing they are dying. Landmark research by Bluebond- Langner (1978) suggests despite parents and HP attempts to protect the dying child with leukemia from knowing his or her fate, the child is very much aware of the fact that he or she is indeed dying. Further, research by Hinds et al., (2005) demonstrated children as young as 10 understood their prognosis and were able to engage in decision making that may result in their death. As difficult as it may be 
to discuss an impending death with a child, to not do so when they are already aware of this fact may be considered unethical.

A second concept that is present in the literature yet missing in this dataset, involves concepts of faith and religiosity. Only three participants recognized religious sacraments or faith as factors associated with a good death, and only one participant identified faith as supportive in meeting their own care needs when caring for children at EOL. Previous studies frequently discuss faith as a means of support for families and HP caring for children at EOL (Liben, Papadatou, \& Wolfe, 2008; Longden, 2011; Robinson, Thiel, Backus, \& Meyer, 2006). Further research related to HP comfort providing faithbased support may be warranted in this setting.

\section{Theoretical Considerations}

The association of concepts surrounding bad death as influencing HP report of lingering distress supports previous research. Additionally, HP ability to meet their needs after caring for children at EOL and successful resolution of feelings or distress are highly related as identified in this study and existing literature. This suggests the possibility of future development of a mid-range theory connecting these three concepts.

\section{Limitations}

There are limitations resulting from the design of this study that warrant consideration. First, while HP perspective on good and bad pediatric hospital death is valuable in its own right, it has been previously demonstrated that HP report is a poor proxy for family perceptions, limiting the transferability of these findings. Also, as is common to quantitative studies, it is difficult to know if the measures intended are in line with participant understanding. For example, several respondents in this study qualified 
the death event as "best possible" but then went on to contextualize this response by entering into the comments "for the situation". This has greater implications in the quantitative versus qualitative analysis, but is important to consider. Due to the deidentified and anonymous nature, it cannot be known whether various HP are describing the same death event. However, an interesting finding was discovered relative to this. Four separate participants all described a death event this researcher inferred may be the same death event, given the similarly detailed descriptions in the comments, as well as completing the survey within a short time frame, and reporting providing care in the same care area. Of these four participants, the reported quality of death included, best possible, good, neutral, and worse possible. If these participants are describing the same death event, it raises questions regarding how individuals define good or bad deaths. A final limitation related to the de-identified nature of the data, specifically in qualitative research, is one of epistemic closeness. The qualitative data analysis of open text comments on an anonymous survey does not allow the researcher to close the hermeneutic circle, by validating findings among individuals. Despite these limitations, findings provided important data and new information on the phenomena of "good death" and "bad death".

\section{Recommendations}

Findings from this study have practical applicability for HP caring for dying children and their families. Policies and educational activities can provide much needed assistance in maximizing the likelihood of a good death and HP self-care needs being met, and also reduce HP lingering feelings. 
Administration may desire to implement specific procedures for caring for children at EOL in the outpatient areas or convalescent care facility. Additionally, increasing specialized team member availability during night shift and weekends would prove valuable to HP working these off-shifts.

There are also things the department management should consider when assigning caregivers to a child at EOL. Allowing an HP time away after providing EOL care has been demonstrated to be valuable for reducing lingering distress and meeting HP selfcare needs. If at all possible, consider allowing the HP to go home "when the work is done". If this isn't possible, avoid assigning the HP a new patient in the same room. Further considerations to support HP include, checking in periodically with HP after the death event, not just immediately thereafter. When a unit has sustained several deaths in a short period of time, management could offer an opportunity for HP to discuss feelings. Finally, being mindful of the "close to home" concept, managers with HP who are at risk of personalizing the death of a child due to proximity in age of their own children may benefit from further support.

Perhaps the most important recommendation derived from this study would be the need for further and ongoing education on how to engage in honest communication with dying children and their parents. Despite recent efforts to improve the education of HP on how to communicate in these difficult situations, HP continue to report discomfort and lack of knowledge surrounding pediatric EOL conversations. This cannot be a single educational event. Opportunities for HP to practice these conversations on a regular basis, using various simulation modalities including standardized patients would likely be of 
value. Also, having readily available resources for HP to access at the time needed would likely reduce these feelings of anxiety when broaching these discussions.

\section{Summary}

This chapter has provided a context for the findings of this study in relation to current understanding of the phenomena under study. It has also discussed new findings, provided theoretical considerations, and suggestions for clinical application and future research. Despite the study's limitations, it adds meaningfully to the science and has relevance to all HP working with these families during this incredibly difficult, yet sacred time. 


\section{References}

Aranda, K. (2006). Postmodern feminist perspectives and nursing research: a passionately interested form of inquiry. Nursing Inquiry, 13, 135-143.

Aycock, N., \& Boyle, D. (2008). Interventions to manage compassion fatigue in oncology nurses [Abstract]. Oncology Nursing Forum, 35, 524.

Baverstock, A., \& Finlay, F. (2008). What can we learn from the experiences of consultants around the time of a child's death? Child: Care, Health and Development, 34, 732-739. doi: 10.1111/j.1365-2214.2008.00875.x

Beckstrand, R. L., Callister, L. C., \& Kirchhoff, K. T. (2005). Providing a "good death": Critical care nurses' suggestions for improving end-of-life care. American Journal of Critical Care, 15, 38-45.

Beckstrand, R. L., Collette, J., Callister, L., \& Luthy, K. E. (2012). Oncology nurses' obstacles and supportive behaviors in end-of-life care: Providing vital family care. Oncology Nursing Forum, 39, e398-e406.

Beckstrand, R. L., Rawle, N. L., Callister, L., \& Mandleco, B. L. (2010). Pediatric nurses' perceptions of obstacles and supportive behaviors in end-of-life care. American Journal of Critical Care, 19, 543-552. doi: 10.4037/ajcc2009497 Bluebond-Langner (1978). The Private Worlds of Dying Children. Princeton, NJ: Princeton University Press. 
Bluebond-Langner, M., Beecham, E., Candy, B., Langner, R., \& Jones, L. (2013).

Preferred place of death for children and young people with life-limiting and lifethreatening conditions: A systematic review of the literature and recommendations for future inquiry and policy. Palliative Medicine, 27, 705-713. doi: $10.1177 / 0269216313483186$

Boslaugh, S. (2007). Secondary data sources for public health: A practical guide. Retrieved from Cambridge University Press Web site: http://assets.cambridge.org/97805218/70016/excerpt/9780521870016_excerpt.pdf

Brown-Saltzman, K., Upadhya, D., Larner, L., \& Wenger, N. S. (2010). An intervention to improve respiratory therapists' comfort with end-of-life care. Respiratory Care, 55, 858-865.

Brunard, P. (2008). A comparative, longitudinal study of stress in student nurses in five countries: Albania, Brunei, the Czech Republic, Malta and Wales. Nurse Education Today, 28, 134-145. Retrieved from

Burns. J. B., \& Rushton, C. H. (2004). End-of-life care in the pediatric intensive care unit: Research review and recommendations. Critical Care Clinics, 20, 467-485. doi:10.1016/j.ccc.2004.03.004

Carton, E. R., \& Hupcey, J. E. (2014). The forgotten mourners: Addressing health care provider grief- a systematic review. Journal of Hospice and Palliative Nursing, 16, 291-303. doi:10.1097/NJH.0000000000067

Chapple, H. S. (2010). No Place for Dying. Walnut Creek, CA: Left Coast Publishing. Clements, P. T., \& Bradley, J. (2005). When a young patient dies. Registered Nurse, $68,(4), 40-43$. 
Conte, T. M. (2011). Pediatric oncology nurse and grief education: A telephone survey. Journal of Pediatric Oncology Nursing, 28(2), 93-99. doi: $10.1177 / 1043454210377900$

Conte, T. M. (2014). The lived experience of work-related loss and grief among pediatric oncology nurses. Journal of Hospice and Palliative Nursing, 16, 40-46. doi: 10.1097/NJH.0000000000000019

Contro, N. A., Larson, J., Scofield, S., Sourkes, B., \& Cohen, H. J. (2004). Hospital staff and family perspectives regarding quality of pediatric palliative care. Pediatrics, $114,1248-1252$.

Cook, K. A., Mott, S., Lawrence, P., Jablonski, J., Grady, M. R., Norton, D.,...Connor, J. A. (2012). Coping while caring for the dying child: Nurses' experiences in an acute care setting. Journal of Pediatric Nursing, 27, e11-e21. doi 10.1016/j.pedn.2011.05.010

Cruzan v. Director, Missouri Department of Health. (1990). Retrieved from http://caselaw.lp.findlaw.com/scripts/getcase.pl?navby $=$ CASE\&court $=$ US\&vol $=4$ $97 \&$ page $=261$

Curtis, J. R., Patrick, D. L., Engelberg, R. A., Norris, K., Asp, C., \& Byock, I. (2002). A measure of the quality of dying and death: Initial validation using after-death interviews with family members. Journal of Pain and Symptom Management. 24, $17-31$.

Davies, B., Clarke, D., Connaughty, S., Cook, K., MacKenzie, B.,...Stutzer, C. (1996). Caring for dying children: Nurses' experiences. Pediatric Nursing, 22, 500-506. 
DelVecchio Good, M.-J., Gadmer, N. M., Ruopp, P., Lakoma, M., Sullivan, A. M., Redinbaugh, E., Arnold, R. M., ... Block, S. D. (2004). Narrative nuances on good and bad deaths: Internists' tales from high-technology workplaces. Social Science and Medicine, $58,939-953$.

Docherty, S. L., Miles, M. S., \& Brandon, D. (2007). Searching for "The dying point:" Providers' experiences with palliative care in pediatric acute care. Pediatric Nursing, 33, 335-341.

Doka, K. J. (1989). Disenfranchised Grief: Recognizing Hidden Sorrow. Lexington, MA: Lexington Books.

Downey, L., Curtis, J. R., Lafferty, W. E., Herting, J. R. \& Engelberg, R. A. (2010). The quality of dying and death (QODD) questionnaire: Empirical domains and theoretical perspectives. Journal of Pain and Symptom Management, 39, 1-21. doi:10.1016/j.jpainsymman.2009.05.012

Duggleby, W., \& Wright, K. (2004). Elderly palliative care patients' descriptions of hopefostering strategies. International Journal of Palliative Nursing, 10(7), 352-366.

Evans, N., \& Walsh, H. (2002). The organisation of death and dying in today's society. Nursing Standard, 16(25), 33-38.

Ferrell, B. R. (2005). Overview of the domains of variables relevant to end-of-life care. Journal of Palliative Medicine, 8 (Suppl. 1), 22-28.

Field, M. J., \& Cassel, C. K. (1997). Approaching death: Improving care at the end of life. Retrieved from http://www.nap.edu/openbook.php?record_id=5801

Fox, N. L. (1974). A good birth, a good life, why not a good death? Journal of Practical Nursing, 24(10), 19-20. 
Gallagher, R., \& Gormley, D. K. (2009). Perceptions of stress, burnout and support systems in pediatric bone marrow transplantation nursing. Clinical Journal of Oncology Nursing, 13, 681-685. doi: 10.1188/09.CJON.681-685

Georges, J. J., Grypdonck, M., \& Dierckx de Caterle, B. (2002). Being a palliative care nurse in an academic hospital: A qualitative study about nurses' perceptions of palliative care nursing. Journal of Clinical Nursing, 11, 785-793. Retrieved from 0 eds.b.ebscohost.com.sally.sandiego.edu/eds/pdfviewer/pdfviewer?sid=aed5ff91a688-47eb-aebd-1dfdfbc5fc65\%40sessionmgr $112 \& v i d=0 \&$ hid $=108$

Gilmer, M. J., Foster, T. F., Bell, C. J., Mulder, J., \& Carter, B. S. (2012). Parental perceptions of care of children at end of life. Journal of Hospice and Palliative Medicine, 30, 53-58. doi 10.1177/1049909112440836

Gott, M., Small, N., Barnes, S., Payne, S., \& Seamark, D. (2008). Older people's views of a good death in heart failure: Implications for palliative care provision. Social Science \& Medicine, 67, 1113-1121.

Graneheim, U. H., \& Lundman, B. (2004). Qualitative content analysis in nursing research: Concepts, procedures and measures to achieve trustworthiness. Nurse Education Today, 24, 105-112. doi: 10.1016/j.nedt.2003.10.001

Hales, S., Zimmerman, C., \& Rodin, G. (2010). Review: The quality of dying and death: A systematic review of measures. Palliative Medicine, 24, 127-144. doi: $10.1177 / 0269216309351783$

Hancock, K., Clayton, J. M., Parker, S. M., Wal der, S., Carrick, S., Currow, D., Ghersi, D., ... Tattersall, M. H. -N. (2007). Truth-telling in discussing prognosis in 
advanced life-limiting illnesses: A systematic review. Palliative Medicine, 21, 507-517. doi:10.1177/0269216307080823

Hansen, L., Goodell, T. T., DeHaven, J., \& Smith, M.-D. (2009). Nurses' perceptions of end-of-life care after multiple interventions for improvement. American Journal of Critical Care, 18, 263-271. doi: 10.4037/ajcc2009727

Hendrickson, K., \& McCorkle, R. (2008). A dimensional analysis of the concept: Good death of a child with cancer. Journal of Pediatric Oncology Nursing, 25, 127-138. doi: $10.1177 / 1043454208317237$

Holloway, I., \& Wheeler, S. (2010). Qualitative research in nursing and healthcare (3rd ed.). West Sussex, United Kingdom: Wiley-Blackwell.

Hinds, P. S., Drew, D., Oakes, L. L., Fouladi, M., Spunt, S. L., Church, C., \& Furman, W. L. (2005). End-of-life care preferences of pediatric patients with caner. Journal of Clinical Oncology, 23, 9146-9154. doi 10.1200/JCO.2005.10.538

Hsieh, H.-F., \& Shannon, S. E. (2005). Three approaches to qualitative content analysis. Qualitative Health Research, 15, 1277-1288. doi: 10.1177/1049732305276687

Irwin, S. (2013). Qualitative secondary data analysis: Ethics, epistemology, and context. Progress in Development Studies, 13, 295-306. doi:10.1177/1464993413490479

Kars, M. C., Grypdonck, M. H., Beishuizen, A., Meijer-van den Bergh, E. M., \& van Delden, J. J. (2010). Factors influencing parental readiness to let their child with caner die. Pediatric Blood Cancer, 54, 1000-1008. doi 10.1002/pbd.22532

Keene, E. A., Hutton, N., Hall, B., \& Rushton, C. (2010). Bereavement debriefing sessions: An intervention to support health care professionals in managing their grief after the death of a patient. Pediatric Nurse, 36, 185-189. 
Kehl, K. A. (2006). Moving toward peace: An analysis of the concept of a good death. American Journal of Hospice and Palliative Care, 23(4), 277-286.

Kent, B., Anderson N. E., \& Owens, R. G. (2012). Nurses' early experiences with patient death: The results of an on-line survey of registered nurses in New Zealand. International Journal of Nursing Studies, 49, 1255-1265. doi:

10.1016/j.ijnurstu.2012.04.005

Kuschner, W. G., Gruenwald, D. A., Clum, N., Beal, A., \& Ezeji-Okoye, S. C. (2009). Implementation of ICU palliative care guidelines and procedures: A quality improvement initiative following an investigation of alleged euthanasia. Chest, 135, 26-32. doi:10.1378/chest.08-1685

Lazzarin, M., Biondi, A., \& Di Mauro, S. (2012). Moral distress in nurses in oncology and haematology units. Nursing Ethics, 19 183-195. doi:

$10.1177 / 0969733011416840$

Leonard, V. W. (1994). In P. E. Benner (Ed.), Interpretive phenomenology: Embodiment, caring and ethics, in health and illness (pp. 827-836). Thousand Oaks, CA: Sage.

Liben, S., Papadatou, D., \& Wolfe, J. (2008). Pediatric palliative care: Challenges and emerging ideas. The Lancet, 371, 852-864. doi:10.1016/S01406736(07)61203-3

Longden, J. (2011). Parental perceptions of end-of-life care on paediatric intensive care units: A literature review. Nursing in Critical Care, 16, 131-139.

Lowey, S. E. (2008). Letting go before death: A concept analysis. Journal of Advanced Nursing, 63, 208-218. doi: 10.1111/j.1365-2648.2008.04696.x 
Luxardo, N., Padros, C. V., \& Tripodoro, V. (2014). Palliative care staff perspectives: The challenges of end-of-life care on their professional practices and everyday lives. Journal of Hospice and Palliative Nursing, 16, 165-172.

Lyndes, K. A., Fitchett, G., Berlinger, N., Cadge, W., Misasi, J., \& Flanagan, E. (2012). A survey of chaplains' roles in pediatric palliative care: Integral members of the team. Journal of Health Care Chaplaincy, 18, 74-93. doi:

$10.1080 / 08854726.2012 .667332$

Macpherson, C. F. (2008). Peer-supported storytelling for grieving pediatric oncology nurses. Journal of Pediatric Oncology Nursing, 25, 148-163. doi: $10.1177 / 1043454208317236$

McCloskey, S., \& Taggart, L. (2010). How much compassion have I left? An exploration of occupational stress among children's palliative care nurses. International Journal of Palliative Nursing, 16, 233-240.

Meade, K., Pope, J., Weise, K., Prince, L., \& Friebert, S. (2012). Distress at the bedside in the PICU: Nurses' and respiratory therapists' experiences in caring for children with complex medical or neurologic conditions. Progress in Palliative Care, 20 , 357-361. doi: 10.1179/1743291X12Y.0000000028

Morgan, D., 2009. Caring for dying children: Assessing the needs of the pediatric palliative care nurse. Pediatric Nursing, 35 86-91.

O'Malley, P., Barata, I., \& Snow, S.(2014). Death of a child in the emergency department. American Academy of Pediatrics, 134, e313-e330. doi: $10.1542 /$ peds. $2014-1246$

Paddy, M. (2011). Influence of location on a good death. Nursing Standard, 26, 33-36. 
Papadatou, D., Papazoglou, I., Petraki, D., \& Bellali, T. (1999). Mutual support among nurses who provide care to dying children. Illness, Crisis, and Loss, 7, 37-48.

Patient Self-Determination Act. (2014). In Wikipedia: The free encyclopedia. Retrieved from http://en.wikipedia.org/wiki/Patient_Self-Determination_Act

Pearson, H. (2020). Managing the emotional aspects of end of life care for children and young people. Paediatric Nursing, 22(7), 31-35.

Peterson, J., Johnson, M., Halvorsen, B., Apmann, L., Chang, P., Kershek, S., Scherr, C., ... Pincon, D. (2010). Where do nurses go for help? A qualitative study of coping with death and dying. International Journal of Palliative Nursing, 16, 432-438. Retrieved from

Poles, K., \& Bousso, R. S. (2011). Dignified death: Concept development involving nurses and doctors in pediatric intensive care units. Nursing Ethics, 18, 694-709. doi: $10.1177 / 0969733011408043$

Poles, K., \& Bousso, R. S. (2009). Dignified death for children: Concept analysis. Revista da Escola de Enfermagem da USP, 43, 207-215.

Polit, D. F., \& Beck, C. T. (2012). Nursing research: Generating and assessing evidence for nursing practice (9th ed.). Philadelphia: Lippincott, Williams, \& Wilkins.

Price, J., Jordan, J., \& Prior, L. (2013). A consensus for change: Parent and professional perspectives on care for children at the end-of-life. Issues in Comprehensive Pediatric Nursing, 36, 70-87. doi: 10.3109/01460862.2013.779765 
Puia, D. M., Lewis, L., \& Beck, C. T. (2013). Experiences of obstetric nurses who are present for a perinatal loss. Journal of Obstetric, Gynecologic and Neonatal Nursing, 42, 321-331. doi: 10.1111/1552-6909.12040

Ringner, A., Jansson, L., \& Graneheim, U. H. (2011). Professional caregivers' perceptions of providing information to parents of children with cancer. Journal of Pediatric Oncology Nursing, 28, 34-42. doi:10.1177/1043454210377175

Robinson, M. R., Thiel, M. M., Backus, M. M., \&Meyer, E. C. (2006). Matters of spirituality at the end of life in the pediatric intensive care unit. Pediatrics, 118 e719-e729.

Rourke, M. T. (2007). Compassion fatigue in pediatric palliative care workers. Pediatric Clinics of North America, 54, 631-644. doi:10.1016/j.pcl.2007.07.004

Saldana, J. (2008). The Coding Manual for Qualitative Researchers ( $2^{\text {nd }}$ ed.) London: Sage.

Sarwar, S. R., Mangewala, W., \& Baron, R. (2013). Helping the angels: A review of understanding and helping dying children. Clinical Neuroscience, 10(3), 3134.

Seale, C. (2004). Media constructions of dying alone: A form of a "bad death." Social Science and Medicine, 58, 967-974.

Sellers, D. E., Dawson, R., Cohen-Bearak, A., Solomond, M. Z., \& Truong, R. D. (2014). Measuring the quality of dying and death in the pediatric intensive care setting: The clinician PICU-QODD. Journal of Pain and Symptom Management, manuscript in preparation. doi: 10.1016/j.jpainsymman.2014.05.004

Symmers, W. S. (1968). Not allowed to die. British Medical Journal, 1(1), 442. 
Timmermans, S. (2005). Death brokering: Constructing culturally appropriate deaths. Sociology of Health \& Illness, 141, 993-1013. doi: 10.1111/j.14679566.2005.00467.x

Treece, P. (2007). Standardized order sets for end of life care. Journal of Hospice and Palliative Nursing, 9, 70-71.

Tucker, T. (2009). Culture of death denial: Relevant or rhetoric in medical education. Journal of Palliative Medicine, 12, 1105-1108. doi:10.1089/jpm.2009.0234

Weitz, R. (2013). The Sociology of Health, Illness and Healthcare: A Critical Approach (6th ed.). Belmont, CA: Wadsworth Cengage.

Welch, S. B. (2008). Can the death of a child be good? Journal of Pediatric Nursing, 23, 120-124. doi: 10.1016/j.pedn.2007.08.015

Wenzel, J., Shaha, M., Klimmek, R., \& Krumm, S. (2011). Working through grief and loss: Oncology nurses' perspectives on professional bereavement. Oncology Nursing Forum, 38, e272-e282.

Wolfe, J., Klar, N., Grier, H. E., Duncan, J., Salem-Schatz, S., Emanuel, E. J., \& Weeks, J. C. (2000). Understanding of prognosis among parents of children who died of cancer. Journal of the American Medical Association, 284, 2469-2475. Retrieved from http://0jama.jamanetwork.com.sally.sandiego.edu/Issue.aspx?journalid=67\&issueID $=476$ $0 \&$ direction $=\mathrm{P}$

Wright, V., Prasun, M. A., \& Hilgenberg, C. (2011). Why is end-of-life care delivery sporadic? Ethical Issues in Newborn Care, 11, 29-36.

doi:10.1097/ANC.0b013e3182085642 
Yao, C. A., Hu, W. Y., Lai, Y. F., Cheng, S. Y., Chen, C. Y., \& Chiu, T. Y. (2007). Does dying at home influence the good death of terminal cancer patients? Journal of Pain and Symptom Management, 34, 497-504. 


\section{Appendix A}

\section{IRB Approval Letter}

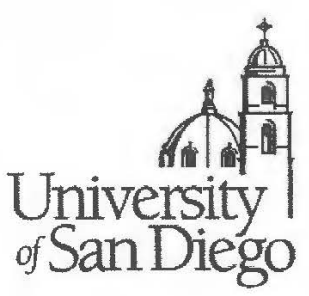

\section{Institutional Review Board Project Action Summary}

Note: We send IRB correspondence regarding student research to the faculty advisor, who bears the ultimate responsibility for the conduct of the research. We request that the faculty advisor share this correspondence with the student researcher.

Modifications Required or Reasons for Non-Approval

None

The next deadline for submitting project proposals to the Provost's Office for full review is N/A. You may submil a project proposal for expedited review at any time.

Dr. Thomas R. Heminton

Administrator, Institutional Review Board

University of San Diego

herrinton@sandiego.edu

5998 Alcalá Park

San Diego, Califomia 92110-2492 


\section{Appendix B}

\section{Survey Questions From Parent Study}

\section{Front Page omitted}

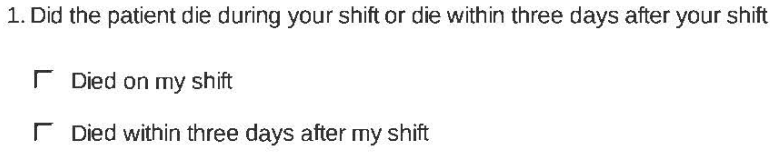

6. During the time the patient was in your care, how much of the time did the patient appear to experience anxiety and/or agitation?

None of the time A little bit of the time Some of the time A good bit of the

7. During the time the patient was in your care, did you feel the patient was at peace?
$r$ Yes
$r$ No
$r$ Sometimes
$r$ Do not know
r Not applicable

Comments 


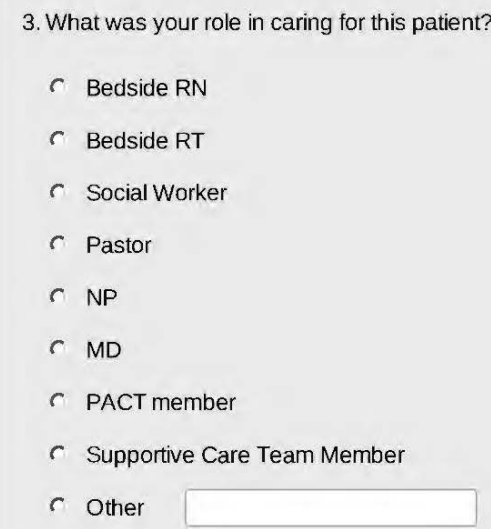

4. During the time the patient was in your care, how much of the time did the patient appear to have pain?
None of the time
A little bit of the time
c
Some of the time
A good bit of the
time
Most of the time
All of the time
$c$

$r$
$r$
$r$
$r$

5. During the time the patient was in your care, how much of the time did the patient appear to have difficulty breathing?
None of the time
A little bit of the time
Some of the time
c
$r$
$r$
A good bit of the

$\begin{array}{ccc}\text { time } & \text { Most of the time } & \text { All of the time } \\ r & r & r\end{array}$

6. During the time the patient was in your care, how much of the time did the patient appear to experience anxiety and/or agitation?
None of the time
A little bit of the time
r
Some of the time
$r$
A good bit of the
time
Most of the time
c
All of the time
$r$

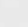

7.During the time the patient was in your care, did you feel the patient was at peace?
r. Yes
r No
r Sometimes
c Do not know
r Not applicable
Comments 
8. Did you have adequate orders to keep this patient comfortable through the dying process?

c Yes

no

c Do not know

r Not applicable

Comments

9. Overall, how would you rate the quality of the patient's dying? *

$\begin{array}{lccccc}\text { Worse Possible } & \text { Poor } & \text { Neutral (neither } \\ \text { bad norgood) } & \text { Good } & \text { Best Possible Do not know Not applicable } \\ \text { Comments } & r & r & r & r\end{array}$

10. Were your needs as a caregiver to a dying child met?
c Yes
r No
c Do not know
Not applicable

Comments

11. After your patient's death, are you having unresolved feelings or stress from this experience?
r Yes
r No
r Do not know
r Not applicable
Comments 
12. Thank you for completing part of this survey. We would appreciate you continuing with this survey so we can further learn from your experience. However, at this point, if you do not have the time to complete it, you may exit the survey at this point.

$r$ Yes, Continue with survey

r No thank you, exit survey

\section{New Page}

13. During the time the patient was in your care, how much of the time did the patient appear to experience symptoms of constipation such as abdominal pain, cramping, or bloating?

None of the time A little bit of the time Some of the time A good bit of the the time

14. Did the patient experience seizures during the time he/she was in your care?
r Yes
$r$ No
c Don'tknow
r Not applicable

15. During the time your patient was in your care, was the patient mostly: *
c Awake and alert
A Agitated or anxious
r Sleepy or tired/fatigued
$r$ Intermittently awake and asleep
r Sedated
r Asleep
$r$ Comatose

Comments 
16. During the time the patient was in your care, did the patient have an acute deterioration and transfer to a higher level of care such as the PICU?
$r$ Yes
n No
Do not know
Not applicable

Comments

17. Was this a sudden, unexpected death such as a code blue?
r Yes
$r$ No

18. During the time the patient was in your care, was the patient on a monitor such as a cardiac-respiratory monitor or pulse $\mathrm{O} 2$ saturation?
$\ulcorner$ Yes
$\ulcorner$ No
$\ulcorner$ Do not know
$\Gamma$ Not applicable

19. During your shift, was your patient on: (select all that apply)

$\Gamma$ Sedatives for the purpose of sedation, such as lorazapam (ativan), diazapam(valium), midazolam (versed), or dexmedetomidine (precedex)?

$\ulcorner$ Pain medications, such as morphine, hydromorphone (dilaudid) or fentanyl?

$\Gamma$ Chemotherapy?

$\Gamma$ Medications to support their blood pressure, such as epinephrine or dopamine?

$\Gamma$ Renal Dialysis?

$\Gamma$ TPN or enteral feeds via NG/NJ/GT?

$\Gamma$ Mechanical ventilation assistance such as a ventilator or BiPAP machine?

\author{
20. During your shift, did your patient have: (check all that apply) \\ $\Gamma$ End-of-life order set \\ $\Gamma$ Signed AND/DNR order
}




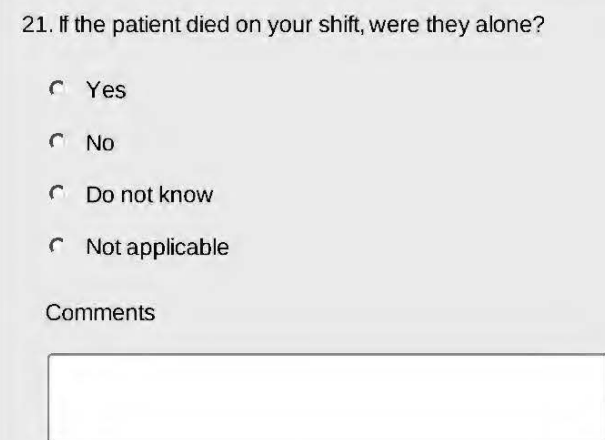

22. During the time the patient was in your care, did you feel the patient's wishes for his/her care was honored?
$\ulcorner$ Yes
$r$ No
$r$ Do not know
C Not applicable

Comments

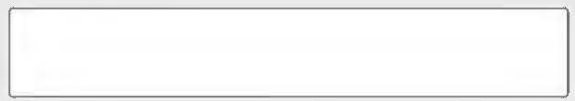

23. During the time the patient was in your care, did you feel that the patient was well supported by family and friends? *
$\ulcorner$ Yes
r No
$r$ Do not know
$\ulcorner$ Not applicable

Comments

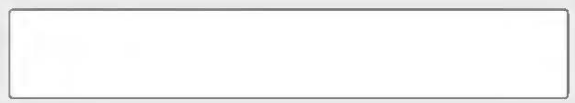

24. During the time the patient was in your care, did you feel the family's wishes for the patient's care were honored?
$\ulcorner$ Yes
$r$ No
$r$ Do not know
$r$ Not applicable

Comments 
25. During the time the patient was in your care, did your patient and/or his family have spiritual support?
c Yes
no
c Do not know
r Not applicable

Comments

26. During the time the patient was in your care, did your patient and their family have their specific cultural needs met? (for example: allowed to have religious or cultural items in room, culturally appropriate foods available, interpreters )
C Yes
C No
c Do not know
r Not applicable

Comments 
27. During the time the patient was in your care, did your patient and their family have support from psychological care team? (which may include child life, chaplaincy, social work, family liaison, supportive care coordinator, Pediatric advanced care team (PACT), psychologists, volunteers, or psychiatrists)?
$c$ Yes
r No
$r$ Do not know
Not applicable

Comments

28. To the best of your knowledge, were memory making activities such as taking foot prints or preserving locks of hair for parents done before or after death?
$\ulcorner$ Yes
$\ulcorner$ No
$\Gamma$ Do not know
$\Gamma$ Not applicable
Comments

29. During the time the patient was in your care, did the patient's family discuss their wishes for end of life care with: (Select all that apply)
$\Gamma$ You
$\Gamma \mathrm{MD}$ or NP
$\Gamma$ Social Worker
$\Gamma$ Religious/spiritual advisor
$\ulcorner$ PAC team
$\ulcorner$ No one
$\Gamma$ Not applicable
$\Gamma$ Don't know
$\Gamma$ Other

Comments 
30. To the best of your knowledge, were there any ethical or legal aspects surrounding the patient's care?
$\Gamma$ Yes
$\Gamma$ No
$\Gamma$ Do not know
$\Gamma$ Not applicable

Comments
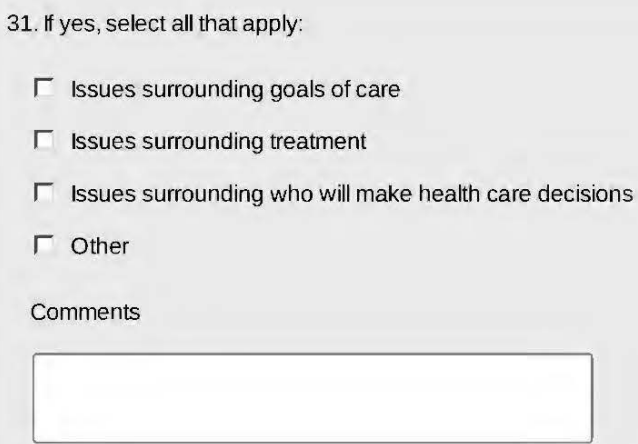

32. To the best of your knowledge was a consult made to: (check all that apply)

$\Gamma$ Ethics Team

$\lceil$ Palliative Advanced Care Team (PACT)

$\Gamma$ Integrative Care Service

$\Gamma$ Chaplaincy

$\Gamma$ No consults were made

$\Gamma$ other

Comments

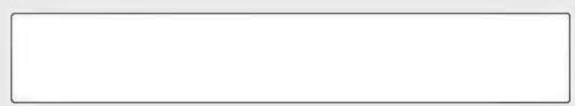


33. How would you rate the quality of care the patient received from the multidisciplinary team (nurses, doctors, social workers, etc....)? *

r Worse Possible

r Poor

Neutral (neither bad nor good)

$r$ Good

r Best Possible

c Do not know

r Not applicable

Comments

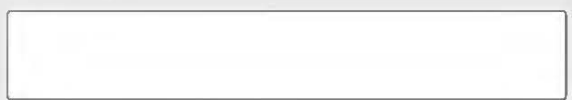

34. What were the good things about this child's end-of-life care?

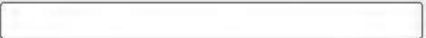

35. What were the challenges about this child's end-of-life care?

36. What would have made this child's end-of-life care better?

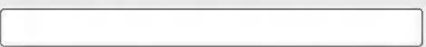

37. Did you feel supported by fellow staff while caring for this patient?
$\Gamma$ Yes
$\Gamma$ No
$\Gamma$ Do not know
$\Gamma$ Not applicable
Comments 
38. Did you feel any distress from: (check all that apply)

$\Gamma$ Family conflict or interactions

$\Gamma$ Legal issues

$\Gamma$ Moral or ethical issues

$\Gamma$ Plan of care

$\Gamma$ Care team members

$\Gamma$ Other

Comments

39. Was there a formal debriefing after this patient's death? A formal debriefing is one which is planned with a trained moderator such as a psychologist or social worker.
$\Gamma$ Yes
$\Gamma$ No
$\Gamma$ Do not know
$\Gamma$ Not applicable
$\Gamma$ Other

40. What shift were you working when you cared for the child?
c AM
r PM
r Nights

\author{
41. What is your gender? \\ $\Gamma$ Male \\ $\Gamma$ Female
}

42. What year were you born? * 


\section{What is your race? \\ ( Black/African American \\ ( Asian \\ Pacific Islander \\ r Native American \\ r White/European \\ o Other}

\section{r Diploma \\ c Associate degree \\ c Baccalaureate \\ r Masters \\ ( PhD \\ $r$ Other}

44. What is the highest degree you have completed?

45. Do you have any professional certifications? If so, what?

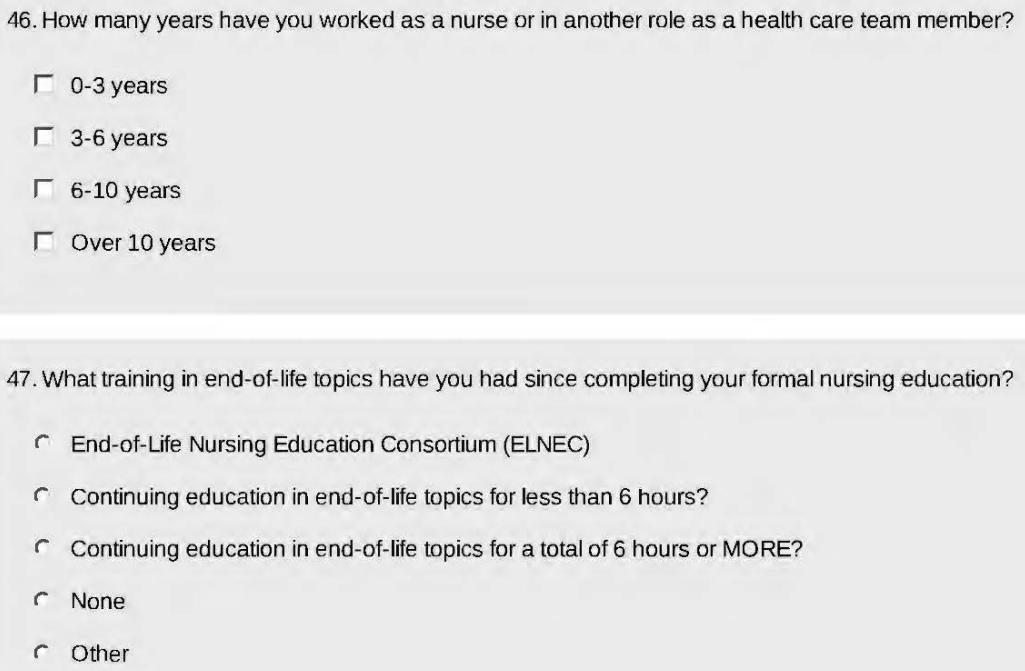

47. What training in end-of-life topics have you had since completing your formal nursing education?

End-of-Life Nursing Education Consortium (ELNEC)

$r$ Continuing education in end-of-life topics for less than 6 hours?

r Continuing education in end-of-life topics for a total of 6 hours or MORE?

r None

$r$ Other

48. If you are willing to discuss this experience with the researchers so we can improve our care for dying children, please give us your name and how best to reach you. Thank you 
We appreciate the time it took to fill out this survey. With your feedback, we can improve the care we give children, families and staff during these stressful and sad times. Please contact Rebecca Bennett, the principal investigator, with any thoughts, suggestions, or feedback on this survey and your experience with caring for dying children here at Rady. Thank you for participating in this research and for all the wonderful care you give your patients and families, Rebecca Bennett RN, MS, FNP/PNP-BC rbennett@rchsd.org 858-494-7246

Thank You!

Thank you for taking our survey. Your response is very important to us. 